Universitá Cattolica di Sacro Cruore

Faculty of Economics

Master thesis in Economics

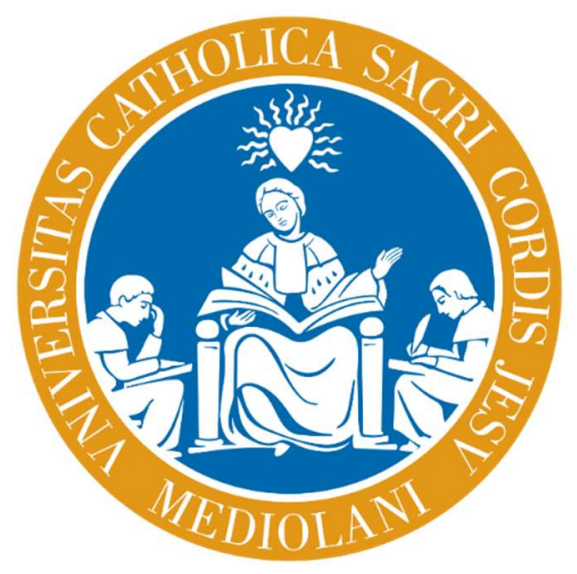

\title{
The economic effect of the 2015 \\ Refugee Crisis in Sweden: Jobs, Crimes, Prices and Voter turnout.
}

The paper exploits the Swedish refugee crisis in 2015 as an exogenous shock and analyzes through a dynamic difference-in-difference estimator if and to what extent it influences the country's labor market, crime level, price levels and political voting pattern.

Author

Arvid Uddfeldt

Supervisor

Claudio Lucifora 


\section{Acknowledgement}

I want to thank my supervisor Claudio Lucifora for all the help, patience, and feedback provided during the thesis work. Further, I want to thank Irene Torrini, who patiently has provided a lot of guidance and practical help. Lastly, I also want to thank Malin Forsberg at Statics Sweden for all help regarding the data, which form the thesis's base. The thesis would not have been the same without the persons mentioned above. 


\begin{abstract}
The civil war in Syria has culminated in a massive refugee crisis in neighboring and European countries. Millions of refugees made their way to Europe between 2014 and 2015, with more than 160000 arriving in Sweden alone. Little is known about the impact of this influx on voting behavior, criminality rates, labor markets, and local price levels. By using data on the Swedish municipalities, the analysis estimates the short-run consequences of the refugee inflow. The results are found through a dynamic difference-in-difference estimator, which compare municipalities in Sweden who received relatively many refugees (treated) compared to those hosting relatively few refugees (control). The quasi-randomized allocation process of refugees in combination with a very high variation among the different municipalities refugee-intake creates stable conditions for reliable estimations through the difference-indifference approach. Regarding the labor market, the findings suggest that the treated groups hosting many refugees face higher unemployment rates and simultaneously lower wage levels. Additionally, the result indicates that the municipalities hosting more refugees face higher crimes committed per capita, particularly regarding assault- and fraud-related crimes. Furthermore, the results stress that the treated group meet higher vote shares in the subsequent national election in favor of the right-wing parties and decreasing support for the center-right, center-left, and left-wing parties. Surprisingly, the vote share of the antiimmigration party SD does not correlate with refugee-influx.
\end{abstract}




\section{Table of content}

1 Introduction.

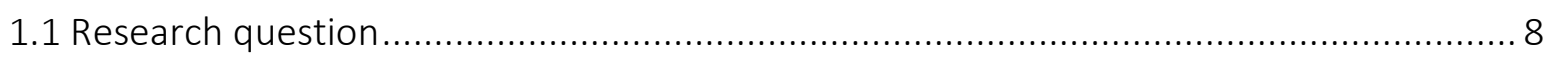

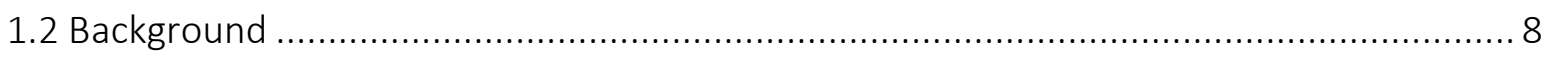

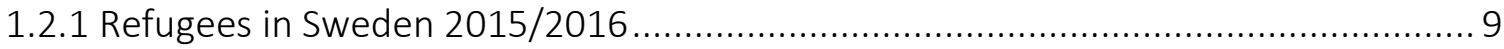

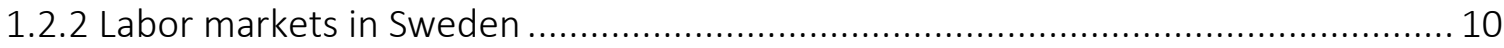

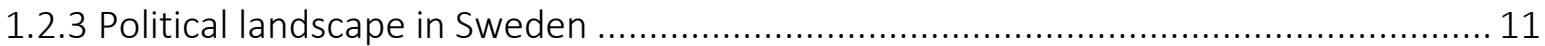

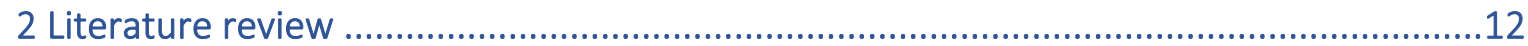

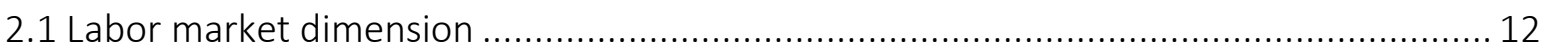

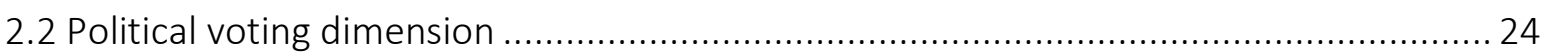

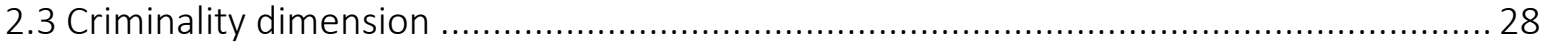

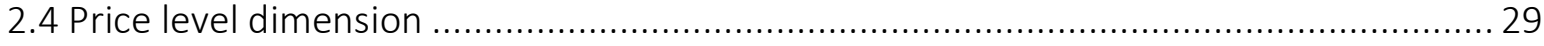

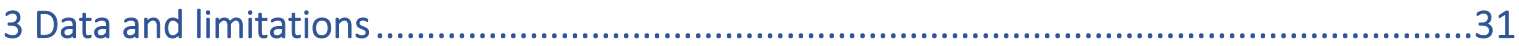

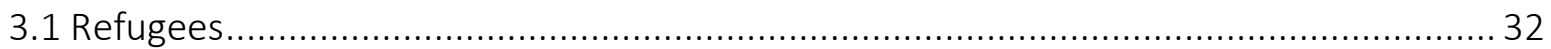

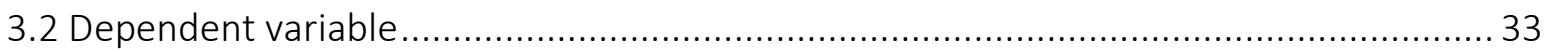

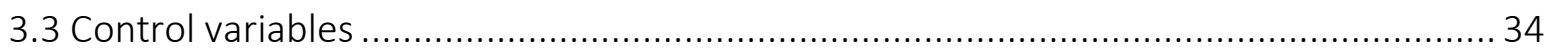

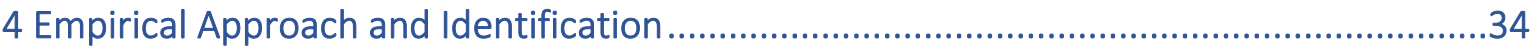

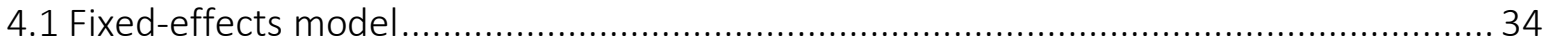

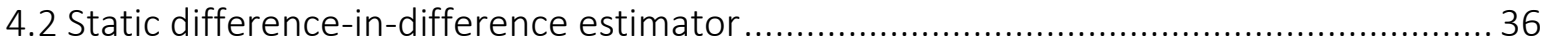

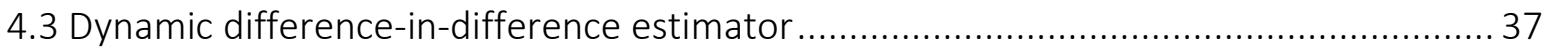

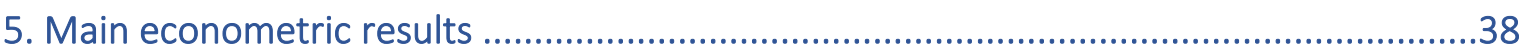

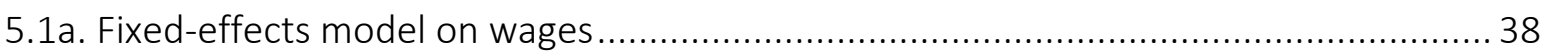

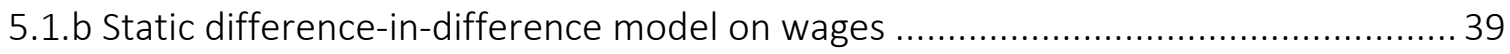

5.1.c Dynamic difference-in-difference model on wages ........................................... 40

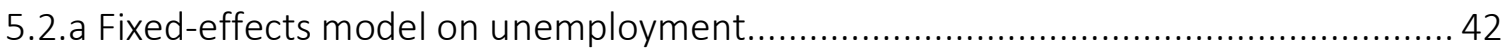

5.2.b Static difference-in-difference model on wages ............................................... 43

5.2.c Dynamic difference-in-difference model on unemployment ................................ 44

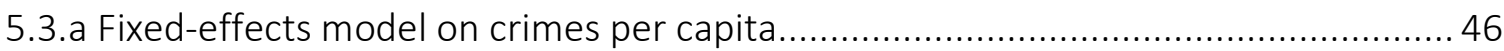

5.3.b Static difference-in-difference on crimes per capita .......................................... 47

5.3.c Dynamic difference-in-difference model on crimes per capita .............................. 50

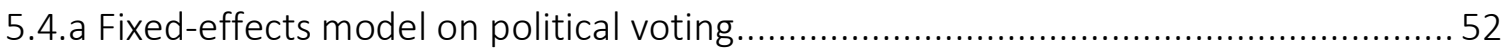

5.4.b Static difference-in-difference model on political voting .................................... 54 
6.1 Difference-in-difference model on local municipality mandates ................................ 58

6.2 Density of immigrants on votes allocated to anti-immigration parties.......................... 58

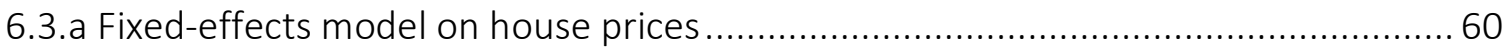

6.3.b Refugee influx on House prices, static difference-in-difference model. .................. 61

6.3.c Dynamic difference-in-difference estimator on house prices .............................. 62

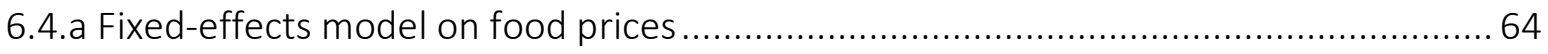

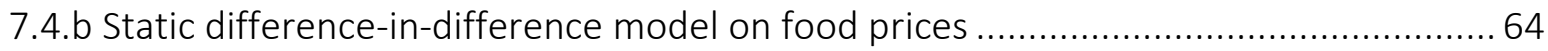

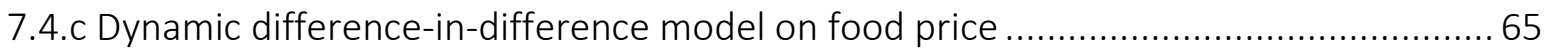

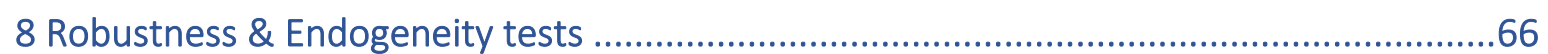

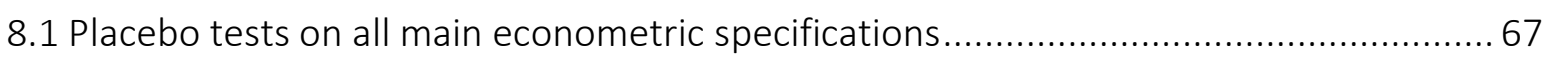

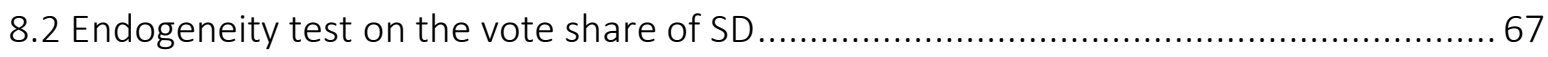

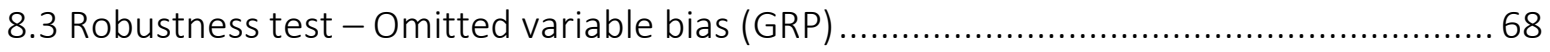

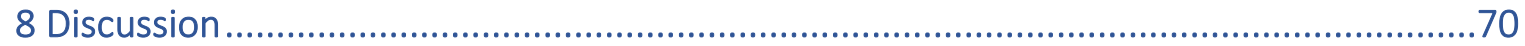

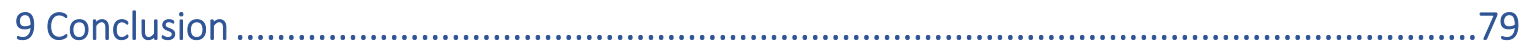

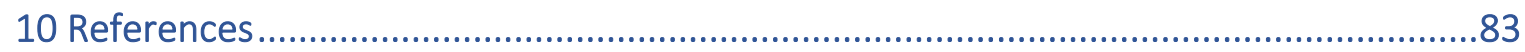

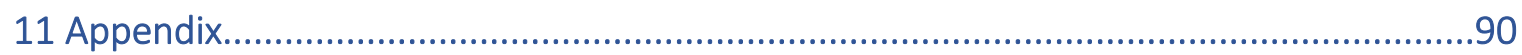




\section{Introduction}

In 2015, Swedish policymakers decided to make a humanitarian effort to respond to the refugee crisis that emerged because of the war in Syria. That year, refugees filed more than 160000 asylum applications in Sweden (SCB, 2015). The high amount of applications implied an enormous impact on operations in 2015 and 2016 as the average processing time for asylum applications was 328 days (EMN, 2017). The number of immigrants applying for a residence permit in the country was the highest throughout history (SCB, 2017).

In February 2016, the newspaper Dagens Nyheter reported that $40 \%$ of the Swedish population considered immigrations and integration the most important political topic in society (Delin, 2016). Furthermore, before the national election 2018, another Swedish newspaper, Aftonbladet, reported that the Swedish population regarded immigration and integration as the most important political topic (Mellin, 2018). The social and fiscal encumbrance foster debate regarding the effects of immigration on society and its economy. Sweden does not put specific criteria regarding work experience or education for refugees. Thus, many immigrants are often low-skilled without knowledge of the Swedish language, which may be an obstacle for the integration into the labor market.

The paper studies the effects of the refugee inflow of 2015 in Sweden and how it affected the Swedish labor market, political voting pattern, crime-levels, and price levels. The analysis uses the refugee inflow as a natural experiment to stimulate a labor supply shock. Similarly, as David Card did regarding the Mariel Lift in Miami (Card, 1980) and Foged and Peri (2015) did regarding a migratory episode in Denmark between 1986 and 1996. The study is relevant because previous scholars find equivocal results. The research and findings on the impact of immigrants and labor supply shocks on the host country's labor market vary conditional upon the approach and assumptions the scholar uses (Aydemir \& Borjas, 2011).

The theories trying to explain whether immigration affects the outcomes of political elections consist of ambiguous results. Scholars such as Barone et al. (2016) and Beker \& Fetzer (2019) find positive correlations between immigration and vote shares in favor of the center-right coalition. On the other hand, Dustman (2019) and the contact theory (Allport 1954) could show and argue for the opposite. The ambiguity calls for more research on the subject, why the political dimension will be included in the analysis.

Gehrsitz \& Ungerer (2017) illuminates that there has been remarkably little research 
on the impact migration might have on crime levels. The debate regarding criminality has received more attention in the last years. The Swedish newspaper Expressen reported in February 2018 that significant parts of the electorate consider crime and penalty the most important political question (Granström, 2018). Furthermore, the Swedish Crime Preventing Council published a report regarding the increase in sexual-related crimes (Brå, 2019). Some co-authors argue for no relation between the increased criminality and immigration, while other co-authors of the same report say the opposite (Nyheter Idag, 2019). Additionally, the report has received critique from economists regarding its methodology (SVD, 2019). Because of the ambiguity and scarcity of research, the analysis includes the criminality dimension.

Alix Garcia and Saah (2010) highlights an issue regarding wage-analysis due to migration, price levels on local markets could often be affected and simultaneously overseen by scholars. Furthermore, Dustmann, Glitz \& Frattini (2008) advocate that besides immigrants' impact on GDP per capita, measures such as prices of goods and the housing market deserve equal attention and should be considered in the design of migration policies. Some studies regarding price levels exist. For example, Hallam (1996) find a positive association between price-levels and immigration, while Landau (2002) does not. Hence, previous results differ among each other, which encourages further investigation. Consequently, the analysis will include the dimension regarding price levels.

As migration-policy fosters much debate and is proven to be a very complicated task, providing more insights about its effects on the labor market, criminality, price levels, and political voting outcomes could mitigate policymakers' complexity. The paper uses a regional approach where Swedish municipalities, in total 290, are compared. The data will take part in 2012, i.e., before the labor supply shock, it will include the year of the shock (2015) and contain all available data in the following years. In this manner, one can follow the same observations before, during, and after the exogenous supply shock.

The study serves two purposes: First, it contributes to the literature by exploiting a natural experiment created by the allocation mechanisms in Sweden during the refugee crisis in 2015. The analysis shows that the policy party allocated migrants to municipalities based on factors uncorrelated to the local labor market conditions, political conditions, or crime level.

Secondly, the paper provides a first estimation of the short-run consequences of the refugee crisis in Sweden. No similar study exists in the literature, even though the event features prominently in the public discourse. The analysis exploits a potential exogenous 
source of variation in migrant inflows to determine the effect of these inflows on unemployment, wage- and price levels, criminality, and voting behavior.

\subsection{Research question}

The research question examines if and to what extent Swedish municipalities were affected by the refugee crisis 2015 regarding its labor market, political voting structure, crime level, and price levels. The null hypotheses take the form below.

H1: Refugee inflow has a decreasing effect on average wage levels within Swedish municipalities

H2: Refugee inflow has an increasing effect on unemployment levels within Swedish municipalities

H3: Refugee inflow has an increasing effect on crime levels within Swedish municipalities

H4: Refugee inflow has an increasing effect on vote shares of anti-immigration parties within Swedish municipalities

H5: Refugee inflow has a decreasing effect on local price levels within Swedish municipalities

Nonetheless, one should expect the effects on wages $(\mathrm{H} 1)$ to be limited due to the high minimum wage and other obstacles such as language-barriers that may harm the integration of the refugees into the labor market. The paper will also mention (discuss) the effects of minimum wage and language barriers in the literature review (discussion).

\subsection{Background}

Before proceeding with the literature review and the empirical model, it is crucial to clarify the environment's peculiarities that could influence the results, especially what type of immigration occurred under 2015. The subsequent section will also describe the Swedish labor markets and political landscape, which will likely impact the results. 


\subsubsection{Refugees in Sweden 2015/2016}

Sweden is a country familiar with immigration. After World War II, the Swedish industrial sector stimulated labor immigrants from neighboring countries and Southern Europe. At the end of the 60's the economic growth decreased, and Sweden started to regulate immigration. Consequently, a residence permit was only given to the workers with guaranteed employment in Sweden (Migrationsverket, 2016). The regulation included a few exceptions, such as Nordic citizens, refugees, and family reunification. Due to stricter regulations, refugee immigration and family reunification became the dominant immigrant group (Migrationsverket, 2016). Since the 80s, refugee immigrants have been the dominant immigration group. In 2016, $17 \%$ of the population in Sweden was born abroad, and one-third of them had a refugee background (Migrationsverket, 2016).

During the last two decades, Sweden has received substantial parts of its refugees from the Middle East. Before the war in Syria, the major emigration countries were Iraq, Afghanistan, and Iran (Migrationsverket, 2017). In 2015, due to the civil war, more than 50 000 of the total asylum applicants were from Syria. In 2018, Syria topped for the seventh year in a row for the most common citizenships among the asylum applicants, followed by Iraq and Iran (SCB, 2019). The education level amongst the immigrants differs depending on their origins. The immigrants from Iraq hold higher education levels than the Syrians, even though only $30 \%$ of Iraqis had upper-secondary education. Iran stands out from the statistics, more than $30 \%$ of Iranian immigrants have upper secondary education, and almost $30 \%$ had higher education for more than three years (SCB, 2013).

In 2018 the Swedish statistical bureau published a report covering the education level among immigrants coming to Sweden 2014-2017 (Table 1 in the appendix). One can immediately notice that the observations generating the supply shock comprise a set of persons where $23 \%$ do not hold an upper secondary level. Instead, $21 \%$ hold an upper secondary education of fewer than three years, while $33 \%$ hold a full (three year) upper secondary degree. $23 \%$ of immigrants possess higher education (SCB, 2018).

To better understand the magnitude of the refugee shock, it is fruitful to read Table 2 , illuminating the number of asylum seekers in Sweden over the last years. An extraordinary inflow occurred in 2015 as it is drastically higher than its previous and subsequent years, illustrated in Table 2. 


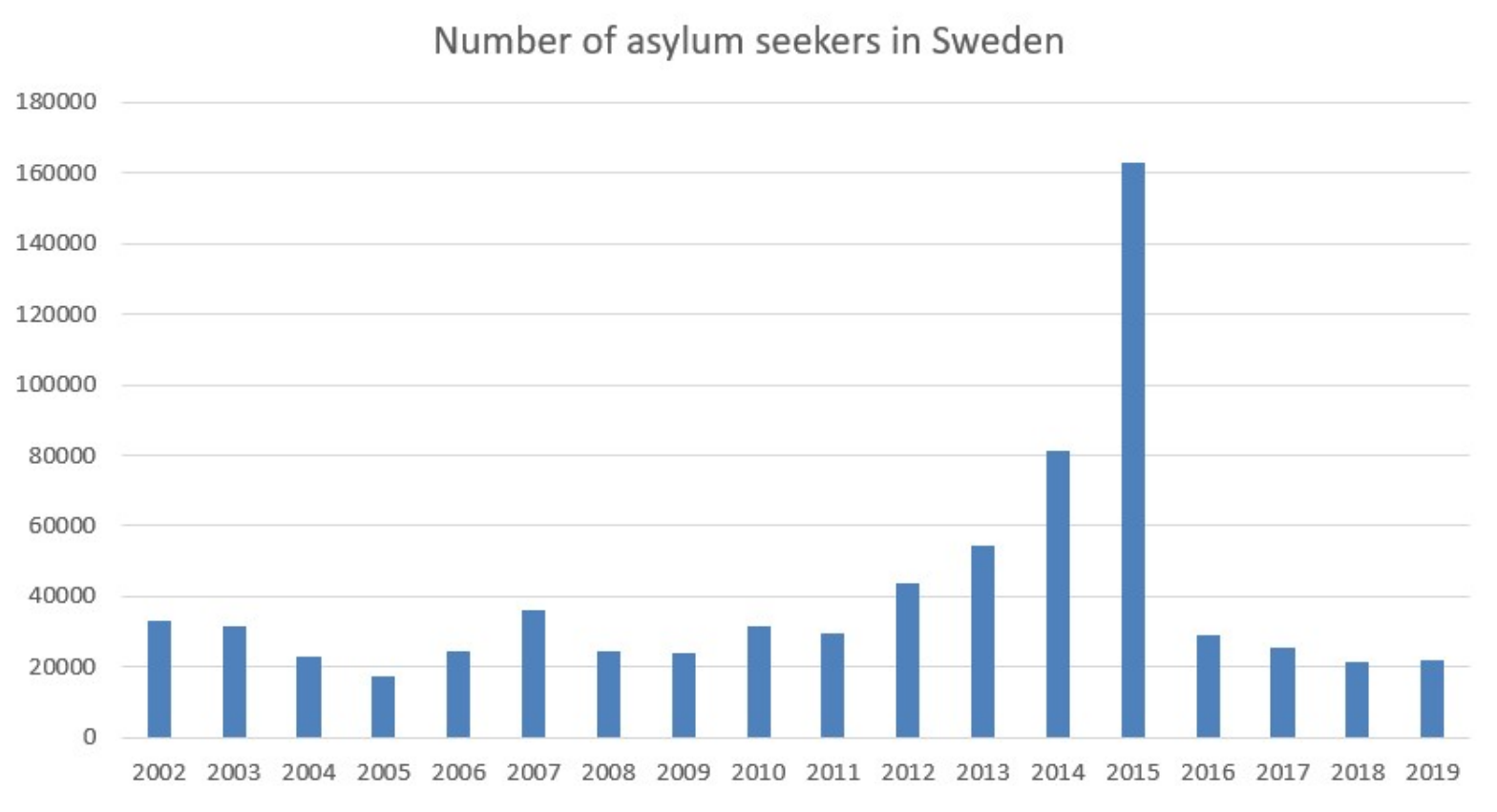

\subsubsection{Labor markets in Sweden}

The labor market in Sweden has high educational requirements. The average unemployment rate during 2015-2018 was 6,9\%, while among the workers without upper-secondary education during the same period was more than twice as high; 14,5\% (OECD, 2020). During the first decade in the 21st century, the labor market in Sweden changed. The service sector now exceeds the industrial one, jobs are getting more centralized in urban areas, and more jobs demand a higher education (Arbetsmiljöverket, 2011). The employment statistics provided by OECD highlight the importance of higher education to enter the labor market. It states that the unemployment rate for individuals with upper-secondary education was 3,4 \% compared to $14,5 \%$ for individuals with lower education (OECD, 2020).

In 2018 the participation in the labor force among natives relative to the foreign-born population in Sweden amounted to $84,1 \%$ compared to $79,1 \%$, i.e., foreign-born participation is still higher than the OECD average. Furthermore, only $5 \%$ of Sweden's jobs demand low-skill, which could induce problems for the low-skilled refugees entering the market (OECD, 2016). Beyond the education that refugees have accumulated in their home country, entering the labor market in a host country may require additional knowledge such as language, social and cultural skills (Duvander, 2001).

In the Swedish labor market, there exist plenty of regulations deemed to protect the employee in various situations: working time act, protection act, vacation act, and the 
parental leave act, et cetera. Such provisions aim to create security and mitigate high volatility driven by recessions and booms (Skedinger, 2010). Even if there is no statutory minimum wage in Sweden, there is a minimum wage on the collective agreement negotiated by trade unions (Fackföreningarna, 2014). Furthermore, the minimum salary in Sweden is one of the highest in Europe. While the average between the EU-countries with minimum wages is $44 \%$ of the median wage, Sweden's minimum wage amounts to $66 \%$ of its median.

Furthermore, the differences in salaries between education levels are small. In 2011, Sweden had the lowest wage-spread among all industrial countries within the OECD (Spector, 2014). The high minimum wages combined with the low wage-spread imply small spaces for wage-development for those with jobs during the work-period. There are only a few thousands of SEK within some sectors between entry, median, and exit-salary (Spector, 2014).

\subsubsection{Political landscape in Sweden}

Sweden is a representative democracy where a political party needs at least $4 \%$ of the total votes to enter the parliament "Riksdagen." Today, eight parties are in it. There exist two parties to the left: Vänsterpartiet (V) and Socialdemokraterna (S). One green party: Miljöpartiet (MP). Two center-right parties: Centerpartiet (C) and Liberalerna (L), and two conservative parties: Kristdemokraterna (KD) and Moderaterna (M). Furthermore, there exists an anti-immigration party: Sverigedemokraterna (SD), which surpassed the $4 \%$ threshold for the first time in 2010. Sverigedemokraterna is the party that grew most during the last years. In the previous election (2018), they received 17,53 \% of the total votes (Valmyndigheten, 2020), compared to 2006, when they solely received $2,93 \%$.

During the last decades, there have been two distinct coalitions, one left-coalition consisting of $V, S$, and $M P$ and one right-coalition consisting of $M, K D, L$, and $C$. Because of the increase in vote share allocated to SD, and much emphasis on the GAL-TAN dimension, the old structures are not as robust as before (Demker, 2018). Consequently, after the election of 2018, the left-wing party S and environmentalist party MP formed a coalition with the two center-right parties $\mathrm{L}$ and $\mathrm{C}$, which today together rule in the parliament. 


\section{Literature review}

This section will go through the different subjects one by one, starting with the effect of migration on labor markets, then it will continue with political voting, price levels, and crime levels. The previous literature treating the impact of immigration on the host country's labor market is immense, and the results vary. The heterogeneity among studies remains because a host country's labor market, policies, and economic fluctuations affect the results. Hence, as these variables change, it is not surprising that the previous research and results differ between countries and periods.

\subsection{Labor market dimension}

In the simplest economic model presented by Dustmann, Glitz, and Frattini (2008), wages are determined by the country's production technology and supply of production factors. For simplicity, one can assume that the potential immigration country, in this case, Sweden, only has one industry and produce only one output good, using both labor and capital. The first question arising is how immigrants enter labor? Early papers assume that immigrants are a distinct production factor, i.e., labor consists of immigrants and natives (Grossman, 1982). Consequently, immigrants and natives are not defined as perfect substitutes.

However, as Dustmann, Glitz, and Frattini (2008) highlight, it is difficult to argue that two equally qualified workers, one a native and the other an immigrant, are not easily substitutable in production. As the scholars emphasize, it seems more rational to draw the distinction between different groups of labor inputs along a skill dimension. Consequently, more recent papers, which the literature review will present, distinguish the production technology between unskilled and skilled labor and assume that immigrants are perfect substitutes with their corresponding native skill category.

Within a specific group, immigrants and natives are perfect substitutes. They are interchangeable. The third factor of production is capital. The model commences by assuming that capital supply is perfectly elastic. It means that firms obtain capital at a fixed interest rate, which could be interpreted as being set on an international market. Furthermore, one can assume that unskilled and skilled labor supply is perfectly inelastic (Dustmann, Glitz, and Frattini, 2008).

Notably, regarding this paper, it is to understand what happens to wages when immigration occurs. One could imagine that the economy consists of skilled and unskilled 
workers in equal proportions, and in a sense, is in equilibrium, employed at equilibrium wages, which may vary by skill level. If the newly arrived immigrants differ in their skill endowment compared to natives, they will create a change in the overall skill composition in the economy. For example, if all immigrants are unskilled, this will lead to a disequilibrium between supply and cost-minimizing demand for different labor-types existing at current wages and output levels (Dustmann, Glitz, and Frattini, 2008). There will be an excess of unskilled workers at the current wage rate. Consequently, the absorption of the new workers into the economy and restoration of equilibrium will involve short-run changes in the wages and employment level of different skill types.

In this set-up, it is essential to understand that immigration will only affect wages and potential employment rates if the immigrants' skill distribution differs from that of the native workforce. If the skill distribution, on the contrary, is equal to that of natives and capital supply is sufficiently elastic. Immigration will simply scale up the economy through an increase in output without affecting wages and employment levels of natives. For example, consider the extreme case where solely unskilled immigrants enter the hosting country, the immigration will lead to an excess supply of unskilled labor at the pre-immigration wages. Because unskilled labor is in excess supply, firms will satisfy their demand for labor even at lower wages. Consequently, the excess-supply leads to a decrease in wage-levels for the unskilled workers (Dustmann, Glitz, and Frattini, 2008).

However, a supply shock consisting of unskilled workers leads to a relative scarcity of skilled workers, driving up their wages. Consequently, skilled workers gain from immigration. Simultaneously as wages of unskilled workers fall, the wages of high skilled workers rise. In the simple example, the surplus accumulating to skilled workers is higher than the loss of unskilled workers, where the difference is referred to as "immigration surplus" (Dustmann, Glitz and Frattini, 2008).

Thus, the simple model suggested by the scholars has, in the worst case, no effect on average wages. How does that sum up with the common perception that immigration is bad for wages on average? Because of the made key assumption, namely that capital is elastic in supply. The assumption is reasonable for a small open economy like the UK (or as in this case, Sweden), and migrations of the magnitude one usually observes. However, by giving up this assumption, redistribution will affect skilled labor and capital, and average wages may decrease because of immigration. 
The arguments above are critical regarding this paper, as Sweden is a relatively small and open economy. Furthermore, average wage levels are relevant, as this paper's data is based on municipalities and cannot distinguish between skilled and low-skilled workers. According to the scholars, the effects on average wages one should except within this simple setting depend on the viewpoint one makes about capital mobility (Dustmann, Glitz and Frattini, 2008). The empirical evidence regarding capital flows and their response to immigrant inflow is quite scarce. However, Ottaviano and Peri (2006) take the capital adjustment into account and estimate the speed at which capital reacts to deviations from its balanced growth path. Following the evidence from the business cycle literature (Islam 1995, Romer 2006), they find a convergence rate of $10 \%$ per year (each year, $10 \%$ of the immigrant induced deviation from the growth path of capital/labor ratio is eliminated by capital inflows). The estimate is likely to be conservative, in particular, for open economies.

In their example, the adjustment speed means that instead of reducing the capital/labor ratio by $11 \%$, and consequently average real wages by 3,6 \%, the immigrant inflows in the U.S. between 1990 and 2004 only reduced the capital/labor ratio by 3,4 \%, which implies a much smaller negative effect of only $1,1 \%$ on average wages (Ottaviano and Peri, 2006). What is essential to understand is that the faster capital can adjust, the smaller the immigrants' effect on average wages in the economy (Dustmann, Glitz and Frattini, 2008).

Countries with high wages are induced to have a higher capital to labor ratio. In Sweden, wages are high, why firms in Sweden are incentivized to invest in capital to reduce the high labor costs. In the model advocated above, one assumption made is that workers supply labor whatever the wage - the supply is completely inelastic. If the labor supply is somewhat elastic, some workers will not want to work if wages decrease and instead choose unemployment. In this situation, there are equilibrium employment effects. Immigration may cause voluntary unemployment among native workers encountering lower wages.

If one expand the model from a one-sector economy, producing only one output into a multitude of the different sectors producing goods that differ in their capital intensity and their relative use of skilled versus unskilled labor, the complexity rises. It gives rise to two alternative adjustment mechanisms, which will be briefly discussed and are essential to make sense of the findings in this paper.

The mix of output goods the economy produces reflects the first mechanism. Suppose, as before, that the immigrants increase the relative supply of unskilled versus skilled 
workers. While in the simple model above, the absorption comes through a decline in unskilled wages. With more than one industry, there is an additional way of accommodating the increase in unskilled labor supply by increasing production of those output goods that use unskilled labor more intensively (Rybczynski, 1955). Suppose the small economy has two industries, one intensive in low-skilled workers and one intensive in skilled workers. In such an economy, the increase in unskilled labor supply induced by the immigrant-influx will drive down wages of unskilled workers (see Gaston and Nelson 2000, for a more detailed description).

The results are the same as in the previous model. However, the wages now lead to a relatively more substantial decrease in unit production cost for the low-skill intensive industry than for the skill-intensive one. Because with fixed output prices (traded on the world market where the small economy does not have an impact on price-setting), there will be more massive profits in the low-skill intensive industry. In a perfect market, this will induce new firms to enter the industry (or firms move from the skill-intensive to the more profitable lowskilled industry), expanding its production and increasing the relative demand for low skilled workers. This expansion, in turn, will drive up unskilled wages. Accordingly, while the shortrun or immediate impact of immigration is to lower wages on unskilled workers, in the long run, wages will increase again (Dustmann, Glitz and Frattini, 2008).

Assuming the eventual equilibrium continues to involve concrete production in all traded good sectors, wages should return to the initial pre-immigration equilibrium. The adjustment process may be swift. For instance, if firms foresee the change in skill composition, or if the required capital for the expanding industries is readily available. Leamer and Levinsohn (1995) refer to this as the hypothesis of factor price insensitivity. The authors advocate that the economy will fully absorb the additional unskilled workers through an increase in production of that good that uses unskilled workers intensively without long-term changes in the relative wage structure. The results can be generalized to multiple input factors and multiple outputs, and non-traded goods, with relevant algebra in trade theory models (see, e.g., Ethier, 1984, and Woodland, 1982).

The second adjustment mechanism works through technology. The idea is simple. As before, suppose that two different industries produce an output good with a given technology and relative factor intensity. Immigration leads to an increase in the relative supply of unskilled workers. Given the change in labor supply, both industries now select, 
endogenously, a production technology out of available technologies. In this case, the economy will be able to absorb the extra influx of unskilled labor without necessarily significant changes in the local wage structure or the local output mix. Empirical evidence shows that computer-substitution and automation expand rapidly in the areas where the relative supply of skilled labor grows fast. Consequently, the adjustment channel regarding technology is essential (Doms and Lewis, 2006).

There is empirical evidence that analyzes which of the two channels are quantitatively more important in absorbing changes in local labor supply (Hanson and Slaughter 2002, Dustmann and Glitz 2008, Lewis 2004, are some examples). The evidence from these studies advocates that the most substantial part of the absorption of additional workers, roughly around two-thirds, is explained by endogenous changes in production technology.

Before digging deeper into the empirical field of studies, one should acknowledge some crucial takeaways from the somewhat tedious but important considerations above. What can be learned from the considerations regarding the wage-structure? First, one should only expect effects if immigrants change the skill structure of the receiving country. Hence, given that, as mentioned in the background, the refugees' inflow to Sweden during the period 2012-2018 has relatively low skill compared to the natives in Sweden, one could notice that this is the situation. Consequently, according to the theory above, in this paper, one is induced to expect impacts on the wage structure.

Second, the effects of immigration impact differently across the distribution of wages. In particular, those workers with similar skill compositions to the immigrants might lose, while workers with different skills may gain. In this context, one could expect slightly different immigration distribution effects if immigrants and natives are only imperfect substitutes within the same skill group (Ottaviano and Peri, 2006). An increase in labor supply due to immigration will primarily affect other immigrants already living in the country (Manacorda et al., 2006). Consequently, most natives experience substantial wage gains from immigration, while the lowest skill-group suffer relatively mild cutbacks (Dustmann, Glitz, and Peri, 2006).

Third, the overall effects on average native wages in the economy are positive, zero, or negative. The view upon the elasticity of capital supply creates the basis of the effects' magnitude. If capital supply is perfectly elastic, migration will not affect average wages, but these will be negative for workers who compete with immigrants and positive for workers who do not. Overall, the effect on average wages is always zero. Due to migration surplus, the 
average wage effect for natives may even be positive (Dustmann, Frattini, and Preston, 2008).

The theory provides us with a myriad of different effects that immigration could have on the labor market. The question that arises for countries is how immigration impacts the particular country in reality? For economists, this translates into the question as to how immigration's effect on employment and wages can be estimated, what the problems of empirical assessment are, and what the evidence is. Before moving to the empirical strategies executed in different countries over the last years, one should acknowledge some issues by measuring wage levels due to immigration, stressed by Dustmann, Frattini, and Glitz (2008).

To understand the underlying mechanism in answering these questions, one could focus on wage and assume that there is a prominent immigration wave in a particular year $t$. The economist observes the economy's wage before the migration occurs (year $t-1$ ), and the wage after the migration has taken place (year $t+1)$. One approach to estimate the effect of migration is to compare average wages in years $t+1$ and $t-1, w_{t}+1-w_{t}-1$ with the wage change that would have taken place if migration had not occurred $w_{t}+1^{*}-w_{t}-1$, and to compare this to the magnitude of immigration, which could be measured as the change in the stock of immigrants $I_{t}+1-I_{t}-1$. Consequently, the effect immigration has on native wages is then the parameter

$$
\frac{\left(w_{t+1} *-w_{t-1}\right)-\left(w_{t+1}-w_{t-1}\right)}{I_{t+1}-I_{t-1}} .
$$

The issue with the parameters is the hypothetical wage $w_{t}+1^{*}$, which is unobservable as one does not know wages in the hypothetical absence of migration. The hypothetical wage will be referred to as the missing counterfactual. To obtain a credible estimate of the effects immigration has on wages, the counterfactual has to be reconstructed. The substance of the empirical literature on the impact of migration is concerned with reconstructing this missing counterfactual (Dustmann, Frattini, and Glitz, 2008). Doing it always requires some assumptions - these assumptions will be referred to as identification assumptions. The credibility an analyst can give to his empirical work is determined by how credible these identification assumptions are.

So how can one reconstruct the missing counterfactual? One way to do so is to segment the labor market in different submarkets and compare wage changes in markets that experienced an influx of migration with markets that did not. The most common approach in 
the literature, followed in this paper, is to distinguish between different regional labor markets. Suppose that a particular region, let us call it "South" has a higher wage growth and that immigrants correctly expect this, leading to a higher inflow. In this potential case, our estimate above would give us a positive number (suggesting that immigration increases wages) even if the causal effect of immigration on wages is equal to zero (Dustmann, Frattini, and Glitz, 2008).

To evade this issue, one can choose different channels. First, in some circumstances, it may be that immigrants have no choice of initial settlement and are allocated to particular areas. For instance, this is the case regarding immigrant dispersal policies in Sweden (Edin, Fredriksson and Aslund, 2003) and Denmark (Damm 2006). These government policies are a source of exogenous regional allocation of immigrants by designating them to particular labor markets upon arrival and avoiding immigrants from endogenously moving to areas offering more favorable marketing conditions. This paper will derive its exogenous allocation from similar policies like the one mentioned, where $50 \%$ of the refugees were distributed independently of labor market conditions.

A second approach is to predict immigrants' distribution to different regions by using variables that are not correlated with the expected shock to wages in the future. An example of such a variable could be immigrants' historic settlement pattern, making use of the observation that immigrants tend to settle where other individuals from their community have settled before (Bartel 1989). Under the assumption that past migration decisions are unrelated to contemporary wage shocks, it is feasible to obtain an estimate of immigrant inflow exogenous to current wage shocks. It allows the identification of the "true" causal impact of immigration on wages. This procedure, which is usually implemented by using past immigration as an instrumental variable for contemporary changes, has found widespread use in migration literature (Dustmann, Frattini, and Glitz, 2008).

However, the last problem arises from the fact that local labor markets are not closed economies, and workers are free to move in our out. Consequently, if immigration drives down local wage for certain skill groups, one would expect there to be a pressure for current resident workers of that skill type to move elsewhere to gain higher wages. Therefore, the wage impact will be dispersed throughout the national economy and undermine the capability to identify the wage impact from analyzing effects within localities. It implies estimates of the effect of immigration on wages and employment of workers currently 
residing in local labor markets, which are not as negative as the effects one would have obtained without the internal migration responses. Whether or not this is a severe problem remains disputed. Many scholars find little or no evidence for this phenomenon; Wright, Ellis and Reibel (1997), Card and DiNardo (2000), and Card (2001, 2005) While some scholars consider it a far more important factor: Filer $(1992)$, Frey $(1995,1996)$, Borjas $(2003,2006)$ and Hatton and Tani (2005).

Dividing the labor market by region is one way to estimate the effect. Another possibility is to divide the market by occupation or skill group and use the fact that immigration occurs to a different extent in different skill groups. Borjas (2003) treat skill groups by experience and education and eliminate regional variation, using only the variation of inflows across these experience-education observations. The strategy allows him to stress criticism that immigration may lead to out-migration of natives of some regions, consequently, dispersing effects of immigration across the national economy. Furthermore, it addresses the problem of the selection of immigrants into regions that do economically well. However, the problem that the individuals immigrating belongs to the high skill group remains. Additionally, and more importantly, the approach depends on the assumption that immigrants are perfect substitutes with natives within specific skill categories. This assumption could be violated if immigrants degrade in an unpredictable manner, which Dustmann, Frattini, and Glitz (2008) find for the UK, and Weiss and Eckstein (2004) regarding Israel.

Studies employing quasi-experimental designs or exogenous shocks to investigate labor market outcomes and avoid the issues emphasized by Dutsmann, Frattini, and Glitz (2008) are relatively few. A prominent paper concerned the Miami boatlift in the early 1980s by Card (1990), who find little effects on wages and employment from an incoming migration wave. Hunt (1992) and Carrington and De Lima (1996) study the impact of the repatriates from the African colonies to France and Portugal, respectively, and find negative effects on employment and wages. These studies' potential problem is that repatriates can choose to settle in areas with better economic prospects, leading to underestimated employment and wage effects.

A recent example of a quasi-experiment rooted in political turmoil is Glitz (2012), who exploits German migration regulations in 1989 to identify the effects of Germans in Eastern Europe returning to Germany. The scholar finds small negative effects on wages and internal 
migration. Except for Card (1990), the reviewed literature on the impact of migration of labor market outcomes using quasi-experimental techniques is informative regarding the effects of returning co-ethnics or repatriates from colonies on the local labor market. Still, these incoming migrants tend to be relatively high skilled or have the required knowledge of the language to adapt relatively quickly to their living environment.

As pointed out by Akgündüz et al. (2015), at least in Europe, the center of debates usually concerns the migration of poor and unskilled immigrants and refugees driven away from their home country by war and civil unrest or more developed countries. This type of immigration could lead to different results rather than, for example, work-related migration. It is also upon this type of immigration this paper will direct its focus.

The best solution to avoid underestimating wage effects due to geographical correlations is to exploit exogenous shocks leading to large-scale immigration. However, they can also be challenging to analyze (Akgündüz et al., 2015). If no measures limit the immigrant location choices within the host country, it will not be easy to construct a control group. The randomization mechanism in the allocation process of refugees in Sweden during the crisis 2015 (where approximately $50 \%$ where randomly allocated to their location) and the dramatic speed at which refugees started crossing the Swedish border makes it possible to avoid many of the practical issues discussed by Dustmann, Glitz, and Frattini (2008) above.

Large scale refugee-influxes generally occur in areas where both the county from which people are fleeing and the host country are underdeveloped. For example, Tanzania's refugee crisis hosted many refugees fleeing from Rwanda in the 1990s (Baez, 2011). Consequently, the resulting labor markets are also likely to be underdeveloped and thus challenging to estimate the impact of the refugee influx (Akgündüz et al. 2015). The Syrian civil war has instead created a situation where refugees flee to more developed countries with different languages and cultures. They are also likely to lack the host country-specific skills such as language.

As mentioned before, Card (1990), in his study regarding the arrival of "Marielitos" to Miami, concluded that immigration does not significantly affect the wages of natives. However, one should regard the fact that the Miami labor market was not a generic American one. The market was particularly suited to prepare the "Marielitos" arrival compared to the control cities (other American cities such as Houston, Atlanta, and Los Angeles). The suitability consists because of two specific characteristics. First, its industry was structured to 
incorporate low-skilled workers easily. Second, the lack of English-proficiency was not a substantial entry barrier because a large part of the population in Miami talks Spanish (Card 1990). Both these particularities differ significantly from this study. First, the lack of Swedish proficiency serves as a barrier. Second, the Swedish labor industry is ill-structured to incorporate low-skilled workers.

Furthermore, Glitz (2012) measure skill-specific labor market effects of immigration because of the fall of the Berlin wall. This type of regional approach used by both Glitz (2012) and Card (1990) has received critique for the endogenous problem caused by the positive correlation between immigration and labor market conditions. Glitz (2012) used the exogenous allocation of the ethnic Germans living in Eastern Europe to who was allowed to migrate to Germany between 1987 and 2011. This exogenous allocation partly solved the endogenous problem. Glitz (2012) did not find any significant wage effects regarding the whole population. By separating the working-age population by gender, he found negative results, the immigration shock affected women more than men.

Glitz (2012) assumes that the insignificant effects were a result of wage rigidity, collective agreements, and labor unions, which together leave little space for regional differences. Importantly, Glitz (2012) stresses that adjustments in unemployment are more likely to appear than the wage effects, at least in the short run - due to the wage rigidity. Therefore, in this study, one could be tempted to expect somewhat similar results as Glitz (2012), because the Swedish labor market is characterized by wage rigidity, collective agreements, and labor unions.

A recent and similar study to this paper, conducted by Foged and Peri (2015), attempted to overcome the limitations of a regional approach by concentrating on a migratory episode which occurred in Denmark between 1986 and 1996 when thousands of refugees from conflict countries such as Afghanistan, Somalia, Lebanon, and Vietnam immigrated to Denmark. Importantly, after their arrival, they were distributed by the Danish authorities between different cities according to the availability of public housing. Furthermore, the refugees' distribution was executed without considering immigrants' socioeconomic characteristics or their geographical preferences. Hence this kind of set-up demonstrates an increase in the supply of labor independently of the local economic conditions. Their paper measures the massive influx of refugees on low-skilled workers' working-conditions during 1991-2008. The scholars analyzed low-skilled workers since 
refugees can be considered substitutes to them as they generally have a low-skill level compared to the host country. Furthermore, refugees often have a shallow knowledge of the language and are thus often concentrated in low-qualified occupations characterized by a high degree of manual tasks (Foged and Peri, 2015).

The study found three main results. First, the influx of refugees distributed the natives into more complex occupations with a lower degree of manual tasks. Second, a zero or positive effect on the level of employment and wages of the natives was estimated. Third, the effects persisted over time. Hence, the scholars concluded that immigrant workers have characteristics different from the natives and are not perfect substitutes in the labor market. The third point is interesting as it diverges from Dustmann, Frattini, and Glitz (2008), who assume natives and immigrants to be perfect substitutes within the same skill group. While immigrants usually focus on occupations with a higher content of manual tasks, natives reallocate to occupations with less manual occupations with a higher degree of specialization and sophistication (Foged and Peri, 2015).

Instead of the approach explained above, i.e., measuring different regions, there is another approach to measure labor markets, namely a national approach. As one can derive from its name, the national approach targets the whole national level instead of dividing the market into smaller fractions. For example, Borjas (2003) analyzes the impact of immigration on unemployment and wage levels on the national level. He stresses that the regional approach underestimates the consequences of migration. It assumes that factors of production, labor, and capital, as well as goods, do not adjust quickly to the increase in labor supply caused by immigration.

Additionally, he also identified two problems with the regional approach. First, immigrants are not randomly distributed among labor markets (this was, however, party the case in my, and unambiguously the case in Foged and Peri's (2015) study). Borjas (2003) argues, which I mentioned before, that immigrants tend to settle down in areas with thriving economies - which creates a correlation between immigration and wages. Second, the emigration of locals from labor markets with a high immigrant-density would bias results. If locals move because of migration, an interregional comparison of the wages of native workers could show little or no difference since immigration spread throughout the national economy, not because immigration did not have economic effects.

Regardless of the exogenous placement, the impact of immigration on wage levels has 
been small or modest in the studies (Kugler et Yuksel, 2008). A plausible reason for the missing effect is proposed by the two arguments advocated by Borjas (2003) above.

Consequently, constructing the counterfactual for areas facing immigration is difficult since regions that could serve as a control group may be at the receiving end of internal migration. Nevertheless, the size of the internal migration effect is contested by Card (2005), who claims that there is little evidence of immigrants (to the US) harming employment opportunities of natives.

Cortes (2005) provides evidence for Borjas's hypothesis but further advocates that displacement effects cannot be the only explanation. When Cortes exploit cross-city variation, she finds adverse wage effects for immigrants and native Hispanics. She argues that her result points to different reasoning; low skilled natives and low skilled immigrants are not perfect substitutes. Thus, a low-skilled immigration shock should mostly affect the wages of other low-skilled immigrants and have a smaller effect on low-skilled natives' wages. Furthermore, Borjas (1986) finds that a $10 \%$ increase in immigrants' supply reduces the immigrant wage by about 10 percent. Thus, one could from the studies of Cortes (2005) and Borjas (1986) be induced to think that immigrants' main competitors in the labor market are other immigrants. The wage progression for natives is a different story. Grossman (1982, p.600) finds that a 10 percent increase in the number of immigrants reduces the native-born wage by between 0,2 and 0,3 percent.

To fully grasp this paper, it is essential to understand what a supply shock on the labor market is. Intuitively an increase in the labor force causes a shift of the labor supply curve to the right. If the exogenous wage level remains the same, the labor supply shock will generate unemployment in the short run. Based on this model, due to the shift in labor supply, one expects to obtain adverse effects in terms of decreased wages. This conjecture is based on the idea that a labor supply shock increases the number of workers willing to accept work on a lower wage level.

In Sweden, there exist unions and minimum wages, which could affect the magnitude of the shift. The theory of labor unions and minimum wages is based on the premise that wages through collective agreements are higher than the natural wage level $w^{*}$, which implies a higher wage level. A minimum wage level wu equals a wage level determined by labor demand and supply, but also the "union mark-up" $(1+u), w_{u}=w^{*} \cdot(1+u)$. Ceteris paribus, the union mark-up, will raise the relative wages, which leads to higher 
unemployment since fewer firms can afford to pay it. Labor unions tend to have a higher power in low-skilled markets. Consequently, the low-skilled workers are more affected by the "union mark-up" (Gottfries, 2013).

A minimum wage only affects low-skilled markets since the high wage level wh is higher than the minimum wage, while the opposite holds for the low-wage level. The minimum wage deters firms from hiring low-skilled workers since the minimum wage is higher than the equilibrium wages.

\subsection{Political voting dimension}

The effects of immigration on the receiving countries have been extensively investigated. However, the literature has focused mainly on labor market aspects. Another important, but less analyzed issue concerns the relation between immigration and voting behaviors of the natives, who potentially could have strong views and prejudices (Barone et al., 2016). This issue is relevant as immigration policy is at the center of the debate on the future of the European Union. Furthermore, political parties against the Euro area are often associated with more protectionist views on immigration (Barone et al., 2016). The Front National in France, the Dutch Freedom Party, the United Kingdom Independence Party in the UK, the Italian Lega Nord (Northern League), and the Swedish Democrats are some examples of the political positions.

Although the existing literature is scarce, there are some examples. Mendez and Cutillas (2014) investigate Spain's case regarding election outcomes in 1996-2011, a period influenced by a sharp increase in immigration shares. They analyze 48 provinces and use province-level fixed-effects and instrument-variable analysis following (Card, 2001). The past migration pattern is the instrument for the present, i.e., that immigrants tend to move to an area where a group of immigrants of the same ethnicity is already present. The authors find that immigration does not have any robust effect on higher vote shares for anti-immigration coalitions (Mendez and Cutillas, 2014). However, when the authors split the immigrant partition by nationality, a positive impact on anti-immigration coalitions occurs when African immigrants are considered. Another recent contribution is given by Otto and Steinhardt (2014), who analyze the effects of immigration inflows on 103 districts in Hamburg 19871998. The scholars use an OLS fixed-effects estimation, which shows that a one-percentagepoint increase in immigrants' share causes a 0.225 percentage-point increase in the share of 
extreme right-wing parties. The results cover both federal and national elections (with a corresponding decrease for the left-wing Green party).

Gerdes and Wadensjö (2008) investigate how the influx of refugees has affected voting outcomes regarding the main political parties at Denmark's municipality levels. The analysis covers a period that includes four local government elections and four general elections between 1989 and 2001. According to their OLS and fixed-effects estimation, refugee shares are positively associated with the two main anti-immigration parties. At the same time, mixed results are found for the other parties.

The findings differ among each other. There are also different theories trying to explain whether and why immigration can affect political elections outcomes. Barone et al. (2016) analyze immigration's role in shaping electoral outcomes in Italy's case, where they focus on the national parliamentary elections of 2006, 2008, and 2011. Their results suggest that a one-percentage-point increase in immigrants' share in a municipality causes a 0,86percentage-point increase in the share of voting going to the center-right coalition. Hence, the author suggests a positive causal effect. Higher immigration leads to larger vote shares for anti-immigration parties. Similar results are found by, for example, Halla et al. (2016) investigating the case of Austria and by Becker \& Fetzer (2016) regarding the UK.

Dustman et al. (2019) find similar results but also distinguish their analysis between rural and urban areas, where different voting-behavior as a response to immigration potentially could be explained by the contact theory invented by Allport (1954). According to Allport, the interaction between ethnic groups can lead to a deeper understanding and reduce prejudice under the four conditions: equal group status, common goals, intergroup cooperation, and authority support. Dustman et al. (2019) advocate that there is a higher probability for a person in a rural area to have an immigrant friend or colleague, hence fulfilling the conditions stated by Allport (1954), which could mitigate the tendency to vote for anti-immigration parties.

Another dimension that may play a role in the relationship between voting-behavior and migration is the extent of saliency carried out by the minority group (the immigrants). By acknowledging that immigrants are a minority group, the paper written by Colussi et al. (2019) becomes interesting as they measure how the saliency of minority groups can affect election-outcomes. By comparing elections far in time from Ramadan - they find that in elections where the minority group is more salient and hence, closer to Ramadan, the vote 
shares increase for the anti-immigration parties.

Furthermore, Barone at al. (2016) stresses that not only national election outcomes are of interest since many political decisions which potentially influence the relationship between natives and immigrants are taken at the municipality level. Examples include allowing the construction of a new mosque, managing waiting lists for primary education, et cetera. Consequently, the mechanisms behind the two election levels could differ. For instance, one could argue that at the local political level, ideological and cultural determinants of the voters' stance on immigration might play a less significant role, as voting is potentially more connected with the concrete costs and benefits to a residence in a given place (Barone et al., 2016).

The same authors analyze voting microdata of 3000 interviews after the 2001 general election in Italy. They analyze why some voters stated that they interpret "immigration as a very important issue." The authors stress four different channels explaining the statement. The first channel advocates the cultural dimension, the fact that immigration might represent a threat to the Italian culture. The channel is relevant for the Swedish environment, where public discourse often treats the Swedish culture and how it is potentially affected by high immigration densities.

The second channel regards the competition of immigrants in the labor market. As mentioned before, the literature has stressed that native-immigrant-contest for jobs should be more difficult for unskilled native workers in a developed country. This channel is particularly relevant regarding Sweden because most immigrants, contrary to, for example, Canada, are unskilled.

The third channel concerns competition for public services, with a focus on the elderly and children. The authors mention that immigrants have a very high fertility rate, especially compared to Italians, which is relatively low. Consequently, this generates intense competition between immigrants and natives for public services for children, especially regarding admission to public schools.

A fourth channel, also relevant for the Swedish case, refers to the perception by natives that immigration can lie behind an increase in criminal activities. The correlation is quite a standard claim in the Swedish political campaign. Furthermore, it has been traditionally evoked by conservative parties, which often stress the importance of law and order (TT Nyhetsbyrån, 2019). For example, in the last years in Sweden, there has been a big 
debate on the importance and failure of the police, and the importance of hiring and educating police officers to create order and reduce criminality. Consequently, one could argue that people who fear that immigrants cause violence are induced to vote for more traditional parties stressing the importance of law, order, and more police-enforcement.

For example, some studies, one conducted by Bianchi et al. (2012), suggest that immigration does not raise the crime rate. Nonetheless, what matters is the natives' perception, which can be affected by political campaigns (Barone et al., 2016). Such campaigns have been conducted during the last years in Sweden. For example, the Swedish municipality Staffanstorp with conservative rule (M) has received much critique for spreading a marketing video where they try to associate natives with order and immigrants with criminality (Mattsson \& Ronge, 2020). The video they created received much attention in media as it actively staged white persons in calm and safe environments, representing Staffanstorp. For example, according to the vice president in the municipality, the Sausagekiosk owner, an immigrant, was interchanged with a white actor in the movie (Matsson \& Rongde, 2020). At the same time, the video tried to associate other municipalities with nonethnics as more violent. The video-link to the campaign is available in the appendix (see Video 1).

Bordignon et al. (2019) stress that some academic papers point out that antiimmigration parties often have higher success in areas hosting fewer immigrants. The authors advocate that immigrants often live in bigger cities. Hence, small towns are more likely to vote for anti-immigration parties than bigger urban areas. They highlight that this phenomenon persists in many countries. For example, during the 2017 French Presidential elections, Emmanuel Macron scored better in big urban areas, while Marine Le Pen, who promised to stop immigration, received more electoral support in rural areas, where usually fewer immigrants live. Similar evidence applied to other countries (e.g., the success of Donald Trump, Matteo Salvini, and Vox). Analogous results are underlined by Dustmann et al. (2019) regarding the consequences of refugee reception in Denmark.

Furthermore, Bordignon et al. (2019) provide new evidence that helps to explain the anti-immigration vote puzzle. They use data from municipalities of the wealthiest and most populated Italian Region (Lombardia). The scholars suggest that natives and immigrants compete for the same low skilled jobs in the local labor market in smaller towns and rural areas with less substantial immigration-densities. On the opposite, in larger urban areas, 
where more immigrants live, natives work in high skilled jobs and immigrants in the low skilled ones, and thus immigrants are a complement for natives in the labor market (Bordignon et al., 2019).

The evidence provided by the scholars is consistent with an occupational upgrade story already described by the literature (Cattaneo, Fiorio, and Peri, 2015), which suggests that in labor markets with higher immigrant densities, natives are more likely to switch to occupations related with higher skills and wages. As explained by the same authors, this occupation-upgrade protects natives from the increased competition on the labor market.

\subsection{Criminality dimension}

Bianchi et al. (2012) stress that surprisingly little research considers the effect immigration has on crime rates even though it can be critical knowledge for policymakers. They acknowledge that some studies have been done, for example, in the United States, Butcher and Piehl (1998b, 2005) at the micro-level find that current immigrants have lower incarceration rates than natives, while the pattern is reversed regarding the early 1900s (Moehlig and Piehl 2007). Furthermore, at the aggregate level, Butcher and Piehl (1998a) investigate a sample of metropolitan areas in the US over the 1980s and conclude that new immigrant's inflow had no impact on crime rates. Borjas, Grogger, and Hanson (2010) advocate that recent immigrants have increased the criminal activity of black males by displacing them from the labor market. Bianchi et al. (2012) are the first to conduct a similar study in a European country. They investigate the empirical relationship between immigration and crime across Italian provinces during the period 1990-2003. Later, also Bell et al. (2013) investigated the association between the UK, Piopiunik and Ruhose (2015) regarding Germany, and Gehrsitz and Ungerer (2017) analyze the migration crisis from Syria and how it affected Germany.

The mentioned studies have not found effects of immigration on crime, with a few exceptions. Bianchi et al. (2012) find moderate effects on property crimes, while Gehrsitz \& Unger (2017) find tiny increases in crime, particularly concerning drug offenses and faredodging. Furthermore, Piopiunik and Ruhose (2015) find positive correlations between crime and immigration while studying how migration due to the Soviet Union's collapse affected Germany's crime levels.

In 2019 the Swedish Crime Preventing Council published a report regarding the 
increasing trend in filed sexual-related crimes and whether it was correlated with the last year's increase in refugee-influx. The report analyzed the timespan 2005-2017, which is characterized by a substantial increase in filed sexual-related crimes. The analysis is general and based on a tentative analysis. One of the co-authors, Jerry Sarnecki, stressed that there was no found relationship between the high influx of immigrants in the previous years and the sharp increase in sexual-related crimes. However, another co-author, Stina Holmberg, advocate that the interpretation of the results, made of her colleague Jerry Sarnecki is wrong, as their analysis is based on two analyses, which of neither one of them is based on origin (Nyheter Idag, 2019).

The report has received critique in the debate. Tino Sanandaji, a Swedish economist, argues in one of Sweden's most prominent newspapers, SvD, that the Crime Preventive Council uses a politicized analysis with very low quality. He further mentions that the report and the statements conducted by the Council reduce the trust for authorities and that the report induces people to believe that they are trying to hide something (SvD, 2019). The ambiguous interpretation of the results and the contemporary debate makes the following result section regarding the criminality dimension very relevant.

Furthermore, as mentioned in the previous section, Barone et al. (2015) stress that an increased perception of crimes due to refugee influx could generate more votes for right-wing parties. Therefore, including both the political and the crime-dimension in the same paper allows for interesting and meaningful discussions.

\subsection{Price level dimension}

An issue of analyzing wage levels due to migration-influx that often is overseen is the potential impact it can have on the local markets. Alix Garcia and Saah (2010) advocate that a sudden influx of migrants of substantial size could lead to increases in food and housing prices. Consequently, the increasing prices would decrease real wages for the households spending a large proportion of their income on basic goods, even if their nominal wages adjusted for general inflations remain constant.

The same authors argue that this might be one factor that explains the usually quite small impact migration has on wage-levels. Therefore, to grasp the effects migration has on labor markets, it is crucial to add a price-level analysis. Alix Garcia and Saah (2010) focus mainly on how refugee camps impact prices on nearby markets. Their studies cover mainly 
Tanzania and Rwanda. Nevertheless, the topic is not one dimensional; there exist other studies with similar and contradicting results. Dustmann, Glitz \& Frattini (2008) also stress that, besides immigration's impact on GDP per capita, dimensions such as prices of goods, the housing market deserve equal attention and should be taken into account in the design of suitable migration policies.

Hallam (1996) and Whitaker (1999) discuss large price spikes and advocate that local populations suffer. On the other hand, Landau (2002) compares a market near the refugee camps in Tanzania with one in the central part of the country and finds little evidence of any impact on prices.

Quite recent work by Lach (2007) finds that the movement of refugees from the former Soviet Union to Israel in the 1990s caused price-falls. Lach attributed this effect to higher price sensitivity among immigrants, who have not yet constructed the same brand and store familiarity as the local population and thus are likely to look more intensively for lower prices. Using models that exploit cross-city variation in immigrants' densities, Lach (2007) finds that a one-percentage-point increase immigrants' ratio to natives decreases prices by 0.5 percentage points. He argues that higher elasticity of demand of immigrants and their lower search cost created incentives for retailers to reduce their prices to attract new customers. These findings by Lach (2007) is relevant, as he mentions, regarding the short run.

Cortes (2008) studies the effect low-skilled immigration has on price levels in the hosting regions. She focuses on the prices of unskilled-intensive goods and services that the immigration bids down, thus increasing consumers' welfare. The type of services Cortes discuss includes, amongst others: gardening, housekeeping, and dry cleaning. She finds that, at current immigration levels, a 10 percent increase in the share of low-skilled-immigrants in the labor force decreases the price of immigrant-intensive services by 1,3 percent and of other non-traded goods by 0,2 percent (Cortes, 2008).

Roos (2006) shows that the regional price level differences in Germany are considerable and persistent. The scholar identifies population size and wage levels as critical drivers of regional price level variation. A recent study, which analyzes the same refugee crisis as in this very paper, is conducted by Akgündüz et al. (2015). The study suggests that the refugee inflows from Syria to Turkey increased food prices and, to a lesser extent, housing prices in the regions hosting them. While they simultaneously found after analyzing the inflation in hotels and restaurants, i.e., non-basic goods, that they did not share the same 
price-increase as the basic ones. Their results are consistent with the idea that the refugees increase demand mostly in basic survival goods.

\section{Data and limitations}

The data is collected from Statistics Sweden (Statistiska centralbyrån), the Swedish Migration Service (Migrationsverket), the Crime Preventing Council (Brottsförebyggande rådet), and the Swedish National Pensioners' Organization (Pensionärernas riksförbund). The observations are based on all the 290 Swedish municipalities. Therefore, because the panel consists of 7 years, the total number of observations is $2030(7 * 230)$.

The Crime Preventing Council (BRÅ) covers data regarding filed crimes dated back to 1975. Furthermore, BRÅ allows one to create customized tables in their archives. The archives are flexible, which makes it possible to make distinctions between different types of criminal activity. Consequently, instead of solely retrieving data on general levels, the archives allow one to extract the data regarding all Swedish municipalities during 2012-2018 on the following subsets of criminal activity: assault, drugs, fraud, theft, and sexually related crimes. The data from BRÅ can be exported in Excel, which mitigates the amalgamation-process with the other sources' data.

Statistics Sweden (SCB) is the Swedish authority responsible for official statistics. Their data is supplied for decision-making, social debate, and science. They are known for their high-quality data, which furthermore, is very easily accessible and flexible. In their archives, one can adjust for variables such as age, gender, and ethnicity. Most of the data used in this paper stem from SCB. Some examples are wage levels, house price levels, education levels, and unemployment levels, everything on a municipality level. Furthermore, the tables one can create from the SCB-archives are exportable into Excel. SCB provides statistics regarding average GDP per municipality. However, the data only cover 2012-2017 why it is excluded in the analysis. The exclusion could potentially bias the coefficients of interest. This matter will be discussed further in the subsequent chapters.

Both the Migration Service and Statistic Sweden account for many data regarding immigrants, residence permits, refugees, and asylum-seekers. The data is distinguishable between different ages, different reasons for obtaining residence-permit, and gender. To get a higher concentration upon refugees, it is more efficient to exclude persons who receive a residence permit due to study or work-related reasons. Statics Sweden supplies such a rich 
data-structure. Furthermore, it is available on a municipality-level, which is optimal for this study.

The Swedish National Pensioners' Organization (PRO) is an interest organization that organizes a price inquiry throughout the nation each year. The inquiry is assiduously commented on in media and by the government. However, a drawback of PRO's data is that it solely regards the 20 biggest regions in Sweden. Hence, even though one can derive the municipalities from the regions, the data is far from being as precise as the other data available on the municipality-level. Consequently, the data regarding food prices is not as sophisticated as the other variables. However, the data is extractable to Excel and is included in the overall dataset.

Even though the different data-sources are all exportable to Excel, the structure and separation differ slightly among them. Consequently, the structure demand manual manipulations to create an optimal structure. The manual manipulations are subject to individual mistakes why measurement errors are possible. However, many quality-tests have been conducted to minimize the probability. Ultimately, all data integrates into one comprehensive file regarding all 290 municipalities. The Excel-file is imported in Stata and, from there, exported into a DTA-file. Consequently, the dataset is original and manually sorted from different secondary data sources and available for the public upon publication.

\subsection{Refugees}

To estimate the effects of the refugee inflow on the dependent variables, each municipality's refugee inflow will be used as the independent variable. In the regressions, refugee inflows' natural logarithm is considered to analyze what economists call elasticities, i.e., how a percentage change in the refugee inflow affects the dependent variable. The variable "Refugee" for each municipality is computed as the inflow of refugees aged 16-64. In the fixed-effects model, the inflow of refugees aged $16-64$ per $1000^{\text {th }}$ capita is considered. The same inflow is compared between the municipalities with the highest and lowest refugeeinflow in the static and dynamic difference-in-difference model. The group of municipalities with the least inflow will form the control group while the municipalities with the highest inflow form the treated group. One finds more detailed descriptions in chapter 4.

In Sweden, roughly $50 \%$ of the refugees choose to find accommodation, whereas the Swedish Migration Agency arranges it for the remaining 50 \% (Migrationsverket, 2017). As 
mentioned earlier, this type of endogenous allocation where refugees themselves choose municipality/accommodation might bias the findings. The Swedish Migration Agency's data of refugees regard all new immigrants who received residence permits. The data include refugees, asylum seekers, family members of refugees, and others who have received a residence permit due to difficult circumstances in the country of origin (Migrationsverket, 2017). Furthermore, the data also include non-refugees who received a residence permit due to study or work-related reasons, even though they represent a minority. The manipulated dataset excludes this minority to concentrate more on the categories mentioned above. Table 2 illustrates informative statistics regarding the independent variable.

Table 2. The mean number of refugees per 1000 inhabitants, its standard deviation, minimum and maximum value between municipalities during 2012-2018

\begin{tabular}{|ccccc|}
\hline Year & Mean & Standard Deviation2 & Minimum & Maxmimum \\
\hline 2012 & 5,61 & 2,18 & 0,51 & 13,15 \\
\hline 2013 & 5,88 & 2,34 & 0,6 & 13,27 \\
\hline 2014 & 6,1 & 2,54 & 0,5 & 14,35 \\
\hline 2015 & 6,49 & 2,66 & 0,49 & 15,49 \\
\hline 2016 & 6,54 & 2,79 & 0,46 & 15,77 \\
\hline 2017 & 6,68 & 2,88 & 0,48 & 17,95 \\
\hline 2018 & 6,58 & 5,13 & 0,48 & 53,56 \\
\hline
\end{tabular}

The standard deviation is quite high, which implies that there is a significant variance within the sample. Furthermore, one can notice that the interval among the minimum and maximum intakes varies a lot. For example, in 2015, the municipality with the highest intake had 0,49, while the highest had 15,49. These conditions create a solid base for a difference-indifference analysis, as the different intake-levels allow one to form treated and control groups. Consequently, one can compare the municipalities with relatively little inflow (control) and the municipalities with relatively high inflow (treated). The empirical approach will be explained more thoroughly in section 4.2 (static difference-in-difference model).

\subsection{Dependent variable}

The dependent variable will differ among the regressions. It will vary between average yearly income, percentage of unemployment, average house price level, average food price level, the vote share of political party $p$, and crime per capita, everything evaluated in the same municipality $m$. The wage, house price, and food price will be expressed in Swedish 
crowns (SEK), and the data regarding the wage and house price will be reported in the value of thousands. Often, in the regressions, the dependent variable will be expressed as the natural logarithm for a more straightforward interpretation of the results.

\subsection{Control variables}

To generate reasonable estimations given the differences in the economic structure between municipalities, the model will include the following control variables: density of highly educated inhabitants, level of unemployment, average wage levels, and crime per capita levels. When the dependent variable is one of the listed above, it is not also used as a control variable. The reason for including control variables comes from the chosen empirical models, a fixed-effect model, a static difference-in-difference, and a dynamic difference in difference estimator, including fixed effects. The time fixed error term $a_{i}$ captures unobserved differences between municipalities.

However, in the timespan 2012-2018, other shocks might affect regions differently, such as the consequences of the Euro crisis in 2008. There can be differences in unemployment, education, or criminality levels in different regions. These differences may cause a correlation between the independent variable (Refugee-inflow) and the idiosyncratic error term if the refugees choose their settlement city based on economic, political, or social conditions. Consequently, they generate biased results. The empirical models are discussed more in-depth in the following chapter.

\section{Empirical Approach and Identification}

A panel data analysis will be used to estimate the effects which the exogenous supply shock in terms of refugee inflows has on the different independent variables in Swedish municipalities. The empirical approach will include three different panel data methods, quite similar to those of Foged and Peri (2015). First, a fixed-effect model. Second, a static difference-in-difference approach. Third, a dynamic difference-in-difference approach.

\subsection{Fixed-effects model}

The outcomes of municipality $m$, at time $t$, is indicated as the variable $y_{m t}$ in regression (1). The model includes the following outcome variables: average wages, unemployment-levels, crimes per capita, the vote share of political party $p$, and price levels. As the variables are expressed in natural logarithms, the vertical axis measures the proportional difference in the 
interest variables. The primary explanatory variable is the refugee-influx aged 16-64 per $1000^{\text {th }}$ capita in municipality $m$ and year $t, R m t$, calculated as $R I_{m t} / T I_{m t}$. $R I_{m t}$ is the refugee intake and $T I_{m t}$, represents the total number of inhabitants in municipality $m$ and year $t$. The regressions have the structure below

$$
Y_{m t}=X_{m t} \alpha+B R_{m t}+\phi_{m}+\delta_{t} T_{t}+\varepsilon_{m t}
$$

The variable $X_{m t}$ is a vector of time-varying municipality characteristics that include unemployment-levels, education-levels, average wage levels, and crimes per capita. $\delta_{t} T_{t}$ is a time dummy, which includes 2012-2018. The variable $\phi_{m}$ are the municipality-fixed-effects capturing municipality-specific time patterns. Furthermore, they cover unobserved effects that vary between municipalities but are time-invariant. It is reasonable to assume that the municipality-fixed-effects cover different characteristics such as municipality-specific integration programs, and attitudes toward hiring immigrants and economic circumstances. In each regression, there will be three specifications. The first one will exclude both the timeinvariant vector $X_{m t}$ and the municipality fixed effects $\phi_{m}$. The second will exclude the timeinvariant vector $X_{m t}$ but include the municipality-fixed-effects. The third will precisely follow the structure of equation (1). Thus, it will include both the municipality-fixed-effects and the vector $X_{m t}$. Following this structure, one can get insights about the municipality-fixed effects and the time-invariant controls by comparing the different specifications.

The idiosyncratic error term $\varepsilon_{m t}$ includes the unobserved component, which is timevariant (Wooldridge, 2008). Due to the limited access to data, the regressions exclude factors that are likely to affect refugees' employability and wages. For example, language skills and previous working experience could play a significant role in integrating refugees into the labor market.

To generate unbiased results, the exogeneity-assumption must hold, i.e., the error term $\varepsilon_{m t}$ must have zero correlation with the independent variables in the vector $X_{m t} . \mathrm{A}$ change in the independent variables should not significantly affect the error term (Stock \& Watson, 2015). If the exogenous assumption does not hold, the causal effects will be misleading. In this paper, the placement of the refugees and the factors behind that may bias the results. 


\subsection{Static difference-in-difference estimator}

The second approach includes a difference-in-difference design to identify immigrants' shortrun effect on the labor market, the vote shares, price levels, and criminality levels for municipalities in Sweden regarding 2015 and the subsequent years. By using this approach, one can follow outcomes before, during, and after the crisis. It is rational to choose 2015 as the beginning of the treatment period as that year is when Sweden received the most refugees. The model measures the different refugee-influx levels for each municipality in the years 2015 and 2016. One should include the year 2016 to fully grasp the influx of 2015, as the average processing time for an asylum seeker is around 320 days. The model specifies "exposed" or "treated" those municipalities in the top quartile and "non-exposed" or "control" those municipalities in the bottom quartile.

This set-up makes it possible to define a pre-treatment period consisting of 20122014, during which immigration in Sweden was not as intense as in 2015. The treatment period 2015, during which the number of refugees had its peak. Simultaneously, data is kept regarding 2016-2018 as a post-period to catch consequences due to the treatment period. The next step is to implement the difference-in-difference estimation in a regression setting.

The variable $Y_{m t}$ represents an outcome for municipality $m$ in year $t$ as in equation (1). The outcomes are the natural logarithms of average wage levels, unemployment levels, crimes per capita, the vote share of political party $p$, and price levels. $M_{m}$ is the treatment dummy, equal to 1 if municipality $m$ is in the upper quartile of the difference in predicted refugee inflow, and 0 if the municipality is in the lower quartile of the change in predicted

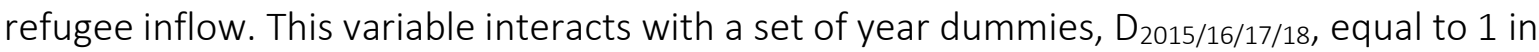
the treatment (2015) and post-treatment (2016-2018) year and 0 otherwise. The key coefficient of interest is $\beta$, the coefficient of the interaction between the municipality and time dummies. It is interpreted as the causal effect of the refugee inflow on the independent variable $Y_{m t}$. The vector $X_{i t}$ contains the same control variables as in the fixed effects model, equation (1). Similarly, as in the first equation, $\delta_{t} T_{t}$ is a time dummy. Finally, $\phi_{m}$ represents municipality-fixed-effects. The equation takes the following form

$$
\mathrm{Y}_{m t}=\mathrm{X}_{m t} \alpha+ц \mathrm{M}_{m}+\beta \mathrm{M}_{m} \mathrm{D}_{2015 / 16 / 17 / 18}+\delta_{t} \mathrm{~T}_{t}+\varepsilon_{m \mathrm{~m}}
$$

To be able to measure whether time-invariant differences between the municipalities persist, one should add municipality-fixed-effects. However, as the "treated" variable ц $\mathrm{M}_{m}$ already is 
time-invariant, to avoid multicollinearity - one must exclude ц $\mathrm{M}_{\mathrm{m}}$. Consequently, one must drop $ц M_{m}$ and then add $\phi_{m}$ to include the municipality-fixed-effects. Thus, the estimated equation is expressed as

$$
Y_{m t}=X_{m t} \alpha+\beta M_{m} D_{2015 / 16 / 17 / 18}+\phi_{m}+\delta_{t} T_{t}+\varepsilon_{m t}
$$

\subsection{Dynamic difference-in-difference estimator}

The third approach resembles the second but is slightly richer. A dynamic difference-indifference estimator is potentially more suitable than a static difference-in-difference estimator. It is not always reasonable to assume that the treated units are exposed to the same effect every year. Instead, it makes sense to assume they differ, captured by a full set of time-dummies for each group.

Similarly, as in the second model, $Y_{m t}$ represents an outcome for municipality $m$ in year $t$ as in equation (1). The outcomes are the same except the one regarding the political voting dimension, which will not be included as it will be identified as the static difference-indifference because there is only one year in the post-treatment period. The explanatory variable of interest is the treatment dummy $\mathrm{M}_{m}$ equal to 1 if municipality $m$ is in the upper quartile of the difference in predicted refugee inflow, and 0 if the municipality is in the lower quartile of the change in predicted refugee inflow. This variable interacts with a set of year dummies, $D($ year $=s)$, equal to 1 in year $s$ and 0 otherwise. The vector $X_{m t}$ contains the same control variables as the fixed effects model, equation (1). Finally, $\phi_{m}$ represents municipalityfixed-effects. The estimated equations take the following form

$$
Y_{m t}=X_{m t} \alpha+ц M_{m}+\sum \Upsilon_{s} M_{m} D(\text { year }=s)+\phi_{m}+\delta_{t} T_{t}+\varepsilon_{m t}
$$

As in the second model, to add municipality-fixed-effects, one must exclude the time-variant parameter $ц \mathrm{M}_{m}$ to avoid multi-collinearity. Consequently, the equation including the municipality-fixed-effects is structured slightly different from equation (4)

$$
Y_{m t}=X_{m t} \alpha+\sum \Upsilon_{s} M_{m} D(\text { year }=s)+\phi_{m}+\delta_{t} T_{t}+\varepsilon_{t m}
$$

The delta-coefficients $\Upsilon^{\prime}$ sillustrate the difference in municipality outcomes from 2016 to 2018 between treated and non-treated municipalities. These interaction-variables will be referred to in the result section. Finally, $\varepsilon_{m t}$ represents the idiosyncratic error, as in equation (1), the 
error term includes the unobserved component, which is time-invariant. Some factors likely affecting the dependent variables will be excluded due to the limited access to data.

\section{Main econometric results}

In this section, the found results will be presented separately for each of the investigated dimensions. The wage dimension will be treated first, followed by the other dimensions in the order: unemployment, crime-rates, voting patterns, and price levels.

\section{1a. Fixed-effects model on wages}

Table 3 illustrates the results obtained from the fixed-effect regressions. One can see that a one-percentage increase in refugee-influx is negatively correlated with average wages in the first specification (1) when the municipality-fixed-effects are not included. The adverse effects of the refugee inflows are consistent with the simple labor supply-demand model.

Table 3. Refugee influx on wages, fixed effects model.

\begin{tabular}{|l|lll|}
\hline $\ln$ (Wage) & $(1)$ & $(2)$ & $(3)$ \\
\hline In(Refugeeper) & $-0,0770^{* * *}$ & $-0,00235$ & $-0,00321^{*}$ \\
& $(0,00489)$ & $(0,00190)$ & $(0,00185)$ \\
& & & $0,142^{* * *}$ \\
In(Higheduper) & & & $(0,0132)$ \\
& & & yes \\
\hline time fe & yes & yes & yes \\
municipality fe & no & yes & 0,975 \\
\hline$R^{\wedge} 2$ & 0,278 & 0,974 & \\
\hline
\end{tabular}

The significance of the coefficients is denoted by stars (* significance on the $10 \%$ significance level, ** 5\% and $* * * 1 \%$, respectively). Standard errors are in brackets and they are computed on the $5 \%$ significance level.

The R-squared coefficient describes how well the independent variables explain variation in the dependent variable (Stock \& Watson, 2015). By comparing the R-squared to the standard errors, finding the model explaining the statistics best is possible. When the municipalityfixed-effects are added (specification 2), the specification obtains lower standard errors and a higher R-squared. One can notice that in the fixed-effects model, more than $97 \%$ of the wage average variation within the municipalities is explained by the coefficients. The results differ from the first regression, the sign is still the same, but the magnitude varies significantly, the adverse effect is lower when including the municipality-fixed-effects. However, importantly, the coefficient In(Refugeeper) is no longer statistically significant. 
Finally, one should investigate the third specification, which also includes the vector of time-varying control variables. Regarding the covariates, both In(Unempper) and In(Crime) are omitted as one could argue that wages causally affect unemployment and criminality levels. I.e., they come after the independent variable in the causal chain, why they should be excluded. Even if the GDP per municipality data were available for 2012-2018, it would not have been included as a covariate due to the very same reason.

The rationale for including control variables is that they correlate with both the dependent and independent variables. For example, education level is highly likely to affect the wage level. Thus, if not accounting for it, it will end up in the idiosyncratic error term and bias the findings through what economists call omitted variable bias. By adding the covariates, the magnitude of the effect increases in absolute terms. Furthermore, the coefficient did is now, including the covariate and municipality-fixed-effects statistically significant at the $10 \%$ level. The third specification suggests that a one-percentage-point increase in refugee influx in municipality $m$ induce a 0,00321 \% change in the average wage level in municipality $m$.

The second model, namely the static difference-in-difference estimator, could be more suitable for this type of data, as it is based on a natural experiment that allows for comparison between treated and controlled groups.

\section{1.b Static difference-in-difference model on wages}

Table 4, refugee influx on wages, static difference-in-difference estimator.

\begin{tabular}{|c|c|c|c|}
\hline $\ln$ (Wage) & (1) & $(2)$ & (3) \\
\hline treated & $\begin{array}{l}-0,109 * * * \\
(0,00940)\end{array}$ & & \\
\hline did & $\begin{array}{l}-0,0106 \\
(0,0125)\end{array}$ & $\begin{array}{l}-0,0106^{* * *} \\
(0,00120)\end{array}$ & $\begin{array}{l}-0,0114 * * * \\
(0,00117)\end{array}$ \\
\hline In(Higheduper) & & & $\begin{array}{l}0,122^{* * *} \\
(0,0178)\end{array}$ \\
\hline $\begin{array}{l}\text { time fe } \\
\text { municipality fe }\end{array}$ & $\begin{array}{l}\text { yes } \\
\text { no }\end{array}$ & $\begin{array}{l}\text { yes } \\
\text { yes }\end{array}$ & $\begin{array}{l}\text { yes } \\
\text { yes }\end{array}$ \\
\hline$R^{\wedge} 2$ & 0,394 & 0,974 & 0,976 \\
\hline
\end{tabular}

The significance of the coefficients is denoted by stars (* significance on the $10 \%$ significance level, ** 5\% and ***1\%, respectively). Standard errors are in brackets and they are computed on the 5\% significance level. 
In the first specification (1), one can see the results from equation (2) defined in the empirical section, excluding the vector of time-invariant control variables. As the main coefficient of interest $\beta$, in the table represented by did is not statistically significant, it does not provide insight. However, by dropping the time-variant coefficient "treated" in equation (1) denoted as $M_{m}$, and adding municipality-fixed-effects, one finds the second specification (2), which now yield significant results. The specification advocates a negative relation between refugeeinflow and wage levels, statistically significant at the $1 \%$ level. Finally, by including the vector of time-invariant control variables, one estimate exactly the third equation in the econometric model, in the table represented in specification (3). The model suggests a negative relationship between the refugee-influx and wages. The specification advocates that the average difference between treated and controlled units amount to $-0,0114 \%$, significant at the $1 \%$ level. During the timespan of interest, the average wage across all municipalities was 298250 SEK.

Consequently, the difference between the treated and non-treated amounted to approximately 3400 SEK $(298250 * 0,0114)$. This would then not only affect the individual working, receiving the lower wage but furthermore the municipality and state income in terms of fewer tax-revenues. The average income-taxes in Sweden were in 2018, 43 \%, according to OECD (OECD, 2020). Thus, the tax base in the treated municipalities compared to the controlled would be reduced by 1448 SEK per worker. Furthermore, one could expect the treated municipalities to encounter less demand and consumption as the decrease in wages directly relates to disposable income, affecting consumption.

\section{1.c Dynamic difference-in-difference model on wages}

The same analysis but using the dynamic difference-in-difference model is conducted. The coefficients did16, did17, and did18 are the interaction terms of interest who multiply the treated groups with the specific year-dummy. Table 5 presents the results. 
Table 5. refugee influx on wages, dynamic difference-in-difference estimator

\begin{tabular}{|l|lll|}
\hline In(Wage) & $(1)$ & $(2)$ & $(3)$ \\
\hline treated & $-0,0761^{* * *}$ & & \\
& $(0,00601)$ & & \\
did16 & $-0,00623$ & $-0,00623^{* * *}$ & $-0,00718^{* *}$ \\
& $(0,0134)$ & $(0,00144)$ & $(0,00173)$ \\
did17 & $-0,00957$ & $-0,00957^{* * *}$ & $-0,0108^{* * *}$ \\
& $(0,0137)$ & $(0,00144)$ & $(0,00172)$ \\
did18 & $-0,0109$ & $-0,0109^{* * *}$ & $-0,0127^{* * *}$ \\
& $(0,0138)$ & $(0,00144)$ & $'(0,00172)$ \\
In(Higheduper) & & & $0,113^{* * *}$ \\
& & & $(0,0179)$ \\
\hline time fe & & & yes \\
municipality fe & yes & yes & yes \\
\hline $\mathrm{R}^{\wedge} 2$ & 0,265 & 0,975 & 0,975 \\
\hline
\end{tabular}

The significance of the coefficients is denoted by stars (* significance on the $10 \%$ significance level, ** 5\% and ***1\%, respectively). Standard errors are in brackets and they are computed on the $5 \%$ significance level.

As in the fixed-effects model, the estimations provide a negative correlation. However, the results differ regarding the significance levels. One can immediately see that the coefficients of interest did16, did17, and did18 in the first specification are negative but not statistically significant. After including the municipality-fixed-effects in the second specification, the coefficients keep the same sign but become statistically significant at the $1 \%$ level. Lastly, by adding the vector of time-variant control variables, one can conclude that the treated group, i.e., the municipalities with a relatively high refugee intake, had significantly lower wage levels than the control group.

To interpret the estimators, one could from the third specification see that in 2018, the average difference between treated and controlled units (did18) is -0,0127\%. In similar reasoning, the results show that in 2017, the average difference between treated and controlled units two years after the event (did17) is $-0,0108 \%$, both years are significant at the $1 \%$ level. Furthermore, regarding the coefficient did16, the average difference between treated and controlled units one year after the event is -0,00718\% and statistically significant at the $5 \%$ level. The model seems to have spotted a negative trend as the coefficient's magnitude in absolute terms increases with time. 


\section{2.a Fixed-effects model on unemployment}

The analysis regarding unemployment levels will share the same structure as wages, commencing with the fixed-effects model. The results are presented below in table 6 .

Table 6. The effect of the refugee influx on unemployment, fixed effects model

\begin{tabular}{|l|lll|}
\hline In(Unemp) & $(1)$ & $(2)$ & $(3)$ \\
\hline In(RefugeePer) & $0,912^{* * *}$ & $0,0433^{* *}$ & $0,0517^{* * *}$ \\
& $(0,0259)$ & $(0,0190)$ & $\begin{array}{l}(0,0185) \\
\text { In(HigheduPer) }\end{array}$ \\
& & & $\begin{array}{l}-0,697^{* * *} \\
(0,119)\end{array}$ \\
\hline time fe & yes & yes & yes \\
municipality fe & no & yes & yes \\
\hline $\mathrm{R}^{\wedge} 2$ & 0,730 & 0,375 & 0,412 \\
\hline
\end{tabular}

The significance of the coefficients is denoted by stars (* significance on the $10 \%$ significance level, ** 5\% and ***1\%, respectively). Standard errors are in brackets and they are computed on the 5\% significance level.

The estimation suggests, as expected, that there is a positive correlation between migration and unemployment. The first specification, excluding the unit fixed effects, suggests that a one-percentage-point increase in migration entails a 0,912 \% change in unemployment. The coefficient is highly significant. In the second specification, the model includes municipalityfixed-effects to see whether the estimates improve. The significance level becomes less significant as it moves from the $1 \%$ to the $5 \%$ level.

Furthermore, including the vector of time-variant control variables in specification three, the coefficient increases from 0,0433 to 0,0517. In the specification, the control variables $\ln$ (Crimesper) and $\ln$ (Wage) are omitted. They are most likely endogenous as they come after the independent variable, unemployment, in the causal chain. I.e., unemployment cause changes in wages and criminality. Similarly, as in the wage-dimension, even if GDP per municipality were available in the data set, it would have been omitted due to the same reason (endogeneity). Hence, one should omit them to ensure exogeneity. It remains significant at the $5 \%$ level. To interpret the results, one can notice that a one-percentagepoint increase in refugee inflow in the municipality $m$ induce a $0,0517 \%$ increase in unemployment-level in the same municipality $m$. However, one could expect the second model to provide more accurate estimates. The results are presented in the following section. 


\section{2.b Static difference-in-difference model on wages}

The results from the second model is represented in Table 7.

Table 7. Refugee influx on unemployment, static difference-in-difference estimator.

\begin{tabular}{|l|lll|}
\hline $\ln ($ Unemp) & $(1)$ & $(2)$ & $(3)$ \\
\hline treated & $2,373^{* * *}$ & & \\
& $(0,0649)$ & & \\
did & 0,118 & $0,118^{* * *}$ & $0,126^{* * *}$ \\
& $(0,0862)$ & $(0,0115)$ & $(0,0112)$ \\
& & & $-1.170^{* * *}$ \\
In(Higheduper) & & & $(0,170)$ \\
& & & yes \\
\hline time fe & yes & yes & yes \\
municipality fe & no & yes & 0,423 \\
\hline $\mathrm{R}^{\wedge} 2$ & 0,766 & 0,391 & 0 \\
\hline
\end{tabular}

The significance of the coefficients is denoted by stars (* significance on the $10 \%$ significance level, ** $5 \%$ and ***1\%, respectively). Standard errors are in brackets and they are computed on the 5\% significance level.

In the first specification (1), one can see the results from equation (3) defined in the empirical section. As the main coefficient of interest $\beta$, in the table represented by did is not statistically significant, it does not provide insight. However, by dropping the time-variant coefficient "treated" in equation (1) denoted as $\mathrm{M}_{m}$, and adding municipality-fixed-effects, one finds the second specification (2), which yields significant results. The model stresses a positive relation between refugee inflow and unemployment levels, statistically significant at the $1 \%$ level. Finally, by including the vector of time-invariant control variables, one estimate exactly the third equation in the econometric model, in the table represented in specification (3). The sign remains negative. Regarding the covariates, $\ln$ (Wage) and In(Crimes) are omitted to ensure exogeneity for the same reason as in the previous model. The model suggests that the average difference between treated and controlled units amount to $0,126 \%$, statistically significant at the $1 \%$ level.

To grasp the results' direct consequences, one can compare the magnitude to the average unemployment level, which in 2015 among the municipalities was 7,758 \%. Furthermore, one could look at the average number of inhabitants within the age-span 16 and 64 in the same year, which amounted to 21085 . Consequently, while the municipality before the crisis could expect to have 1598 unemployed inhabitants within the relevant agespan, the treated municipalities, hosting more immigrants, could expect 1662. Because the 
average wage was, as mentioned previously, 298250 SEK, the loss in employment yields approximately 19088000 (298 250*64) in wage loss for the individuals, considering that the average wage-tax in Sweden was 43 \%, a loss of taxes amounting to 8207840 SEK on average is expected in the treated municipality. The numbers stem from averages values, which should not be recognized as absolute for individual cases. However, the figures provide a general appreciation of the impact.

Except for the income and tax loss, unemployment also demands other resources such as employment-services and subsidies. Consequently, the increase in unemployment has two adverse effects, one stemming from the income and tax loss, the second, from the increase in government spending. Furthermore, studies show that unemployment is highly likely to cause both mental and physical illness and an increased probability of the individual committing crimes, while simultaneously reducing volunteerism. Sullivan \& Von Wachter (2009) show that job-displacement have a causal effect on mortality-rates. The scholars find that for highseniority male workers, mortality-rates in the year after displacement are 50-100 \% higher than would otherwise have been expected (Sullivan \& Von Wachter, 2009). Consequently, estimating the exact impact of the increase in unemployment is difficult, or rather impossible, but one could comprehend that the consequences are substantial from the figures and arguments demonstrated above.

\section{2.c Dynamic difference-in-difference model on unemployment}

The results regarding unemployment-levels analyzed through the difference-in-difference estimator are presented in table 8. 
Table 8. Refugee influx on unemployment, dynamic difference-in-difference

\begin{tabular}{|l|lll|}
\hline In(Unemp) & $(1)$ & $(2)$ & $(3)$ \\
\hline \multirow{4}{*}{ treated } & $1,428 * * *$ & & \\
& $(0,0474)$ & & \\
& 0,0886 & $0,0886^{* * *}$ & $0,109 * * *$ \\
& $(0,108)$ & $(0,0145)$ & $(0,0167)$ \\
did17 & 0,101 & $0,101^{* * *}$ & $0,131^{* * *}$ \\
& $(0,108)$ & $(0,0145)$ & $(0,0167)$ \\
did18 & 0,079 & $0,0789^{* * *}$ & $0,0853^{* * *}$ \\
& $(105)$ & $(0,0145)$ & $(0,0167)$ \\
In(Higheduper) & & & $-1,075^{* * *}$ \\
& & & $(0,173)$ \\
\hline time fe & yes & yes & yes \\
municipality fe & no & yes & yes \\
\hline R^2 & 0,344 & 0,402 & 0,404 \\
\hline
\end{tabular}

The significance of the coefficients is denoted by stars (* significance on the $10 \%$ significance level, ** 5\% and ***1\%, respectively). Standard errors are in brackets and they are computed on the 5\% significance level.

In the first specification, including time-fixed-effects, the interaction variables are not significant, why one cannot draw any conclusions from them. In the second specification, including municipality-fixed-effects and consequently, omitting the variable treated, the magnitude and sign remain constant, but the estimators now become significant at the $1 \%$ level. By adding the vector of time-variant control variables in the third specification, the significance levels remain constant. Furthermore, the magnitude of the coefficients of interest decreases. To make sense of the table, one should scrutinize the third specification as it includes both types of fixed-effects and the vector of time-variant control variables. Focusing on the interaction terms, which are the variables of interest, one can observe that all are significant at the $1 \%$ and $5 \%$ level.

Additionally, the results suggest that the average difference between treated and controlled units one year after the event (did16) is 0,109\%, two years after the event (did17) is $0,131 \%$, and three years after the event (did18) is $0,0853 \%$. Simply put, the results advocate a positive correlation between unemployment levels and refugee inflow. The direct 
impacts on society are similar to those found in (5.2.b), with slight adjustments on the magnitude of the change. The argumentation is identical.

\section{3.a Fixed-effects model on crimes per capita}

Table 9 presents the findings regarding crimes per capita through the fixed-effects-model.

Table 9. Refugee influx on crimes per capita, fixed effects model

\begin{tabular}{|l|lll|}
\hline $\ln$ (Crimesper) & $(1)$ & $(2)$ & $(3)$ \\
\hline In(RefugeePer) & $0,0911^{* * *}$ & 0,0207 & 0,0309 \\
& $(0,0265)$ & $(0,0236)$ & $(0,0237)$ \\
& & & 0,139 \\
In(HigheduPer) & & & $(0,176)$ \\
In(Unempper) & & & $-0,0622^{*}$ \\
& & & $(0,0351)$ \\
In(Wage) & & & $-0,899^{* * *}$ \\
& & & $(0,351)$ \\
\hline time fe & yes & yes & yes \\
municipality fe & no & yes & yes \\
\hline$R^{\wedge} 2$ & 0,007 & 0,034 & 0,053 \\
\hline
\end{tabular}

The significance of the coefficients is denoted by stars (* significance on the $10 \%$ significance level, ** $5 \%$ and ***1\%, respectively). Standard errors are in brackets and they are computed on the $5 \%$ significance level.

The first specification proposes a positive correlation between municipalities with relatively higher refugee inflow and higher crime-rates, statistically significant at the one-percentage level. When including the municipality-fixed-effects in the second specification, one can see that the estimator is no longer significant. The results do not change when adding controls in the third specification. They are still not statistically significant - why the model cannot explain the relationship between refugee inflow and crime levels.

To enrichen and deepen the analysis regarding the crime levels, similarly as Gehrsitz \& Ungerer (2017), one can distinguish between different types of crimes to see whether the magnitude and significance differ. To be able to make a comparison between different types of crimes, table 8 represent results regarding the subsets of the set crime: assault, theft, 
sexual, fraud, and drug-related crimes. The specification includes both the vector of timevariant control variables and municipality- and time-fixed-effects.

Table 10. Refugee influx on the subsets: Assault, Drugs, Fraud, Sexual and Theft, fixed effects model

\begin{tabular}{|c|c|c|c|c|c|}
\hline In(Crimes per capita) sorted by: & Assault & Drugs & Fraud & Sexual & Theft \\
\hline In(Refugeeper) & $\begin{array}{l}0,118^{* * *} \\
(0,0380)\end{array}$ & $\begin{array}{l}0,138^{*} \\
(0,0759)\end{array}$ & $\begin{array}{l}0,0237 \\
(0,0770)\end{array}$ & $\begin{array}{l}0,0655 \\
(0,0843)\end{array}$ & $\begin{array}{l}0,0347 \\
(0,0278)\end{array}$ \\
\hline In(Higheduper) & $\begin{array}{l}0,8774^{* * *} \\
(0,282)\end{array}$ & $\begin{array}{l}-0,155 \\
(0,563)\end{array}$ & $\begin{array}{l}-1,427^{* *} \\
(0,572)\end{array}$ & $\begin{array}{l}1,273^{* *} \\
(0,627)\end{array}$ & $\begin{array}{l}0,327 \\
(0,206)\end{array}$ \\
\hline In(Unempper) & $\begin{array}{l}0,0541 \\
(0,0563)\end{array}$ & $\begin{array}{l}-0,150 \\
(0,112)\end{array}$ & $\begin{array}{l}-0,0285 \\
(0,114)\end{array}$ & $\begin{array}{l}0,128 \\
(0,125)\end{array}$ & $\begin{array}{l}-0,0323 \\
(0,0411)\end{array}$ \\
\hline In(Wage) & $\begin{array}{l}0,109 \\
(0,563)\end{array}$ & $\begin{array}{l}-1,789 \\
(1,123)\end{array}$ & $\begin{array}{l}-4,436^{* * *} \\
(1,140)\end{array}$ & $\begin{array}{l}1,615 \\
(1,251)\end{array}$ & $\begin{array}{l}0,129 \\
(0,411)\end{array}$ \\
\hline $\begin{array}{l}\text { time fe } \\
\text { municipality fe }\end{array}$ & $\begin{array}{l}\text { yes } \\
\text { yes }\end{array}$ & $\begin{array}{l}\text { yes } \\
\text { yes }\end{array}$ & $\begin{array}{l}\text { yes } \\
\text { yes }\end{array}$ & $\begin{array}{l}\text { yes } \\
\text { yes }\end{array}$ & $\begin{array}{l}\text { yes } \\
\text { yes }\end{array}$ \\
\hline$R^{\wedge} 2$ & 0,084 & 0,023 & 0,175 & 0,094 & 0,231 \\
\hline
\end{tabular}

The significance of the coefficients is denoted by stars (* significance on the $10 \%$ significance level, ** $5 \%$ and $* * * 1 \%$, respectively). Standard errors are in brackets and they are computed on the $5 \%$ significance level.

Positive correlations hold for all subsets. However, the specifications Fraud, Sexual, and Theft are not significant at neither the 1, 5 or, $10 \%$ level why one cannot conclude from them. Regarding the coefficients Assault and Drugs, the model generates positive and significant coefficients, the variable Assault at the $1 \%$ level and Drugs at the $10 \%$ level. Because the variables are transformed into natural logarithms, the coefficients represent elasticities. The estimators suggest that a one-percentage increase in the density of immigrants in municipality $m$ evoke a 0,118 \% increase in assault-related crimes and a 0,138 \% increase in drug-related crimes in the same municipality $m$.

\section{3.b Static difference-in-difference on crimes per capita}

The findings regarding Crimes per capita, analyzed through the second model are presented in table 11. 
Table 11. Refugee influx on crimes per capita, static difference-in-difference estimator

\begin{tabular}{|l|lll|}
\hline $\ln$ (Crimesper) & $(1)$ & $(2)$ & $(3)$ \\
\hline treated & $0,168^{* *}$ & & \\
& $(0,0659)$ & & \\
did & 0,0295 & $0,0295^{*}$ & $0,0373^{* *}$ \\
& $(0,0849)$ & $(0,0165)$ & $(0,0180)$ \\
& & & 0,208 \\
$\operatorname{In}$ (Higheduper) & & & $(0,261)$ \\
& & & $-0,0898$ \\
$\operatorname{In}$ (Unempper) & & & $(0,0567)$ \\
& & & $-0,141$ \\
$\operatorname{In}$ (Wage) & & & $(0,542)$ \\
& & & yes \\
\hline time fe & yes & yes & yes \\
municipality fe & no & yes & 0,047 \\
\hline$R^{\wedge} 2$ & 0,021 & 0,043 & 0.04 \\
\hline
\end{tabular}

The significance of the coefficients is denoted by stars (* significance on the $10 \%$ significance level, ** $5 \%$ and $* * * 1 \%$, respectively). Standard errors are in brackets and they are computed on the $5 \%$ significance level.

As in the previous cases regarding the second model, the first specification, including the time-fixed effects, is statistically insignificant. However, dropping the variable treated (to avoid multi-collinearity) and instead including municipality-fixed-effects creates a statistically significant correlation at the $10 \%$ level (specification (2)). In the third specification, also the time-variant vector with control variables are included. From it, one can read that the average difference between treated and controlled municipalities is 0,0373\%.

To grasp the direct consequences, one can relate the figures to the total crimes and divide by each $1000^{\text {th }}$ capita aged 16-64. The average inhabitants aged 16-64 amount to 21 085, the average amount of total crimes committed amounts to 4201 . Consequently, the treated municipalities will expect 207 crimes committed per $1000^{\text {th }}$ capita aged 16-64, while the controlled one should expect 199,24 -alternatively, 156 more crimes committed in total during the year. However, as one does not know what type of crimes it regards, drawing clear conclusions is difficult. Table 12 present the results regarding the subsets. 
Table 12. Refugee influx on the sub-sets: Assault, Drugs, Fraud, Sexual and Theft, static difference-indifference model

\begin{tabular}{|l|lllll|}
\hline In(Crimes per capita) sorted by: & Assault & Drugs & Fraud & Sexual & Theft \\
\hline did & $0,0883^{* * *}$ & 0,0867 & $0,238^{* * *}$ & 0,0861 & $-0,0276$ \\
& $(0,0280)$ & $(0,0557)$ & $(0,0558)$ & $(0,0629)$ & $(0,0201)$ \\
In(Higheduper) & $1,235^{* *}$ & $-0,365$ & $-2,189^{* * *}$ & $1,1889^{* *}$ & $0,442^{* *}$ \\
& $(0,405)$ & $(0,803)$ & $(0,809)$ & $(0,908)$ & $(0,292)$ \\
In(Unempper) & 0,128 & $-0,325^{*}$ & $-0,166$ & 0,0972 & $-0,00396$ \\
& $(0,0879)$ & $(0,175)$ & $(0,176)$ & $(0,197)$ & $(0,00396)$ \\
In(Wage) & $1,493^{*}$ & 0,306 & $-1,444^{* * *}$ & 2,475 & 0,152 \\
& $(0,0841)$ & $(1,669)$ & $(1,679)$ & $(1,885)$ & $(0,606)$ \\
\hline time fe & yes & yes & yes & yes & yes \\
municipality fe & yes & yes & yes & yes & yes \\
\hline $\mathrm{R}^{\wedge} 2$ & 0,098 & 0,023 & 0,163 & 0,102 & 0,256 \\
\hline
\end{tabular}

The significance of the coefficients is denoted by stars ${ }^{*}$ significance on the $10 \%$ significance level, ** $5 \%$ and *** $1 \%$, respectively). Standard errors are in brackets and they are computed on the $5 \%$ significance level.

The results advocate that the average difference between treated and controlled municipalities is 0,0883 \% regarding assault-related crimes and 0,238\% regarding fraudrelated crimes. One can relate the figures to the average levels of criminal activity. As the average level of assault-related crimes per municipality was 278 and the average level of fraud-related crimes per municipality was 233 , the treated municipalities could expect 13,18 assault-related and 11,05 more fraud-related crimes per $1000^{\text {th }}$ capita aged $16-64$ compared to the controlled ones. The increasing amount of crimes affect the safety environment and, thus, the general feeling of happiness and well-being. To what extent they affect resources allocated to the policy, and safety enforcement is difficult to say. Assault-related crimes may have traumatizing effects on its victims.

Furthermore, there is new literature regarding "life skills" that positively impact earnings and performance. One of the few things that are likely to affect the so-called "lifeskills" negatively is traumatizing events, such as being the victim of an assault (Schurer, 2017). Additionally, plenty of literature and studies exist among different scientific fields, analyzing the adverse effects of being the victim of an assault, which will not be treated further in this paper. Even though not being vast in number, the figures have a substantial impact on personal lives, and in the end - the municipalities' functionality. 


\section{3.c Dynamic difference-in-difference model on crimes per capita}

Table 13 represents the results regarding crime per capita analyzed through the dynamic difference-in-difference estimator.

Table 13. Refugee influx on crimes per capita, dynamic difference-in-difference estimator

\begin{tabular}{|l|lll|}
\hline In(Crimesper) & $(1)$ & $(2)$ & $(3)$ \\
\hline treated & $0,0790^{* *}$ & & \\
\multirow{4}{*}{ did16 } & $(0,0402)$ & & \\
& 0,00527 & 0,00527 & 0,00561 \\
did17 & $(0,0872)$ & $(0,0240)$ & $(0,0186)$ \\
& 0,0184 & 0,0184 & 0,0173 \\
did18 & $(0,0906)$ & $(0,0184)$ & $(0,0197)$ \\
& 0,0464 & $0,0464^{* *}$ & $0,0428^{* *}$ \\
In(Higheduper) & & & $(0,0187)$ \\
& & & 0,121 \\
In(Unempper) & & & $(0,177)$ \\
& & & $-0,0649^{*}$ \\
In(Wage) & & & $(0,0355)$ \\
& & & $-0,779^{* *}$ \\
\hline time fe & & & $(0,355)$ \\
\hline municipality fe & yes & yes & yes \\
\hline$R^{\wedge} 2$ & 0,006 & 0,052 & yes \\
\hline
\end{tabular}

The significance of the coefficients is denoted by stars (* significance on the $10 \%$ significance level, ** $5 \%$ and $* * * 1 \%$, respectively). Standard errors are in brackets and they are computed on the $5 \%$ significance level.

While only considering the time-fixed-effects, the model provides positive correlations for all interacted variables. However, the variables are not significant at neither the 1, 5, or $10 \%$ level why they do not offer valuable insight-adding the municipality-fixed-effects in the second specification yields significant estimates regarding 2018. One can immediately notice that the average change between the treated and non-treated groups amounts to 0,0464 \%, statistically significant at the $5 \%$ level. After adding the control-variables, only did18 remains significant. The significance is constant at the $5 \%$ level between the specifications, but the coefficient's magnitude decreases from 0,0464 to $0,0428 \%$. Hence, the model suggests that the crime levels are statistically insignificant in 2016 and 2017 due to refugees' inflows in 2015 but show a significant impact on 2018, i.e., municipalities with many registered asylum 
seekers 2015-2016 show higher crime-levels in 2018. Table 13 shows that the average difference between treated and controlled units three years after the event (did18) is 0,0428 $\%$.

Table 14 represents the results from the dynamic difference-in-difference model regarding the five sub-sets of crimes per capita.

Table 14. Refugee influx on the sub-sets Assault, Drugs, Fraud, Sexual and Theft, dynamic difference in difference model

\begin{tabular}{|l|llll|}
\hline In(Crimes per capita) sorted by: & Assault & Fraud & Sexual & Theft \\
\hline \multirow{2}{*}{ did12 } & $-0,108^{* * *}$ & $-0,233^{* * *}$ & $-0,135$ & $0,0930^{* * *}$ \\
& $(0,0403)$ & $(0,0807)$ & $(0,0909)$ & $(0,0289)$ \\
did13 & $-0,128^{* * *}$ & $-0,258^{* * *}$ & $-0,0321$ & 0,00574 \\
& $(0,0394)$ & $(0,0789)$ & $(0,0888)$ & $(0,0283)$ \\
$\operatorname{did} 14$ & $-0,0378$ & $-0,224^{* * *}$ & $-0,0936$ & $-0,00585$ \\
& $(0,0382)$ & $(0,0764)$ & $(0,0856)$ & $(0,0274)$ \\
In(Higheduper) & $01,158^{* * *}$ & $-2,201^{* * *}$ & $1,842^{* *}$ & $0,546^{*}$ \\
& $(0,408)$ & $(0,816)$ & $(0,916)$ & $(0,293)$ \\
$\operatorname{In}$ (Unempper) & 0,114 & $-0,171$ & 0,103 & 0,00825 \\
& $(0,0881)$ & $(0,176)$ & $(0,197)$ & $(0,0632)$ \\
In(Wage) & $1,586^{*}$ & $-1,445$ & 2,610 & $-0,0534$ \\
& $(0,845)$ & $(1,691)$ & $(1,898)$ & $(0,606)$ \\
\hline time fe & yes & yes & yes & yes \\
unit fe & yes & yes & yes & yes \\
\hline $\mathrm{R}^{\wedge} 2$ & 0,102 & 0,163 & 0,103 & 0,265 \\
\hline
\end{tabular}

The significance of the coefficients is denoted by stars (* significance on the $10 \%$ significance level, ** $5 \%$ and *** $1 \%$, respectively). Standard errors are in brackets and they are computed on the $5 \%$ significance level.

The specification Sexual is statistically significant in 2017 but insignificant regarding 2016 and 2018. The model does not provide unambiguous insights into the relation between refugee's influx and sexual-related crimes. Instead, regarding the specifications Assault and Fraud, the opposite holds. Almost all the dynamic variables are significant and positive; why one can conclude that the treated group have on average higher levels of crimes than the controlled ones for the years 2016 (only regarding Assault), 2017, and 2018. Moving on, analyzing the specification Drugs, none of the coefficients are statistically significant. The model does not suggest any relation between refugee inflow and drug-related criminal activity.

Interestingly, the table shows that regarding the subset Theft, the results advocate a negative statistically significant relation between refugee inflow and theft per capita. For 
example, the average difference between treated and controlled units two years after the event (did17) is $-0,0543 \%$, one year after the event (did16) is $-0,0480 \%$. Similar conclusions can be drawn from all the specifications in the table. The specification with the highest level of significance is Assault. The results suggest that the average difference between treated and controlled units three years after the event (did18) was 0,0786 \%, two years after the event (did17) 0,0834\%, and one year after the event (did16) 0,0861\%. As in the previous chapter (5.2.b), a similar analysis can be done regarding the results impact on society.

However, given the big debate regarding sexual-related crimes in Sweden, what is further interesting is the specification Sexual. The coefficient did17 suggest that in 2017 , the treated municipalities encountered an average difference of 0,153\% because of the refugee inflow. The number of sexual-related crimes is in general, fewer compared to the other subsets. The average sexual-related crimes per year during the period amounted to 55 . Consequently, the treated municipalities could expect to encounter 2,6 sexual-related crimes per $1000^{\text {th }}$ capita aged $16-64$ more than a municipality belonging to the control group. Even though the figure is not massive in terms of numbers, the result can have vast effects on the individual's well-being, development of life-skills, and in the end - its possibility to contribute to society.

\section{4.a Fixed-effects model on political voting}

Table 15 illustrate the results regarding refugees' impact of votes share allocated to the antiimmigration party SD, analyzed through the fixed effects model. 
Table 15. Refugee influx on the vote share of SD, fixed effects model

\begin{tabular}{|c|c|c|c|}
\hline In(Voteshare SD) & (1) & (2) & (3) \\
\hline In(Refugeeper) & $\begin{array}{l}0,207 * * * \\
(0,0205)\end{array}$ & $\begin{array}{l}-0,0204 \\
(0,0206)\end{array}$ & $\begin{array}{l}-0,0200 \\
(0,0207)\end{array}$ \\
\hline In(Crimesper) & & & $\begin{array}{l}0,0450^{*} \\
(0,0447)\end{array}$ \\
\hline In(Higheduper) & & & $\begin{array}{l}-0,148 \\
(0,203)\end{array}$ \\
\hline In(Unemp) & & & $\begin{array}{l}0,109 * * \\
(0,0447)\end{array}$ \\
\hline In(Wage) & & & $\begin{array}{l}0,990^{* * *} \\
(0,429)\end{array}$ \\
\hline $\begin{array}{l}\text { time fe } \\
\text { municipality fe }\end{array}$ & $\begin{array}{l}\text { yes } \\
\text { no }\end{array}$ & $\begin{array}{l}\text { yes } \\
\text { yes }\end{array}$ & $\begin{array}{l}\text { yes } \\
\text { yes }\end{array}$ \\
\hline$R^{\wedge} 2$ & 0,342 & 0,904 & 0,907 \\
\hline
\end{tabular}

The significance of the coefficients is denoted by stars (* significance on the $10 \%$ significance level, ** 5\% and *** $1 \%$, respectively). Standard errors are in brackets and they are computed on the $5 \%$ significance level.

While the regression solely including the time-fixed-effects presents significant results, the second specification, including the municipality-specific fixed-effects, does not. Neither does the third specification, including the time-invariant vector of control variables. Therefore, the fixed-effects model cannot explain a significant relationship between refugee inflow and Vote share allocated to SD.

As not only the vote shares regarding the anti-immigration party is relevant for the analysis, adding the vote shares for all the other political parties with $>4 \%$ votes (which is the threshold to enter parliament in Sweden) enrichens the analysis. The specification will include time- and municipality-fixed-effects and the vector of time-variant control variables. Table 16 illustrates the findings. 
Table 16. Refugee influx on the vote share of $M, K D, L, C, S, M P$ and $V$, fixed effects model

\begin{tabular}{|c|c|c|c|c|c|c|c|}
\hline In(Voteshare) sorted by: & M & KD & $\mathrm{L}$ & C & $\mathrm{s}$ & MP & v \\
\hline In(Refugeeper) & $\begin{array}{l}-0,0207 \\
(0,0165)\end{array}$ & $\begin{array}{l}0,0832^{* *} \\
(0,0418)\end{array}$ & $\begin{array}{l}0,00712 \\
(0,0295)\end{array}$ & $\begin{array}{l}-0,0920^{* *} \\
(0,0406)\end{array}$ & $\begin{array}{l}-0,0216 \\
(0,0143)\end{array}$ & $\begin{array}{l}0,0156 \\
(0,0254)\end{array}$ & $\begin{array}{l}-0,0354 \\
(0,0277)\end{array}$ \\
\hline In(Crimesper) & $\begin{array}{l}0,0722^{* * *} \\
(0,0220)\end{array}$ & $\begin{array}{l}0,0962^{*} \\
(0,0557)\end{array}$ & $\begin{array}{l}-0,0832^{* *} \\
(0,0393)\end{array}$ & $\begin{array}{l}0,0303 \\
(0,0540)\end{array}$ & $\begin{array}{l}-0,0635^{* * *} \\
(0,0191)\end{array}$ & $\begin{array}{l}0,0315 \\
(0,0338)\end{array}$ & $\begin{array}{l}-0,126^{* * *} \\
(0,0368)\end{array}$ \\
\hline In(Higheduper) & $\begin{array}{l}-0,154 \\
(0,162)\end{array}$ & $\begin{array}{l}0,152 \\
(0,410)\end{array}$ & $\begin{array}{l}0,321 \\
(0,289)\end{array}$ & $\begin{array}{l}-0,565 \\
(0,398)\end{array}$ & $\begin{array}{l}0,016 \\
(0,140)\end{array}$ & $\begin{array}{l}-0,389 \\
(0,249)\end{array}$ & $\begin{array}{l}-0,119 \\
(0,271)\end{array}$ \\
\hline In(Unempper) & $\begin{array}{l}-0,112^{* * *} \\
(0,0357)\end{array}$ & $\begin{array}{l}-0,0879 \\
(0,0904)\end{array}$ & $\begin{array}{l}-0,218^{* * *} \\
(0,0637)\end{array}$ & $\begin{array}{l}-0,188^{* *} \\
(0,0877)\end{array}$ & $\begin{array}{l}0,0892^{* * *} \\
(0,0309)\end{array}$ & $\begin{array}{l}0,104^{*} \\
(0,0548)\end{array}$ & $\begin{array}{l}0,195^{* * *} \\
(0,0598)\end{array}$ \\
\hline In(Wage) & $\begin{array}{l}-1,514^{* * *} \\
(0,342)\end{array}$ & $\begin{array}{l}-2,147^{* * *} \\
(0,867)\end{array}$ & $\begin{array}{l}-0,988 \\
(0,611)\end{array}$ & $\begin{array}{l}-0,532 \\
(0,841)\end{array}$ & $\begin{array}{l}0,565 * * * \\
(0,297)\end{array}$ & $\begin{array}{l}2,241^{* *} \\
(0,525)\end{array}$ & $\begin{array}{l}1,210^{* * *} \\
(0,573)\end{array}$ \\
\hline $\begin{array}{l}\text { time fe } \\
\text { municipality fe }\end{array}$ & $\begin{array}{l}\text { yes } \\
\text { yes }\end{array}$ & $\begin{array}{l}\text { yes } \\
\text { yes }\end{array}$ & $\begin{array}{l}\text { yes } \\
\text { yes }\end{array}$ & $\begin{array}{l}\text { yes } \\
\text { yes }\end{array}$ & $\begin{array}{l}\text { yes } \\
\text { yes }\end{array}$ & $\begin{array}{l}\text { yes } \\
\text { yes }\end{array}$ & $\begin{array}{l}\text { yes } \\
\text { yes }\end{array}$ \\
\hline$R^{\wedge} 2$ & 0,796 & 0,827 & 0,072 & 0,582 & 0,838 & 0,947 & 0,771 \\
\hline
\end{tabular}

The significance of the coefficients is denoted by stars $(*$ significance on the $10 \%$ significance level, ** $5 \%$ and $* * * 1 \%$, respectively). Standard errors are in brackets and they are computed on the $5 \%$ significance level.

The output suggests a positive correlation for the conservative party KD and a negative effect for the center-right party C. All other specifications remain statistically insignificant.

Consequently, one can conclude that municipalities with high refugee inflow on average had higher vote shares allocated to KD and lower to C. However, as many of the coefficients are insignificant - the results do not speak very clearly. Consequently, the difference-in-difference models could be more interesting.

\section{4.b Static difference-in-difference model on political voting}

The impact of refugee influx on the vote share of SD, analyzed through the static differencein-difference estimator is displayed in table 17. 
Table 17. Refugee influx on the vote share of SD, static difference-in-difference estimator

\begin{tabular}{|l|lll|}
\hline $\ln$ (Voteshare SD) & $(1)$ & $(2)$ & $(3)$ \\
\hline treated & $0,279^{* * *}$ & & \\
& $(0,0475)$ & & \\
did & $-0,0149$ & $-0,0149$ & $-0,0248$ \\
& $(0,0672)$ & $(0,0166)$ & $(0,0178)$ \\
& & & $0,0631^{*}$ \\
& & & $(0,0373)$ \\
In(Crimesper) & & & $-0,0612$ \\
& & & $(0,285)$ \\
In(Unemp) & & & 0,0779 \\
& & & $(0,0779)$ \\
In(Wage) & & & 0,0675 \\
& & & $(0,640)$ \\
\hline time fe & & & yes \\
municipality fe & no & yes & yes \\
\hline R^2 & 0,342 & 0,905 & 0,908 \\
\hline
\end{tabular}

The significance of the coefficients is denoted by stars (* significance on the $10 \%$ significance level, ** $5 \%$ and ***1\%, respectively). Standard errors are in brackets and they are computed on the $5 \%$ significance level.

The first specification suggests that the average difference between treated and controlled units three years after the event (did18) is $-0,0149 \%$. However, the estimate is not statistically significant. By adding the municipality-fixed-effects, the magnitude and significance level remain constant, why one cannot draw conclusions from it. When adding the vector of time-variant control variables, the magnitude decreases, and the coefficient of interest is still statistically insignificant on the 1, 5, and $10 \%$ level. The results do not advocate any relation between refugee inflow and increasing vote shares for SD. Table 18 presents all the political parties' results. 
Table 18. The effect of the refugee influx on the vote share of $M, K D, L, C, S, M P$ and $V$, static difference in difference estimator

\begin{tabular}{|l|llllllll|}
\hline In(Voteshare) sorted by: & $M$ & KD & L & C & S & MP & V \\
\hline \multirow{2}{*}{ did } & $0,0608^{* * *}$ & $0,103^{* * *}$ & $-0,0123$ & $-0,232^{* * *}$ & $-0,0757^{* * *}$ & 0,00695 & $-0,117^{* * *}$ \\
& $(0,0142)$ & $(0,0346)$ & $(0,0261)$ & $(0,0315)$ & $(0,0209)$ & $(0,0234)$ & $(0,0214)$ \\
In(Crimesper) & $0,0687^{* * *}$ & $0,0627^{* *}$ & $-0,186^{* * *}$ & 0,0586 & $-0,0336$ & 0,0442 & $-0,0760^{*}$ \\
& $(0,0297)$ & $(0,0723)$ & $(0,0546)$ & $(0,0658)$ & $(0,0229)$ & $(0,0488)$ & $(0,0556)$ \\
In(Higheduper) & $-0,337$ & 0,936 & 0,0738 & $-0,618$ & 0,109 & $-0,296$ & 0,490 \\
& $(0,227)$ & $(0,552)$ & $(0,417)$ & $(0,502)$ & $(0,175)$ & $(0,373)$ & $(0,341)$ \\
In(Unempper) & $-0,118^{* *}$ & $-0,0318$ & $-0,162$ & $-0,156$ & $0,0874 *$ & 0,115 & $0,203^{* *}$ \\
& $(0,0576)$ & $(0,140)$ & $(0,106)$ & $(0,127)$ & $(0,0443)$ & $(0,0945)$ & $(0,0864)$ \\
In(Wage) & $-0,247$ & $-2,672 * *$ & $-0,531$ & $-1,228 * * *$ & $-0,285$ & $2,395 * * *$ & $-0,457$ \\
& $(0,510)$ & $(1,239)$ & $(0,936)$ & $(1,128)$ & $(0,392)$ & $(0,837)$ & $(0,765)$ \\
\hline time fe & yes & yes & yes & yes & yes & yes & yes \\
municipality fe & yes & yes & yes & yes & yes & yes & yes \\
\hline$R^{\wedge} 2$ & 0,798 & 0,830 & 0,140 & 0,717 & 0,852 & 0,943 & 0,812 \\
\hline
\end{tabular}

The significance of the coefficients is denoted by stars (* significance on the $10 \%$ significance level, ** 5\% and ***1\%, respectively). Standard errors are in brackets and they are computed on the 5\% significance level.

The results regarding KD are similar as in the fixed-effects model. Namely, municipalities with a high refugee influx have a higher growth rate in KD's vote share. However, the specification $M$ suggests that also the vote share of the other conservative party, $M$, is significant. Consequently, municipalities with high refugee-influx have higher average vote shares allocated to $M$ and KD. As before, the center-right party $C$ faces a negative effect.

Furthermore, one can also notice a reduction for the left-wing party $\vee$ and the centerleft party S. Consequently. The results conclude that the treated municipalities encountered increasing rates for the vote share of KD and $\mathrm{M}$. In contrast, negative or statistically insignificant results for all center-right, center-left, left-wing and environmentalist parties. The results suggest a trend that conservative parties increase their vote share. The highest magnitudes affect the conservative party KD and the center-right party $C$. The average difference between treated and controlled units three years after the event (did18) is 0,103\% regarding $\mathrm{KD}$ and $-0,232 \%$ regarding $\mathrm{C}$. Both coefficients are statistically significant at the $1 \%$ level.

Before moving on, to be able to comment on Bordignon et al. (2019) findings in the following discussion regarding urban cities being associated with lower votes to antiimmigration parties, it is crucial to add another regression. In the regression, the treated group is the top quantile regarding population, and the control group is the bottom quantile. 
I.e., the model compares relatively big urban municipalities with relatively small rural municipalities. Table 19 represents the findings.

Table 19. The difference between rural and urban municipalities on the vote share of SD, static difference-in-difference estimator

\begin{tabular}{|l|lll|}
\hline $\ln$ (Voteshare SD) & $(1)$ & $(2)$ & $(3)$ \\
\hline did & $-0,242^{* * *}$ & 0,0132 & $0,0369^{* *}$ \\
& $(0,0470)$ & $(0,0162)$ & $(0,0172)$ \\
In(Crimesper) & & & $0,114^{* * *}$ \\
& & & $(0,0387)$ \\
In(Higheduper) & & & 0,0165 \\
& & & $(0,259)$ \\
$\operatorname{In}$ (Unemp) & & & 0,0313 \\
& & & $(0,0666)$ \\
$\operatorname{In}$ (Wage) & & & $-0,482$ \\
& & & $(0,593)$ \\
\hline time fe & & & yes \\
municipality fe & no & yes & yes \\
\hline $\mathrm{R}^{\wedge} 2$ & 0,285 & 0,912 & 0,908 \\
\hline
\end{tabular}

The significance of the coefficients is denoted by stars (* significance on the $10 \%$ significance level, ** $5 \%$ and *** $1 \%$, respectively). Standard errors are in brackets and they are computed on the $5 \%$ significance level.

In the first regression, the result provides, as Bordignon et al. (2019) suggest, a negative correlation. However, by including the vector of time-variant control variables and the municipality-fixed-effects, one can notice a positive coefficient, statistically significant at the 5 $\%$ level. The average difference between treated and controlled units three years after the event (did18) is $0,0369 \%$.

Adding the political dimension's results in the third model would be superfluous because the data cover the national elections 2014 and 2018. Thus, the second and third models' results will perfectly converge. The coefficient did, and did18 would share an identical magnitude, sign, and statistical significance level.

\section{Additional findings}

In this section, findings that are not as sensible or significant as the previously mentioned are presented. Furthermore, they will be less emphasized in the subsequent discussion. 


\subsection{Difference-in-difference model on local municipality mandates}

Following the reasoning of Bordignon et al. (2019), a specification that investigates the local election results is made, which will be further commented in the discussion. The results are represented below in Table 20.

Table 20. Refugee influx on local elections, static difference-in-difference estimator

\begin{tabular}{|c|c|c|c|c|c|c|c|}
\hline In(MandateShare) sorted by: & M & KD & L & C & $\mathrm{s}$ & MP & v \\
\hline did & $\begin{array}{l}0,112^{* * *} \\
(0,0320)\end{array}$ & $\begin{array}{l}-0,161^{* *} \\
(0,0706)\end{array}$ & $\begin{array}{l}-0,0819 \\
(0,0667)\end{array}$ & $\begin{array}{l}-0,290^{* * *} \\
(0,0486)\end{array}$ & $\begin{array}{l}0,00089 \\
(0,0231)\end{array}$ & $\begin{array}{l}0,121^{*} \\
(0,0648)\end{array}$ & $\begin{array}{l}-0,175^{* * *} \\
(0,0581)\end{array}$ \\
\hline In(Crimesper) & $\begin{array}{l}0,00359^{* *} \\
(0,0709)\end{array}$ & $\begin{array}{l}0,00942 \\
(0,164)\end{array}$ & $\begin{array}{l}-0,217 \\
(0,169)\end{array}$ & $\begin{array}{l}0,248^{* *} \\
(0,107)\end{array}$ & $\begin{array}{l}0,0226 \\
(0,0483)\end{array}$ & $\begin{array}{l}0,047 \\
(0,149)\end{array}$ & $\begin{array}{l}-0,0464 \\
(0,120)\end{array}$ \\
\hline In(Higheduper) & $\begin{array}{l}-0,767 \\
(0,572)\end{array}$ & $\begin{array}{l}0,830 \\
(1,385))\end{array}$ & $\begin{array}{l}-0,753 \\
(1,261)\end{array}$ & $\begin{array}{l}1,785^{* *} \\
(0,778)\end{array}$ & $\begin{array}{l}0,492 \\
(0,368)\end{array}$ & $\begin{array}{l}-0,793 \\
(1,156)\end{array}$ & $\begin{array}{l}-0,132 \\
(0,930)\end{array}$ \\
\hline In(Unempper) & $\begin{array}{l}-0,0417^{* *} \\
(0,132)\end{array}$ & $\begin{array}{l}0,159 \\
(0,307)\end{array}$ & $\begin{array}{l}-0,0455 \\
(0,278)\end{array}$ & $\begin{array}{l}0,146 \\
(0,195)\end{array}$ & $\begin{array}{l}0,00777 \\
(0,0934)\end{array}$ & $\begin{array}{l}-0,394 \\
(0,249)\end{array}$ & $\begin{array}{l}0,475^{* *} \\
(0,0864)\end{array}$ \\
\hline In(Wage) & $\begin{array}{l}-0,595 \\
(1,171)\end{array}$ & $\begin{array}{l}-1,057 \\
(2,761)\end{array}$ & $\begin{array}{l}-0,772 \\
(2,634)\end{array}$ & $\begin{array}{l}2,024 \\
(1,761)\end{array}$ & $\begin{array}{l}-0,2025^{* *} \\
(0,828)\end{array}$ & $\begin{array}{l}2,161 \\
(2,305)\end{array}$ & $\begin{array}{l}1,860 \\
(2,050)\end{array}$ \\
\hline $\begin{array}{l}\text { time fe } \\
\text { municipality fe }\end{array}$ & $\begin{array}{l}\text { yes } \\
\text { yes }\end{array}$ & $\begin{array}{l}\text { yes } \\
\text { yes }\end{array}$ & $\begin{array}{l}\text { yes } \\
\text { yes }\end{array}$ & $\begin{array}{l}\text { yes } \\
\text { yes }\end{array}$ & $\begin{array}{l}\text { yes } \\
\text { yes }\end{array}$ & $\begin{array}{l}\text { yes } \\
\text { yes }\end{array}$ & $\begin{array}{l}\text { yes } \\
\text { yes }\end{array}$ \\
\hline$R^{\wedge} 2$ & 0,126 & 0,433 & 0,042 & 0,417 & 0,499 & 0,785 & 0,196 \\
\hline
\end{tabular}

The significance of the coefficients is denoted by stars (* significance on the $10 \%$ significance level, ** $5 \%$ and

$* * * 1 \%$, respectively). Standard errors are in brackets and they are computed on the $5 \%$ significance level.

The results are quite similar to the ones in Table 14 . The conservative party $\mathrm{M}$ has a significant increase in the vote share. The main difference is that the environmentalist party MP now positively correlates at the $10 \%$ statistical significance level. Furthermore, instead of a positive correlation, as in the national elections, one can see that the conservative party KD now shows a negative relationship in the local elections. The data differ slightly as the model now analyze the number of mandates given in each municipality, i.e., one does not measure votes, but mandates based on votes. However, quite often, smaller parties do not receive any mandates, why the data is not as sensitive as the one regarding the national election. Consequently, the findings are regarded as "additional."

\subsection{Density of immigrants on votes allocated to anti-immigration parties.}

Another specification is constructed to analyze whether the Swedish environment show similar results as Bordignon et al. (2019). The treated municipalities are the ones with intermediate levels of refugee density, i.e., the two intermediate quantiles. The control group 
is made of the municipalities with either relatively high (top quantile) or low (bottom quantile) level of refugee density. The findings will contribute to discussions in the following chapters.

Table 21. Municipalities with intermediate share of immigrants on the vote share of SD, static difference-in-difference estimator

\begin{tabular}{|l|lll|}
\hline $\ln$ (Voteshare SD) & $(1)$ & $(2)$ & $(3)$ \\
\hline did & $0,0813^{* *}$ & $-0,00836$ & $-0,00980$ \\
& $(0,0332)$ & $(0,0118)$ & $(0,0118)$ \\
In(Crimesper) & & & $0,0449^{*}$ \\
& & & $(0,0276)$ \\
In(Higheduper) & & & $-0,158$ \\
& & & $(0,202)$ \\
In(Unemp) & & & $0,110^{* *}$ \\
& & & $(0,0450)$ \\
In(Wage) & & & $1,013^{* *}$ \\
& & & $(0,428)$ \\
\hline time fe & yes & yes & yes \\
municipality fe & no & yes & yes \\
\hline$R^{\wedge} 2$ & 0,233 & 0,903 & 0,907 \\
\hline
\end{tabular}

The significance of the coefficients is denoted by stars (* significance on the $10 \%$ significance level, ** $5 \%$ and ${ }^{* * *} 1 \%$, respectively). Standard errors are in brackets and they are computed on the $5 \%$ significance level.

Regarding the first specification, the coefficient of interest did18 is both statistically significant at the $5 \%$ level and positive. However, when adding the municipality-fixed-effects and vector of time-variant control variables, the coefficient's statistical significance disappears why one cannot draw any conclusions from the table. Previous scholars have found that municipalities with higher immigrant-densities vote differently from those with low densities. To estimate whether the statement holds regarding Sweden, one must add further specifications. Consequently, by treating the municipalities with the highest densities of foreign-born citizens and letting the municipalities with the lowest form the control, insights are given. Table 22 displays the results. 
Table 22. Municipalities with higher share of immigrants on votes allocated to the anti-immigration party SD, static difference-in-difference estimator

\begin{tabular}{|l|lll|}
\hline In(Voteshare SD) & $(1)$ & $(2)$ & $(3)$ \\
\hline did & $-0,0122$ & 0,00684 & 0,0122 \\
& $(0,0386)$ & $(0,0136)$ & $(0,0140)$ \\
& & & $0,0504^{*}$ \\
In(Crimesper) & & & $(0,0280)$ \\
& & & $-0,181$ \\
$\operatorname{In}$ (Higheduper) & & & $(0,201)$ \\
& & & $0,102^{* *}$ \\
$\operatorname{In}$ (Unemp) & & & $(0,0447)$ \\
& & & $1,077^{* *}$ \\
$\operatorname{In}$ (Wage) & & & $(0,433)$ \\
& & & yes \\
\hline municipality fe & yes & yes & yes \\
unit fe & no & yes & \\
\hline$R^{\wedge} 2$ & 0,2225 & 0,903 & 0,907 \\
\hline
\end{tabular}

The significance of the coefficients is denoted by stars (* significance on the $10 \%$ significance level, ** $5 \%$ and ***1\%, respectively). Standard errors are in brackets and they are computed on the $5 \%$ significance level.

As none of the specifications are significant, no conclusions can be drawn. There is no significant difference between municipalities with high immigrant-density and municipalities with low immigrant-density regarding voting-patterns in favor of SD.

\section{3.a Fixed-effects model on house prices}

The results regarding the effect of refugee influx on house prices are analyzed first through the fixed effects model and represented in table 23 below. 
Table 23. Refugee influx on house prices, fixed effects estimator

\begin{tabular}{|c|c|c|c|}
\hline In(Houseprice) & (1) & (2) & (3) \\
\hline treated & $\begin{array}{l}-1,137^{* * *} \\
(0,0490)\end{array}$ & & \\
\hline did & $\begin{array}{l}-0,0180 \\
(0,0656)\end{array}$ & $\begin{array}{l}-0,180^{* *} \\
(0,00916)\end{array}$ & $\begin{array}{l}-0,0177^{*} \\
(0,00992)\end{array}$ \\
\hline In(Crimesper) & & & $\begin{array}{l}0,0371^{* *} \\
(0,0188)\end{array}$ \\
\hline In(Higheduper) & & & $\begin{array}{l}0,425^{* * *} \\
(0,143)\end{array}$ \\
\hline In(Wage) & & & $\begin{array}{l}-0,435 \\
(0,297)\end{array}$ \\
\hline In(Unempper) & & & $\begin{array}{l}-0,0747^{* *} \\
(0,0311)\end{array}$ \\
\hline time fe & yes & yes & yes \\
\hline municipality fe & no & yes & yes \\
\hline$R^{\wedge} 2$ & 0,569 & 0,821 & 0,825 \\
\hline
\end{tabular}

The significance of the coefficients is denoted by stars (* significance on the $10 \%$ significance level, ** 5\% and ***1\%, respectively). Standard errors are in brackets and they are computed on the $5 \%$ significance level.

In all three specifications, the relationship between refugee-influx and house prices is negative. The third specification, including both time and municipality-fixed-effects, and the vector of time-invariant control variables, suggests that a $1 \%$ increase in refugee influx in the municipality $m$ induce a $0,0487 \%$ decrease in the average house price level in the same municipality. To obtain more credible estimators, one should proceed with the static difference-in-difference model.

\section{3.b Refugee influx on House prices, static difference-in-difference model.}

The relationship between refugee-inflow and house-prices, analyzed through the second empirical mode is illustrated in table 24. 
Table 24. Refugee influx on house prices, static difference-in-difference estimator

\begin{tabular}{|c|c|c|c|}
\hline In(Houseprice) & (1) & (2) & (3) \\
\hline treated & $\begin{array}{l}-1,137^{* * *} \\
(0,0490)\end{array}$ & & \\
\hline did & $\begin{array}{l}-0,0180 \\
(0,0656)\end{array}$ & $\begin{array}{l}-0,180^{* *} \\
(0,00916)\end{array}$ & $\begin{array}{l}-0,0177^{*} \\
(0,00992)\end{array}$ \\
\hline In(Crimesper) & & & $\begin{array}{l}0,0371^{* *} \\
(0,0188)\end{array}$ \\
\hline In(Higheduper) & & & $\begin{array}{l}0,425^{* * *} \\
(0,143)\end{array}$ \\
\hline In(Wage) & & & $\begin{array}{l}-0,435 \\
(0,297)\end{array}$ \\
\hline In(Unempper) & & & $\begin{array}{l}-0,0747^{* *} \\
(0,0311)\end{array}$ \\
\hline $\begin{array}{l}\text { time fe } \\
\text { municipality fe }\end{array}$ & $\begin{array}{l}\text { yes } \\
\text { no }\end{array}$ & $\begin{array}{l}\text { yes } \\
\text { yes }\end{array}$ & $\begin{array}{l}\text { yes } \\
\text { yes }\end{array}$ \\
\hline$R^{\wedge} 2$ & 0,569 & 0,821 & 0,825 \\
\hline
\end{tabular}

The significance of the coefficients is denoted by stars (* significance on the $10 \%$ significance level, ** 5\% and ***1\%, respectively). Standard errors are in brackets and they are computed on the $5 \%$ significance level.

By immediately looking at the third specification, representing equation (3) in the empirical section, one can notice a negative relation - the average difference between municipalities within the treated group and municipalities within the controlled group amount to -0,0177. As the average house price during the investigated period across the municipalities amounts to 1847000 SEK, the treated municipalities could expect house-prices to be approximately 32 691 SEK $(1847000 * 0,0177)$.

\section{3.c Dynamic difference-in-difference estimator on house prices}

The same relationship analyzed through the dynamic difference-in-difference model is represented in table 25 . 
Table 25. Refugee influx on house prices, dynamic difference-in-difference estimator

\begin{tabular}{|l|lll|}
\hline In(Houseprice) & $(1)$ & $(2)$ & $(3)$ \\
\hline \multirow{2}{*}{ treated } & $-0,708^{* * *}$ & & \\
& $(0,0390)$ & & \\
did16 & $-0,0123$ & $-0,00875$ & $-0,00875$ \\
& $(0,0912)$ & $(0,0108)$ & $(0,0108)$ \\
did17 & $-0,0197^{*}$ & $-0,0154^{* * *}$ & $-0,0154$ \\
& $(0,0911)$ & $(0,0109)$ & $(0,0109)$ \\
did18 & $0,0264^{* *}$ & $0,0284^{* * *}$ & $0,0284^{* * *}$ \\
& $(0,0870)$ & $(0,0109)$ & $(0,0109)$ \\
In(Crimesper) & & & 0,00413 \\
& & & $(0,0140)$ \\
In(Higheduper) & & & $0,421^{* * *}$ \\
& & & $(0,103)$ \\
In(Wage) & & & $-0,413^{* *}$ \\
& & & $(0,206)$ \\
In(Unempper) & & & $-0,0905^{* * *}$ \\
& & & $(0,0206)$ \\
\hline time fe & yes & yes & yes \\
municipality fe & no & yes & yes \\
\hline$R^{\wedge}$ 2 & 0,232 & 0,820 & 0,824 \\
\hline
\end{tabular}

The significance of the coefficients is denoted by stars (* significance on the $10 \%$ significance level, ** $5 \%$ and

***1\%, respectively). Standard errors are in brackets and they are computed on the $5 \%$ significance level.

The results are similar to the first model. In the first specification, the results are varying between the years. The interaction coefficient did16 is statistically insignificant, while did17 suggest a negative statistically significant correlation but did18, the contrary, namely a positive one. Adding the municipality-fixed-effects in the second specification does not change the situation. The estimators suggest negative correlations regarding 2016 and 2017 and a positive impact for 2018.

Adding control variables do not change much. The coefficient did17 is not significant anymore. Instead, the result now suggests a lagged significant impact on house prices. The average difference between treated and controlled units three years after the event (did18) is $0,0284 \%$. The different signs and magnitudes make the interpretation less precise compared to the main econometric specifications. Consequently, conclusions will be challenging to draw. The results will be treated as "additional" because of the equivocation regarding the coefficients' sign. 


\section{4.a Fixed-effects model on food prices}

Table 26 present the results produced by the fixed-effects model regarding the average food price level as the independent variable.

Table 26. Refugee influx on food prices, fixed effects model

\begin{tabular}{|c|c|c|c|}
\hline In(Foodpriceper) & (1) & $(2)$ & (3) \\
\hline In(RefugeePer) & $\begin{array}{l}-0,00123 \\
(0,000986)\end{array}$ & $\begin{array}{c}0,00589^{* *} \\
(0,00287)\end{array}$ & $\begin{array}{l}0,00595^{* *} \\
(0,00288)\end{array}$ \\
\hline In(Crimesper) & & & $\begin{array}{l}0,00560^{* *} \\
(0,00283)\end{array}$ \\
\hline In(HigheduPer) & & & $\begin{array}{l}-0,0363^{*} \\
(0,0209)\end{array}$ \\
\hline In(Unempper) & & & $\begin{array}{r}-0,000900 \\
(0,00410)\end{array}$ \\
\hline In(Wage) & & & $\begin{array}{l}0,00274 \\
(0,0414)\end{array}$ \\
\hline $\begin{array}{l}\text { time fe } \\
\text { municipality fe }\end{array}$ & $\begin{array}{l}\text { yes } \\
\text { no }\end{array}$ & $\begin{array}{l}\text { yes } \\
\text { yes }\end{array}$ & $\begin{array}{l}\text { yes } \\
\text { yes }\end{array}$ \\
\hline$R^{\wedge} 2$ & 0,988 & 0,996 & 0,996 \\
\hline
\end{tabular}

The significance of the coefficients is denoted by stars (* significance on the $10 \%$ significance level, ** $5 \%$ and ***1\%, respectively). Standard errors are in brackets and they are computed on the $5 \%$ significance level.

The first specification suggests a negative relationship. However, not statistically significant. Furthermore, the second specification, including municipality-fixed-effects, suggests a positive one. Finally, adding control-variables, one notices that the specification is still positive and significant at the $10 \%$ level, suggesting that a $1 \%$ increase in refugee influx in the municipality $m$ entail a 0,00595 \% increase in the average food price level in the very same municipality $m$.

\section{4.b Static difference-in-difference model on food prices}

The same results are investigated, but now through the second empirical model, presented in table 27 below. 
Table 27. Refugee influx on food prices, static difference-in-difference model

\begin{tabular}{|l|lll|}
\hline In(Foodpriceper) & $(1)$ & $(2)$ & $(3)$ \\
\hline treated & $-0,00362$ & & \\
& $(0,00224)$ & & \\
did & 0,00421 & $0,00438^{* *}$ & $0,00568^{* * *}$ \\
& $(0,00281)$ & $(0,00182)$ & $(0,00197)$ \\
In(Crimesper) & & & $0,00756^{* *}$ \\
& & & $(0,00375)$ \\
In(Higheduper) & & & $-0,0447$ \\
& & & $(0,0290)$ \\
$\ln$ (Wage) & & & 0,0207 \\
& & & $(0,0603)$ \\
In(Unempper) & & & $-0,00963$ \\
& & & $(0,00622)$ \\
\hline time fe & yes & yes & yes \\
municipality fe & no & yes & yes \\
\hline$R^{\wedge} 2$ & 0,988 & 0,995 & 0,995 \\
\hline
\end{tabular}

The significance of the coefficients is denoted by stars (* significance on the $10 \%$ significance level, ** 5\% and ***1\%, respectively). Standard errors are in brackets and they are computed on the $5 \%$ significance level.

All the specifications advocate a positive relation. However, the first one, excluding municipality-fixed-effects, is not statistically significant. Looking at the third specification, representing the third equation in the econometric model, one finds that the average difference between the municipalities belonging to the treated group and the municipalities belonging to the controlled group is $0,00568 \%$. The magnitude of the effect is very small as an average "basket of basic food" amounted to 877 SEK during the period of interest across the municipalities. Consequently, the average difference between the municipalities was 5 $\operatorname{SEK}(877 * 0,00568)$, a negligible number.

\section{4.c Dynamic difference-in-difference model on food price}

Table 28 represents the findings from the third model. The first specification generates insignificant coefficients. Meanwhile, in the second specification, the model shows a statistically significant correlation regarding 2016, where the model suggests that the municipalities with high refugee influx on average two years after the event (did17) encounter a 0,00604 \% increase in food prices compared to the control group, i.e., the municipalities with relatively low intake. Finally, in the third specification, a similar structure remains. The 
only statistically significant year is 2016 . The sign remains constant while the magnitude increases very slightly to $0,00624 \%$. As the price specifications' magnitude is shallow, the coefficients are weakly significant and sometimes highly volatile regarding signs and magnitudes. As mentioned in the data section, the collected data regarding the food price dimension is less precise as it is collected on more significant regions rather than municipalities. Consequently, results are treated as "additional."

Table 28. Refugee influx on food prices, fixed effects model

\begin{tabular}{|l|lll|}
\hline In(Foodpriceper) & $(1)$ & $(2)$ & $(3)$ \\
\hline treated & $-0,00362$ & & \\
did & $(0,00224)$ & & \\
& 0,00421 & $0,00438^{* *}$ & $0,00568^{* * *}$ \\
& $(0,00281)$ & $(0,00182)$ & $(0,00197)$ \\
In(Crimesper) & & & $0,00756^{* *}$ \\
& & & $(0,00375)$ \\
In(Higheduper) & & & $-0,0447$ \\
& & & $(0,0290)$ \\
$\ln$ (Wage) & & & 0,0207 \\
& & & $(0,0603)$ \\
$\operatorname{In}$ (Unempper) & & & $-0,00963$ \\
& & & $(0,00622)$ \\
\hline time fe & yes & yes & yes \\
municipality fe & no & yes & yes \\
\hline$R^{\wedge} 2$ & 0,988 & 0,995 & 0,995 \\
\hline
\end{tabular}

The significance of the coefficients is denoted by stars (* significance on the $10 \%$ significance level, ** $5 \%$ and *** $1 \%$, respectively). Standard errors are in brackets and they are computed on the $5 \%$ significance level.

\section{Robustness \& Endogeneity tests}

The study encounters some issues. First, $50 \%$ of the refugees who allocated themselves might have chosen municipalities with more profitable labor markets. Second, they might have chosen municipalities governed by more friendly immigration platforms, i.e., left-wing, center-right/left, or environmentalist parties. Third, the other half, allocated by the state, may not have been entirely random but governed by political factors. For example, municipalities with more immigration-friendly platforms could be induced to host more immigrants. Furthermore, rather than randomness, the allocation could be due to housing-possibilities: 
The municipalities with more space in terms of available apartments or other housingsolutions could host more immigrants. Consequently, the allocation process and identifying assumptions might be violated by trends not captured by the fixed-effects model. Robustness tests in terms of placebo-tests and endogeneity-tests are conducted to analyze the abovementioned concerns.

\subsection{Placebo tests on all main econometric specifications}

In this section, the placebo tests, and results from the analysis with alternative control groups are presented. A fundamental and crucial assumption for a difference-in-difference analysis is the assumption of a common trend among treated and non-treated groups. In table 30-34 (see the appendix), one can see the results. The findings support the assumption of a common trend. The tables show that there was no similar trend in the placebo-treated group in the pre-crisis period for every dynamic difference-in-difference estimator with significant coefficients of interest. Each placebo-test will be commented one by one in more detail in the discussion.

They are presented with the baseline specification of the dynamic difference-indifference estimators with a placebo-treatment in 2012, 2013, and 2014. One could in table 34 (see the appendix) notice that more refugees seemed to be allocated in municipalities that had higher vote shares in the center-left party $S$, the left-wing party $V$, and the center-right party $C$. The mentioned parties are known for having an immigrant-friendly platform. I.e., municipalities with high vote shares in political parties with immigrant-friendly platforms encountered higher refugee-influx in the treatment-period (2015). This finding supports the issue mentioned previously; allocation processes might be influenced politically and not strictly random. The political influence will be mentioned further in the discussion.

\subsection{Endogeneity test on the vote share of SD}

It is possible to empirically test whether past election results affect present refugee allocation or not. The test will share a similar structure to the one conducted by Dustman et al. (2019). The idea is to examine whether past changes in the municipal council's seat composition (i.e., between election years $\mathrm{t}-2$ and year $\mathrm{t}-1), \Delta Y S_{\mathrm{m} t}-1$ affect current differences in the share of allocated refugees to that municipality (i.e., between $\mathrm{t}-1$ and $\mathrm{t}$ ), $\Delta R S_{\mathrm{m} t}$. To execute the test, one must calculate seat shares after each municipal election for all election years between 2010-2018. Consequently, the dataset is extended from 2012-2018 to 2010-2018 as this then 
includes three elections instead of two and makes the test possible.

Results are reported in Table 29 (See appendix). The explanatory variables express the change in the municipal council's seat, regarding municipality m, between 2014 and 2010, and the dependent variable, the percentage change in refugees in the municipality between 2018 and 2014. If there existed a negative correlation between seats for SD and refugee allocation, the regression would be endogenous. However, as the table expresses, the relationship is i) minimal, ii) positive. Consequently, one can conclude that the quasirandomized process is exogenous: past election results do not affect future refugee-allocation between Swedish municipalities.

\subsection{Robustness test - Omitted variable bias (GRP)}

As mentioned in the data section, data regarding GDP per region, GRP, is only available for the timespan 2012-2017. Consequently, it is omitted as the period of interest stretches to 2018. The omitted variable could potentially bias the main findings. Regarding the wage and unemployment dimensions, the lack of data is irrelevant: the variable GRP would have been endogenous if included as a covariate in the regression. However, the regional GDP could be necessary regarding the criminality and political dimension specifications. Regarding the political dimension, it is impossible to measure, as the election of interest took place in 2018, where the data is missing.

Nevertheless, one can create a parallel dataset containing the years 2012-2017, including the covariates used in the main specifications and GRP, and then measure its effects on the criminality specifications. To see whether the main-specifications are biased because of the omitted variable, one should create a table including the covariates used in the main specifications and another table, including the potentially omitted variable, in this case, GRP. Table 36 includes the identical covariates, as reported in the main section regarding 20122017. Table 37 is identical to 36 but further includes GRP. If the coefficients of interest, did16, and did17 are similar between the tables, the main specification does not suffer from omitted variable bias. By scrutinizing the tables reported on the following page, one can immediately see that the coefficients of interest are perfectly identical, or very similar, in all the specifications. The robustness-check lend support and credibility for the main-results presented in chapter 5. The specifications do not suffer from omitted variable bias due to the scarcity of data regarding GRP. 
Table 36. Refugee influx on crimes and subsets of crimes, dynamic difference-in-difference estimator

\begin{tabular}{|c|c|c|c|c|c|c|}
\hline In(Crimes per capita) sorted by: & Assault & Crimes & Drugs & Fraud & Sexual & Theft \\
\hline did16 & $\begin{array}{l}0,135 * * * \\
(0,0380)\end{array}$ & $\begin{array}{l}0,0233 \\
-0,0233\end{array}$ & $\begin{array}{l}0,0643 \\
(0,0750)\end{array}$ & $\begin{array}{l}0,172 * * \\
(0,0690)\end{array}$ & $\begin{array}{l}0,110 \\
(0,0879)\end{array}$ & $\begin{array}{l}-0,0555^{* *} \\
(0,0273)\end{array}$ \\
\hline did17 & $\begin{array}{l}0,106 * * * \\
(0,0387)\end{array}$ & $\begin{array}{l}0,0483^{* *} \\
-0,02346\end{array}$ & $\begin{array}{l}0,0185 \\
(0,0762)\end{array}$ & $\begin{array}{l}0,264 * * * \\
(0,0701)\end{array}$ & $\begin{array}{l}0,150^{*} \\
(0,0893)\end{array}$ & $\begin{array}{l}-0,0487^{*} \\
(0,0278)\end{array}$ \\
\hline In(Higheduper) & $\begin{array}{l}2,041^{* * *} \\
(0,461)\end{array}$ & $\begin{array}{l}0,492^{*} \\
(0,282)\end{array}$ & $\begin{array}{l}0,489 \\
(0,908)\end{array}$ & $\begin{array}{l}-1,831^{* *} \\
(0,836)\end{array}$ & $\begin{array}{l}2,338^{* *} \\
(1,067)\end{array}$ & $\begin{array}{l}0,443 \\
(0,331)\end{array}$ \\
\hline In(Unempper) & $\begin{array}{l}0,125 \\
(0,0960)\end{array}$ & $\begin{array}{l}-0,0941 \\
(0,0587)\end{array}$ & $\begin{array}{l}-0,317^{*} \\
(0,189)\end{array}$ & $\begin{array}{l}-0,150 \\
(0,174)\end{array}$ & $\begin{array}{l}0,0183 \\
(0,222)\end{array}$ & $\begin{array}{l}-0,00482 \\
(0,0690)\end{array}$ \\
\hline $\ln$ (Wage) & $\begin{array}{l}1,804^{*} \\
(0,957)\end{array}$ & $\begin{array}{l}0,153 \\
-0,585\end{array}$ & $\begin{array}{l}0,802 \\
-0,0261\end{array}$ & $\begin{array}{l}-1,016 \\
(1,735)\end{array}$ & $\begin{array}{l}1,423 \\
(2,236)\end{array}$ & $\begin{array}{l}-0,0761 \\
(0,688)\end{array}$ \\
\hline $\begin{array}{l}\text { time fe } \\
\text { municipality fe }\end{array}$ & \begin{tabular}{|l|} 
yes \\
yes
\end{tabular} & $\begin{array}{l}\text { yes } \\
\text { yes }\end{array}$ & $\begin{array}{l}\text { yes } \\
\text { yes }\end{array}$ & $\begin{array}{l}\text { yes } \\
\text { yes }\end{array}$ & $\begin{array}{l}\text { yes } \\
\text { yes }\end{array}$ & $\begin{array}{l}\text { yes } \\
\text { yes }\end{array}$ \\
\hline$R^{\wedge} 2$ & 0,137 & 0,067 & 0,014 & 0,213 & 0,105 & 0,159 \\
\hline
\end{tabular}

The significance of the coefficients is denoted by stars (* significance on the $10 \%$ significance level, ** $5 \%$ and ***1\%, respectively). Standard errors are in brackets and they are computed on the $5 \%$ significance level.

Table 37. Refugee influx on crimes and subsets of crimes, dynamic difference-in-difference estimator, including the covariate GRP

\begin{tabular}{|c|c|c|c|c|c|c|}
\hline In(Crimes per capita) sorted by: & Assault & Crimes & Drugs & Fraud & Sexual & Theft \\
\hline $\operatorname{did} 16$ & $\begin{array}{l}0,130 * * * \\
(0,0381)\end{array}$ & $\begin{array}{l}0,0227 \\
(-0,0234)\end{array}$ & $\begin{array}{l}0,0626 \\
(0,0753)\end{array}$ & $\begin{array}{l}0,178^{* *} \\
(0,0692)\end{array}$ & $\begin{array}{l}0,110 \\
(0,0879)\end{array}$ & $\begin{array}{l}-0,0556 * * \\
(0,0275)\end{array}$ \\
\hline $\operatorname{did} 17$ & $\begin{array}{l}0,106 * * * \\
(0,0386)\end{array}$ & $\begin{array}{l}0,0482^{* *} \\
-0,0237\end{array}$ & $\begin{array}{l}0,0183 \\
(0,0600)\end{array}$ & $\begin{array}{l}0,264 * * * \\
(0,0701)\end{array}$ & $\begin{array}{l}0,150^{*} \\
(0,0893)\end{array}$ & $\begin{array}{l}-0,0487^{*} \\
(0,0278)\end{array}$ \\
\hline $\ln (G R P)$ & $\begin{array}{l}0,150 \\
(0,110)\end{array}$ & $\begin{array}{l}0,0204 \\
-0,0672\end{array}$ & $\begin{array}{l}0,0575 \\
(0,217)\end{array}$ & $\begin{array}{l}-0,178 \\
(0,199)\end{array}$ & $\begin{array}{l}0,0392 \\
(0,254)\end{array}$ & $\begin{array}{l}0,000861 \\
(0,0790)\end{array}$ \\
\hline In(Higheduper) & $\begin{array}{l}2,032^{* * *} \\
(0,461)\end{array}$ & $\begin{array}{l}0,491^{*} \\
-0,282\end{array}$ & $\begin{array}{l}0,486 \\
(0,909)\end{array}$ & $\begin{array}{l}-1,821^{* * *} \\
(0,836)\end{array}$ & $\begin{array}{l}2,338^{* *} \\
(1,067)\end{array}$ & $\begin{array}{l}0,443 \\
(0,332)\end{array}$ \\
\hline In(Unempper) & $\begin{array}{l}0,116 \\
(0,0962)\end{array}$ & $\begin{array}{l}-0,0953 \\
(0,0589)\end{array}$ & $\begin{array}{l}-0,321^{*} \\
(0,190)\end{array}$ & $\begin{array}{l}-0,139 \\
(0,175)\end{array}$ & $\begin{array}{l}0,0183 \\
(0,222)\end{array}$ & $\begin{array}{l}-0,00487 \\
(0,0692)\end{array}$ \\
\hline In(Wage) & $\begin{array}{l}1,634^{*} \\
(0,570)\end{array}$ & $\begin{array}{l}0,130 \\
(0,591)\end{array}$ & $\begin{array}{l}0,735 \\
(1,903)\end{array}$ & $\begin{array}{l}-0,813 \\
(1,751)\end{array}$ & $\begin{array}{l}1,423 \\
(2,236)\end{array}$ & $\begin{array}{l}-0,0770 \\
(0,694)\end{array}$ \\
\hline $\begin{array}{l}\text { time fe } \\
\text { municipality fe }\end{array}$ & \begin{tabular}{|l|} 
yes \\
yes
\end{tabular} & $\begin{array}{l}\text { yes } \\
\text { yes }\end{array}$ & $\begin{array}{l}\text { yes } \\
\text { yes }\end{array}$ & $\begin{array}{l}\text { yes } \\
\text { yes }\end{array}$ & $\begin{array}{l}\text { yes } \\
\text { yes }\end{array}$ & $\begin{array}{l}\text { yes } \\
\text { yes }\end{array}$ \\
\hline$R^{\wedge} 2$ & 0,139 & 0,067 & 0,014 & 0,214 & 0,105 & 0,159 \\
\hline
\end{tabular}

The significance of the coefficients is denoted by stars (* significance on the $10 \%$ significance level, ** 5\% and $* * * 1 \%$, respectively). Standard errors are in brackets and they are computed on the $5 \%$ significance level. 


\section{Discussion}

The inflow of more than 160000 asylum seekers in 2015 continues to affect the economy and society. Simultaneously it represents a unique natural experiment that allows for an analysis of the labor market, crime-levels, voting behavior, and price levels of the immigrant inflows, which is otherwise, in the absence of a shock, difficult to estimate. This paper analyzes the short-term impacts of this largely unanticipated shock as the post-treatment period is three years and hence, a concise one. After analyzing the implications of the shock, the found results can provide some very distinct contributions.

First, the results are very relevant to policymakers. It is the first study to evaluate the mentioned effects in Sweden of a contemporary key event that has shaped public discourse in Sweden and throughout the world. The results show that a substantial labor supply shock of mainly low-skilled immigrants has a significant negative impact on the wage structure, which implies that they differ from results found by Card (1991), Glitz (2012), and Foged and Peri (2015). As discussed in the literature review, the reason why the findings differ from Card (1991) could be explained by the fact that there is a broader language and culture barrier between middle eastern countries and Sweden relative to the language and culture barrier between Cuba and Miami.

More surprisingly, the results also differ from Glitz (2012). Because the environment in Sweden and Germany are quite similar in terms of wage rigidity and unions, one could be induced to argue that different integration-structures could potentially explain the different results between the host-countries. The results are quite remarkable. As there may be an underlying positive correlation between refugee's self-allocation and prosperous regions, which creates a positive relationship between the variables, the negative effect is rarely found in empirical studies. However, one reason that could explain the found results is that the allocation process in Sweden was in 50 \% of the cases independent of labor markets, hence, mitigating the endogeneity. Following this argument and reasoning, one could be tempted to speculate that the exact estimators would be more adverse, as the $50 \%$ of refugees who selfallocated could have placed themselves in municipalities with high wage levels.

The reason why the results are negative could further be explained by the logic provided by Dustmann, Glitz, and Frattini (2008). They stress that one should only expect effects on wages if immigrants change the receiving country's skill structure. Because the 
inflow of refugees in Sweden has relatively low skill compared to the natives, one should not be surprised that the difference-in-difference models finds significant effects. As the observations consist of municipalities and not individuals, one cannot distinguish between immigrants and native workers, but merely look at average levels. Thus, the results cannot recognize whether the negative wage levels stem from income-reduction, mostly on the accounts of immigrants already living in the municipality. Dustmann, Glitz \& Frattini (2008) argue that if immigrants differ from native workers in skill composition, absorption will imply wage adjustments. Who gains and who loses on immigration depends on the skill mix of immigrants relative to natives. The findings do not diverge from this statement. The redistribution will harm some but lead to gains for others, but the results conclude that the overall effect is negative.

Furthermore, the scholars argue that the average effect will depend on the assumptions one makes about capital supply. If the capital supply is perfectly elastic, the average wage will not decrease. On the contrary, if capital supply is not perfectly elastic, there will be an average gain for the overall economy, but this is party captured by the owners of capital, so that average wages may decrease. The results converge with the second case, i.e., that capital supply is not perfectly elastic; decreasing the average wages. Furthermore, Dustmann, Glitz, and Frattini (2009) argue that wages' average effect is always zero. They advocate that due to migration surplus, the average wage effect for natives may even be positive. The found results do not converge with this statement as they suggest the contrary, a statistically significant adverse effect on average wages.

The paper's results regard short-run effects. Dustmann, Glitz, and Frattini (2008) argue that wages should return to the initial pre-immigration equilibrium in the long run. The scholars stress that the adjustment process may be swift if firms foresee the change in skill composition, or if the required capital for the expanding industries is easily available. However, this might not be the case in Sweden as the migration policies have changed both frequently and drastically. The adjustment-process, if it exists, could be expected to be slow as it is not easy for firms to foresee the changes in skill composition when the policy and refugee-intake vary drastically between years.

The results regarding the wage structure are credible as long as the identifying assumption holds, i.e., that trends in the wage levels would have been the same, or more importantly, non-negative in high migration municipalities as in low migration municipalities 
in the absence of the refugee inflows. A placebo test provides evidence for the validity of the identification strategy. Thus, one should change the time window of the analysis into a period unaffected by the crisis. Specifically, one should re-estimate equation (5) regarding 2012, 2013, and 2014 (rather than 2016, 2017, and 2018) and attribute the refugee inflows from 2015 to 2012, 2013, and 2014. I.e., one analyzes the same treated group but in another period. This analysis's result is displayed in Table 30 (see the appendix). One cannot detect any negative trend: the coefficients are extremely small and positive. The non-existing trend is very comforting for two reasons. First, it lends credibility to the negative effect on wage levels. Second, the finding that more substantial inflows of refugees are associated with decreasing wage-levels does not appear to be driven by the fact that municipalities with large inflows were on a different wage-trajectory before starting the refugee crisis.

Regarding the second sphere of the labor market, namely the unemployment levels, the result shows that the labor supply shock has a significant positive impact on unemployment levels and creates displacement effects on the municipality's workers. Many previous studies focused on whether the displacement effects affect native workers or merely other immigrants. As mentioned, Cortes (2005) and Borjas (1986) argue that the displacement effects driven by increased competition affect mainly other immigrants, i.e., that the main competitors of immigrants in the labor market are other immigrants. Whether this holds in Sweden is not immediate, the empirical approach compares the average levels of municipalities.

The reason for this slow integration of migrants into the labor market, causing the higher unemployment levels, could potentially be significant skill mismatches, where the refugees are ill-adapted for the Swedish labor market. The results somewhat converge or rather shed light on the study of Dustmann, Glitz \& Frattini (2008). They advocate that the way immigration affects outcomes depends crucially on immigrants' skill structure relative to the skill structure of natives and assumptions about the elasticity of capital supply. With this type of argument, one could say that the negative effect stems from the fact that the refugees' skill-composition, mostly stemming from Syria, is very low. Secondly, one could argue that Sweden's capital supply is not, nor near, perfectly elastic.

As in the previous sphere of the labor market, to make sure the results are credible, it is fruitful to construct a placebo test. The estimations regarding unemployment are credible if it did not exist a positive trend before the crisis. If there is no correlation, the results conclude 
that the unemployment levels would have been the same in the absence of the massive inflows in 2015. The results are found in table 25 (see the appendix). The results do not infer any positive effect as the coefficients i) magnitude are negligible and ii) negative. As in the case of the wage structure, this finding is comforting as it lends credibility to the main specifications. Furthermore, the increases in unemployment do not appear to be driven by the fact that municipalities with large inflows were on a different unemployment trajectory before the crisis.

Consequently, the findings do not converge with those of Akgündüz et al. (2015), which are in line with Borjas (2006) main argument; that the impact of immigration on employment may be offset by changing internal migration patterns. The results regarding unemployment coincide with Glitz's (2012) study that low skilled immigration shows significant unemployment effects. In contrast, the results are opposite to the results found by Foged and Peri (2015). Ruist (2015) explains the factors causing variation among different environments. A couple of them are, for example, the degree of regulation on the labor market and the existence of a low-wage sector. Sweden has policies to facilitate the refugees' entry into the labor market. For example, immigrants can attend free language courses and specialized assistance in applying for jobs. Despite these measures, Sweden has reported weak results in OECD measurements (Ruist, 2015). Why this is possible, and why this analysis found the results it did, could be explained by the fact stressed in the literature review, Sweden has higher minimum wages than most OECD countries (Spector, 2014).

Economic theory suggests that high minimum wages can lead to higher unemployment, especially for low skilled groups. Furthermore, it is conceivable that the relative inflexibility of the Swedish labor market (relative to the US or UK) could be an obstacle to a quicker integration of immigrant workers. Ager and Brückner (2013) show that this might result in substantial unemployment effects. Furthermore, Woessman (2015) estimates that around two-thirds of recent arrivals have "not been sufficiently educated to participate in modern society." This statement suggests that the specifications about the unemployment by no means are the end of the story, i.e., further increases in foreign unemployment levels are to be expected if more unskilled workers enter the labor force. Hence, the results, taking both economic theory and the labor market structure of Sweden into consideration, should not be a surprise. The results yield an unambiguous answer to the hypothesis as all specifications are highly significant. 
The static difference-in-difference model advocates a positive correlation between crimes and refugee-influx. In contrast, the dynamic model suggests a lagged effect that crimes increased in 2018 in the treated municipalities. Furthermore, the results regarding the subsets enable deeper discussions. Analyzing the subsets, one can notice that the assault and fraud-related crimes are positive and significant regarding all post-treatment years. Regarding drug-related crimes, the result does not suggest a statistically significant correlation.

Interestingly the theft-related crimes instead decrease in 2016 and 2017, i.e., the municipalities with high refugee inflows faced lower theft-related crimes in subsequent years. The data do not provide unambiguous results regarding the sexual-related crimes, as the positive correlation was only significant in 2017. The results are relevant as there have been extensive debates after the refugee inflow of 2015 regarding their impact on criminality after the crime-preventive-council BRÅ (Boström, 2019) published statistics advocating the opposite; that there was no relation.

Additionally, there seems to be a public perception among people in Sweden that foreign people are more frequently engaged in sexual-related crimes (Boström, 2019). The findings do not shed unambiguous light on this matter as all the interaction-variables are not significant. However, the study gives indications, it also shed light on the importance of further studies on the area, especially when more data are available to measure whether the lagged trend for crimes per capita in general, continued after 2018.

Because the results are derived from a difference-in-difference analysis, it is essential to test the identifying assumption. It is vital to ensure that there was no positive trend between the treated municipalities and criminal activity before the crisis. As in the previous dimensions, a placebo test is provided to create evidence for the identification strategy's validity. In table 32 (see the appendix), one can immediately see no such correlation before the crisis. Because the subsets are partitions of the total crime-activity, one could argue that performing placebo tests for each and single subset would be superfluous. However, to be sure, a placebo-test regarding all statistically significant specifications is created. One can immediately notice from table 33 (see the appendix) that no positive trend persisted before the crisis regarding the positive (post-crisis) correlations: Assault, Fraud, and Sexual, as all interaction-variables are of a negligible magnitude and negative sign. Furthermore, there is no negative trend regarding the coefficient Theft before the crisis as the interaction-variables are positive (see Table 33). The placebo-tests create validity for the identifying assumption and 
makes the main-specifications reliable.

The criminality-dimension results stand out compared to the previous research, where most scholars did not find significant positive associations between immigration and criminality. Bianchi et al. (2010) mention that there might exist a substitution between migrants 'and natives' crimes. It is an interesting point, further mentioned by Gehrsitz \& Ungerer (2017). They advocate that anecdotal evidence suggests that crimes against refugees and arson attacks against accommodation facilities are rising. However, the authors cannot estimate it due to a lack of data. The same issue affects this paper as one cannot include crimes against refugees and arson attacks against accommodation facilities. It is not a separate category among the crime statistics published by the Crime preventive council in Sweden. Why the paper, unfortunately, cannot measure the potential substitution effect stressed above.

While the general rise of the anti-immigration party SD is undeniable, there is little indication that municipalities that experience large migrant inflows vote for the party to a more significant extent. What is interesting about the results is the potential reason as to why they are not significant. As mentioned in the literature study, there exist two opposing arguments: one, advocated amongst other by Allport (1954), the contact theory, suggests that areas with much interaction with the minority group, i.e., treated municipalities should induce lower votes for anti-immigration parties as the interaction between the ethnic groups could lead to a deeper understanding of each other and hence a reduction of prejudice. Following this line of reasoning, one could expect lower vote shares in the treated municipalities, where the immigrant per 1000 inhabitants increased a lot. Hence, the interaction between the group must have increased.

On the contrary, one could think about the concept of saliency and look at the study conducted by Colussi et al. (2019). They suggest that in areas where minorities are more salient, political votes are allocated more frequently to the anti-immigration parties. Following this reasoning, one could argue that the minority's saliency will be higher in the treated municipalities, i.e., in the municipalities where the refugee influx increased the most. Hence, these two contrasting theories could potentially play each other out. The results neither suggest a positive nor a negative relation between immigration and vote-shares for anti-immigration parties. 
Furthermore, the results are contrary to those of Bordignon et al. (2019), who claim that rural areas vote in less extent to anti-immigration parties. The results do not converge with their findings. When using the bigger urban municipalities in Sweden as the treated group and the small rural municipalities as control groups, the results suggest the opposite compared to the authors. Instead, it seems that in Sweden, after the refugee crisis, voters in big urban cities voted to a greater extent in favor of the anti-immigration party SD. The results differ substantially between Italy and Sweden, which might be because of the different environments. Table 29 (see the appendix) presents descriptive statistics about foreign-born people's density in Swedish municipalities year 2015. One can immediately notice that the average percentage of foreign-born people in a municipality is above $13 \%$.

In contrast, Bordignon et al. (2019) use a threshold distinguishing a city with relative high refugee intake or not with a share of immigrants of the total population above or under $3,35 \%$. Consequently, one can notice that the socio-economic structure between the countries is different, why it is not very surprising that the results also differ. Additionally, the different types of political landscapes could be an explaining factor of why the findings diverge. Furthermore, the fact that the dummy variables expressing the big urban cities are not the same dummy variables expressing the cities with the highest refugee-intake per capita shed light on a good distribution process in Sweden. The refugees do not only allocate themselves/or are randomly allocated in big urban cities, but also in smaller ones, why the result regarding the difference between urban and rural cities does not converge with Bordignon et al. (2019) nor the study of Cattaneo, Fiorio, and Peri (2015).

As the vote-share regarding the anti-immigration party is not significant, the discussion proceeds by analyzing the other political parties. One can notice highly significant and positive correlations between refugees and the two conservative parties M and KD. Furthermore, the results find adverse effects for the center-right party $C$, the center-left party $\mathrm{S}$, and the left-wing party $\mathrm{V}$. The vote-shares regarding the environmentalist party MP and center-right party $L$ are insignificant. To investigate the identifying assumption, whether the estimates are credible or not, placebo-tests are created. Regarding the political parties with a positive trend, i.e., KD and $\mathrm{M}$, one should not find a positive correlation in the period before the crisis to ensure that municipalities with large inflows were not on a different trajectory before the start of the crisis.

On the contrary, regarding the political parties with negative correlations in the main 
specifications, the identifying assumption does not hold if the result finds a negative correlation before the crisis. By analyzing Table 28 (see the appendix), one can notice that there is no positive correlation between the period before the crisis and the conservative parties KD and $\mathrm{M}$. Hence, the findings suggest that the results regarding KD and $\mathrm{M}$ are credible. Regarding the parties $\mathrm{V}, \mathrm{S}$, and C, one should further investigate Table 28 (see the appendix). The table suggests that there was no negative trend in the election before the crisis. Hence, the findings conclude that V, S, and C's main specifications are credible. The results are robust.

So far, the discussion focused on national political elections. However, immigration might play a role in shaping mayoral election outcomes as well. In the Swedish context, many political decisions that influence natives and immigrants' relationships are treated at the municipality level. For example, allowing the construction of a new mosque, managing primary education, and other decisions might impact. Consequently, an interesting question is whether and to what extent migration impacts outcomes in the mayoral election and whether it is similar to national elections. To investigate this dimension, one should analyze the link between immigration and voting at the local level, with the dependent variable being the share of mandates in district council to the different parties, measured at the municipality administrative elections. The municipality-level results are very similar to the national ones, except for the environmentalist party having a significant positive correlation.

In contrast, one of the conservative parties, $\mathrm{KD}$, is negative. The other parties remain reasonably constant. A potential explanation could be that a person on a national level is more concerned about criminality levels, economy et cetera. In contrast, the same person on a local level is more concerned about a clean neighborhood. Consequently, the electorate could be induced to vote on the environmentalist-party in the local election while not doing so in the national election.

To understand what channel individuals' vote patterns due to immigration. Barone et al. (2016) investigate responses from 3000 voters who were interviewed after the 2001 general elections in Italy. Furthermore, they ground that votes stating that "immigration is a very important issue" are also more likely to vote for the center-right coalition. This paper does not include similar data, why the results cannot analyze similar structures. However, to interpret the results, one could find similarities from Barone et al. (2016) arguments. The fact that immigration might represent a threat to the Italian culture can be applied to Sweden's 
case. Similar arguments are emphasized in the public debate, where public discourse often treat the Swedish culture and how it is potentially affected by high immigration densities.

The second channel regards the competition of immigrants in the labor market. The literature has stressed, as mentioned, that in a developed country, the native-immigrant contest for jobs should be more challenging for unskilled native workers. This second channel is particularly relevant to Sweden's case, since most immigrants, contrary to, for example, Canada, are unskilled.

A third channel, also relevant for the Swedish case and this paper's results, refers to the perception by natives that immigration can lie behind an increase in criminal activities. The correlation between immigrants and criminality is quite a standard claim in the Swedish political campaign. Furthermore, this has been evoked by the conservative parties, who often stresses the importance of law and order.

During the last years in Sweden, there has been a big debate, most stressed by the conservative parties, on the importance and failure of the police and the importance of hiring and educating more police officers to create order and reduce criminality. Consequently, one could argue that people who fear that immigrants are causing violence are induced to vote for more traditional parties stressing the importance of law, order, and more policeenforcement. The results are in line with this argument, as one can see significant increases in the vote share of the conservative parties. One could consequently emphasize that this type of rhetoric could be used by political parties to gain votes in turbulent times of refugee-influx when the population, in general, have a perception that refugees are associated with crimes. Whether the perception is true or not does not necessarily make a difference, as Bianchi et al. (2016) show. Regarding price level analysis, it will be treated as "additional results" because the house price estimations do not provide precise estimates. Furthermore, the food price data is based on more significant regions rather than municipalities. Hence, it is not as reliable as the other data. The variation among the observations is lower regarding the food price data, and the coefficients are less precise. 


\section{Conclusion}

One can conclude the discussion about the wage structure by recognizing that the results support the first hypothesis; refugee inflow has a decreasing effect on Swedish municipalities' average wage-levels. Furthermore, as mentioned previously, the results are robust as the identifying assumption holds, i.e., that the placebo-tests do not suggest a negative trend before the crisis. Additionally, the novelty of the identification strategy regarding Sweden is that the migration shock in 2015 produced refugees' distribution across municipalities unrelated to labor demand. The massive inflow added significant variation to the exogenously dispersed migrant supply, which was exploited successfully to estimate its effect on average wage levels between the municipalities. The consequences for the treated municipalities are severe, as they, as reported in the result section, not only suffer from income-reductions but also decrease tax-revenues and local demand.

Regarding the second sphere of the labor market, namely the unemployment levels, the result shows that the labor supply shock has a significant positive impact on unemployment levels and creates displacement effects on the municipality's workers. The results unambiguously conclude that the second hypothesis of this thesis holds and cannot be rejected, i.e., that refugee inflow has an increasing effect on unemployment levels within Swedish municipalities.

The results lend support to calls for additional labor market flexibility. Furthermore, they indicate that the analysis raises concerns about the Swedish labor market's ability to absorb this supply shock and, more specifically, its integration-process as it increases the unemployment levels. Even though this paper is an analysis of short-term effects, at this early stage in the post-treatment period, the results suggest that policymakers need to devote more resources to the integration of migrants into the Swedish labor market. Unemploymentlevels induce severe issues not only for the labor market but also for society. At the very least, the results suggest that unemployment rates of crisis country nationals should be carefully tracked. Data on qualifications of migrants should be collected, and training and requalifications efforts should be improved.

Concerning the crime rates in general, the results from the second model advocate a significant positive correlation. Furthermore, the third model suggests a positive correlation in 2018, i.e., a lagged effect. The massive inflow in 2015 would not have a significant correlation 
until 2018. Whether the positive trend continuous after 2018 is difficult to say as the dataset does not cover further years. For this reason, the results from the third model regarding the subsets are more attractive. Analyzing the subsets, one can notice that the assault and fraudrelated crimes are positive and significant regarding all post-treatment years. Consequently, one cannot reject the third hypothesis, i.e., the results tell us that refugee inflow has an increasing effect on crime levels within Swedish municipalities.

The findings do not converge with those of Bianchi et al. (2010). Instead, the findings support the widespread perception of a causal relationship between immigration and crime. However, the results are a bit more complicated compared to the labor market findings. According to the dynamic difference-in-difference findings, the impact on general crime levels is lagged and not significant until 2018. Furthermore, some subsets of crimes are more significant than others. For example, fraud- and assault-related crimes are highly notable, while theft-related crimes show negative correlations. The results suggest that policymakers should pay more attention to the integration processes and policies as crimes, especially assault, and sexually related crimes, severely affect the victims and society.

The analysis regarding crime-levels can be extended in search of further detailed mechanisms. For example, it would be exciting and relevant to explore natives' responses to an increase in immigration. Furthermore, it would be interesting to estimate the effect of official and unofficial immigrants separately. A better understanding of this type of mechanism appears crucial for detailed policy prescriptions. Unfortunately, this analysis does not cover this distinction, why further research on the area is urgent.

Treating the political sphere, one can immediately notice that the fourth hypothesis, contrary to the previous, must be rejected. The results do not advocate that refugee inflow has an increasing effect on the vote share of anti-immigration parties in Sweden. When including the time-variant vector of control variables, the coefficient of interest is not statistically significant in any of the three models. Instead, the findings conclude that the results converge with the results found by Barone et al. (2016). They found that an increase in immigrants' density in a municipality $m$ increased voting share going to the center-right coalition. Regarding this paper and Sweden, a correct statement would be that an increase in immigrants' density in a municipality increased the share of votes going to the right-wing coalition, as one center-right party decreased their vote-share.

The results stress that in municipalities experiencing large immigrants' inflows, the 
electorates have been more willing to vote for the conservative parties with political platforms less favorable to the immigrants. The results also point out that the gain in vote shares for the conservative parties has gone hand in hand with a loss of votes for the centerright and left-wing parties. Furthermore, the coefficients show that the impact of immigration on election outcomes also holds at the local level, with an effect that in magnitude is comparable, yet slightly different from the one in National elections. As mentioned in the discussion, potential explanations behind the findings could be some of Barone's channels at al. (2016). These include cultural diversity, native-immigrant competition in the labor market, and potentially most important for this case, perception of increases in crime levels.

To sum up, the results suggest that policymakers should consider the tensions in the labor market between natives and immigrants when dealing with immigration and labor market policies. A policy lesson of this paper's results is that the development of recruitment agencies and formative courses that enable low skilled individuals to upgrade their skills and deal with labor market competition may help to mitigate the anti-immigrant attitudes in the native population. Both policymakers and academic researchers should study these policies to evaluate their impact on labor market outcomes and anti-immigrant attitudes in the native population. They should become the subjects of future research projects. Furthermore, the paper suggests that policymakers should be attentive regarding crime-levels and analyze what preventive actions could be made to reduce criminality and create smoother integration. The results shed light on variations among different subsets of crimes. For example, suppose policymakers realize that theft-crimes and refugee influx are negatively correlated, and the opposite holds regarding assault-related crimes. In that case, customized policies could be made to reduce the overall levels of crime.

Additionally, the paper sheds light on the effectiveness of political rhetoric strategies that may be more, or less, fruitful in periods determined by high refugee inflow, which is essential for political parties wanting higher vote shares. Furthermore, the findings, in combination with insights about the rhetoric strategies, are essential for policy-makers and citizens in general to understand, as the rhetoric is shown to be successful whether the underlying arguments stem from causal correlations or vague hypothesis, as where shown in the case of Italy (Bianchi et al., 2016).

The data is constructed from different sources of data and creates a unique dataset on a municipality-level. Upon a publication of this paper, the data would be available in the 
appendix. It should be useful to other researchers for future research. Furthermore, the study follows a research design based on a credible natural experiment. It enriches the literature on the labor market, criminality, and voting pattern impacts of immigration.

Additionally, the paper gives new insight into Sweden's environment, which has not been investigated before regarding the refugee crisis 2015. There has been an attempt to analyze the refugee inflows to Sweden, Durán Salvatierra \& Ollila (2017) tries. However, their study uses a dataset over the timespan 2003-2013, which excludes the shock period - why their paper cannot exploit the exogenous variation stemming from the crisis.

Lastly, it is important to stress that the results are to be interpreted for short-terms effects, even though they could be useful indications for long-term outcomes. The experiment is a valuable tool to investigate their impact and design, which could mitigate complex policy decisions. The paper's ambition is to be interpreted as a convincing analysis of the refugee crisis's short-term effects in Sweden and that it can serve as a fundamental point for future analysis of what is likely to remain a substantial economic and social issue for many years. 


\section{References}

Ager, P. and M. Brückner (2013). Cultural diversity and economic growth: Evidence from the us during the age of mass migration. European Economic Review 64, 76-97

Akgündüz, Y., Van den Berg, M., \& Hassink, W. H. (2015). The impact of refugee crises on host labor markets: The case of the Syrian refugee crisis in Turkey.

Alix-Garcia, J., \& Saah, D. (2010). The effect of refugee inflows on host communities: Evidence from Tanzania. The World Bank Economic Review, 24(1), 148-170.

Ayedemir, A. \& Borjas, G. (2011) "Attenuation Bias in Measuring the Wage Impact of Immigration". Journal of Labor Economics, 2011, vol. 29, no. 1.

Arbetsmiljöverket (2011). "Arbetsmarknads i förändring: en analys av regionala branschförändringar över tid och dess betydelse för framtida arbetsmiljöer". Arbetsmiljöverket, rapport 2011:12.

Bianchi, M., P. Buonanno, and P. Pinotti (2012, December). Do Immigrants Cause Crime? Journal of the European Economic Association 10(6), 1318-1347

Blanchflower, D. \& Oswald, A. (1995). "The Wage Curve". ISBN: 9780262023757. The MIT Press. Pages 37-55.

Barone, Guglielmo, De Blasio, Guido, \& Naticchioni, Paolo. 2016. Mr. Rossi, Mr. Hu and Politics: The Role of Immigration in Shaping Natives' Political Preferences. Journal of Public Economics, 136, 1-13.

Bartel, A. P. (1989). Where Do the New U.S. Immigrants Live? Journal of Labor Economics 7 (4), 371-391.

Barro, R. J. (1977). Long-term contracting, sticky prices, and monetary policy. Journal of Monetary Economics, 3(3), 305-316.

Becker, S. O., \& Fetzer, T. (2016). Does migration cause extreme voting?. Center for Competitive Advantage in the Global Economy and The Economic \& Social Research Council, 1-54. 
Boström, H. (2019). "Nya siffror om brott och invandring". Retrieved from https://www.gp.se/ledare/nya-siffror-om-brott-och-invandring-1.15467687

Bordignon, Massimo, et al. "Stop invasion! The electoral tipping point in anti-immigrant voting." IEB Working Paper 2019/11 (2019).

Borjas, G. J. (2003). The Labor Demand Curve is Downward Sloping: Reexamining the Impact of Immigration on the Labor Market. Quarterly Journal of Economics 118 (4), 13351374 .

Borjas, G. J. (2006). Native Internal Migration and the Labor Market Impact of Immigration. Journal of Human Resources 41 (2), 221-258.

Burda, M. \& Wyplosz, C. (2012). "Macroeconomics: A European Text”. ISBN 9780199608645. Sixth Edition. OUP Oxford

Card, D. (1990): "The Impact of the Mariel Boatlift on the Labor Market". Industrial and Labor Relation Review 43(2): 245-57.

Card, D. and J. DiNardo (2000). Do Immigrant Inflows Lead to Native Outflows? American Economic Review 90 (2), 360-367.

Cahuc, P., Carcillo, S. and A. Zilberberg. LaborEconomics. Cambridge, Mass. and London: MIT Press, 2014

Cattaneo, C., Fiorio C. V., and Peri G., "What Happens to the Careers of European Workers When Immigrants "Take Their Jobs"?" Journal of Human Resources, (2015) vol. 50 no. 3 655-693.Colussi, T., Isphording, I. E., \& Pestel, N. (2016). Minority salience and political extremism.

Cortes, P. (2008). The effect of low-skilled immigration on US prices: evidence from CPI data. Journal of political Economy, 116(3), 381-422.

Demker, M. (2018). "Svensk politik går in i en ny tid". Retrieved from https://www.dagensarena.se/essa/svensk-politik-gar-en-ny-tid/

Delin, M. (2016). "Invandring den viktigaste frågan för väljarna”. Dagens Nyheter, Politik. Retrieved from https://www.dn.se/nyheter/sverige/invandring-den-viktigaste-fraganfor-valjarna-2/ 
Doms, M. and E. G. Lewis (2006). Labor Supply and Personal Computer Adoption. Federal Reserve Bank of Philadelphia Working Paper No. 06-10.

Dustmann, C., Glitz, A., \& Frattini, T. (2008). The labour market impact of immigration. Oxford Review of Economic Policy, 24(3), 477-494.

Dustmann, C., Vasiljeva, K., \& Piil Damm, A. (2019). Refugee migration and electoral outcomes. The Review of Economic Studies, 86(5), 2035-2091.

Durán Salvatierra, Paula, and Saana Ollila. "The impact of the refugee inflow on the Swedish labour market: Low-skilled labour supply shock." (2017).

Edin, P.-A., P. Fredriksson, and O. Aslund (2003). Ethnic Enclaves and the Economic Success of Immigrants - Evidence from a Natural Experiment. Quarterly Journal of Economics 118 (1), 329-357.

Eurofound. (2018) "Living and working in Sweden". Retrieved from https://www.eurofound.europa.eu/country/sweden

European Migration Network, EMN (2017). “Annual Report on Migration and Asylum 2016 Sweden". Retrieved from www.emnsweden.se

Filer, R. K. (1992). The Effect of Immigrant Arrivals on Migratory Patterns of Native Workers. In G. J. Borjas and R. B. Freeman (Eds.), Immigration and the Work Force: Economic Consequences for the United States and Source Areas, Chapter 8, pp. 245-269. Chicago: University of Chicago Press.

Foged, M. \& Peri, G. (2015). “ Immigrants' Effect on Native Workers: New Analysis on Longitudinal Data". IZA DP No. 8961.

Frey, W. H. (1995). Immigration and Internal Migration Flight - A California Case Study. Population and Environment 16 (4), 353-375.

Frey, W. H. (1996). Immigration, Domestic Migration, and Demographic Balkanization in America: New Evidence for the 1990s. Population and Development Review 22 (4), 741-763.

Gehrsitz, M., \& Ungerer, M. (2017). Jobs, crime, and votes: A short-run evaluation of the refugee crisis in Germany. 
Glitz, A. (2012). "The Labor Market Impact of Immigration: A Quasi-Experiment Exploiting Immigrant Location Rules in Germany". Journal of Labor Economics, Vol. 30, No. 1. Pages175213.

Gottfries, N (2013) Macroeconomics. ISBN: 978-0-230-27597-3. Palgrave Macmillan.

Granström, K. (2018). "Brott och straff - väljarnas viktigaste fråga". Retrieved from https://www.expressen.se/tv/politik/bara-politik/brott-och-straff-valjarnas-viktigastefraga/

Haefke, C., Sonntag, M., \& Van Rens, T. (2013). Wage rigidity and job creation. Journal of monetary economics, 60(8), 887-899.

Hall, R. E. (1991). Labor demand, labor supply, and employment volatility. NBER macroeconomics annual, 6, 17-47.

Halla, M., Wagner, A. F., \& Zweimüller, J. (2017). Immigration and voting for the far right. Journal of the European Economic Association, 15(6), 1341-1385.

Hatton, T. J. and M. Tani (2005). Immigration and Inter-Regional Mobility in the UK, 19822000. Economic Journal 115 (507), F342-F358.

Kugler, A. \& Yukel, M. (2008). "Effects of low-skilled immigration on U.S. natives: Evidence from Hurricane Mitch". University of Houston, NBER, CEPR and IZA.

Manacorda, M., A. Manning, and J. Wadsworth (2006). The Impact of Immigration on the Structure of Male Wages: Theory and Evidence from Britain. CReAM Discussion Paper No. 08/06.

Mattsson \& Rongde, (2020). "Staffanstorps reklamfilm sågas: "Ett vidrigt tilltag".

Retrieved from https://www.expressen.se/kvallsposten/staffanstorps-reklamfilmsagas-ett-vidrigt-tilltag/

Mellin, L. (2018) "Nu är flyktingar och invandring valets viktigaste fråga". Aftonbladet, politik. Retrieved from https://www.aftonbladet.se/nyheter/kolumnister/a/gPeAKB/nu-ar-flyktingar-ochinvandring-valets-viktigaste-fraga 
Landau, L. B. (2002). Document. The humanitarian hangover: transnationalization of governmental practice in Tanzania's refugee-populated areas. Refugee Survey Quarterly, 21(1_and_2), 260-299.

Pekkala,S. \& Kerr, W. (2011). "Economic Impacts of Immigration: A Survey". The National Bureau of Economic Research.

Perloff, J. (2014): "Microeconomics with Calculus". ISBN 978-0-13-301993-3.Pearson Education. Pages179-185.

Piopiunik, M. and J. Ruhose (2015). Immigration, Regional Conditions, and Crime: Evidence from an Allocation Policy in Germany. Technical report, Unpublished Manuscript.

Skedinger, P. (2006). Minimum wages and employment in Swedish hotels and restaurants. Labour Economics, 13(2), 259-290.

Skedinger, P. (2010). “Employment Protection Legislation Evolution, Effects, Winners and Losers". ISBN 9781848447561. Edward Elgar Publishing

Migration Policy Institute, MPI (2011) “Canada's Immigration Policy: a Focus on Human Capital"Retrieved from: https://www.migrationpolicy.org/article/canadasimmigration-policy-focus-human-capital

Schurer, S. (2017). "Does education strengthen the life skills of adolescents?". Schurer, S. (2017). Does education strengthen the life skills of adolescents?. IZA World of Labor.

Statistics Sweden, SCB. (2001). "Standard för svensk yrkesklassificering 1996". Meddelande i samordningsfrågor för Sveriges officiella statistik

Statistics Sweden, SCB (2013). "Utbildningsbakrund bland utrikesfödda". Temarapport 2014:6, utbildning.

Statistics Sweden, SCB. (2014). “Integration - etablering på arbetsmarknaden: Två av tre flyktingar i arbete efter tio år". Retrieved from http://www.scb.se/sv_/Hittastatistik/Statistik-efteramne/Levnadsforhallanden/Levnadsforhallanden/Integrationanalys/224581/224589/Behallarefor-Press/379538/[2017-03-09]. 
Statistics Sweden, SCB. (2016) “Rekordstor invandring under 2015". Enheten för befolkningsstatistik. Retrieved from http://www.scb.se/sv_/Hittastatistik/Artiklar/Rekordstorinvandring-under-2015/. [2017-04-03].

Statistics Sweden, SCB. (2016). "Var fjärde i Sverige är högutbildad". Retrieved from http://www.scb.se/hitta-statistik/sverige-i-siffror/utbildning-jobb-ochpengar/befolkningensutbildning/[2017-05-05]

Statistics Sweden, SCB. (2017) "Från massutvandring till rekordinvandring". Enheten för befolkningsstatistik. Retrieved from http://www.scb.se/hitta-statistik/sverige-isiffror/manniskornai-sverige/in-och-utvandring/ [2017-03-20].

Statistics Sweden, SCB. (2017). "EU:s regioner - NUTS". Statistiska CentralbyrånInternationell Statistik. Retrieved from http://www.scb.se/Grupp/Hitta_statistik/Internationell_statistik/_Dokument/NUTS_2 003.pdf. [2017-03-20].

Statistics Sweden, SCB. (2017)."The Statistical Database". Statistical database. Retrieved from http://www.statistikdatabasen.scb.se/pxweb/sv/ssd/?rxid=d46b69c8-07ac-43b3bb10-19eac835c6fe [2017-04-01]

Statistics Sweden, SCB. (2015). “Utbildning viktigaste frågan I 2014 års riksdagsval”. Statistical database.

Statistics Sweden, SCB. (2019). "Utbildningsbakgrund bland utrikes födda”. Retrieved from https://www.scb.se/hitta-statistik/statistik-efter-amne/utbildning-ochforskning/befolkningens-utbildning/befolkningensutbildning/pong/publikationer/utbildningsbakgrund-bland-utrikes-fodda/

Statistics Sweden, SCB. (2019). "Asylsökande i Sverige". Statistical database. Retrieved from https://www.scb.se/hitta-statistik/sverige-i-siffror/manniskorna-i-sverige/asylsokandei-sverige/

Stock, J. H., \& Watson, M. W. (2015). Introduction to econometrics.

Sullivan, Daniel, and Till Von Wachter. "Job displacement and mortality: An analysis using administrative data." The Quarterly Journal of Economics 124.3 (2009): 1265-1306. 
OECD (2020), Taxing Wages-Sweden. Retrieved from

https://www.oecd.org/tax/taxing-wages-20725124.htm

OECD (2020), Native-born participation rates (indicator). doi: 10.1787/afed6c9e-en (Accessed on 09 February 2020)

OECD (2020), Unemployment rates by education level (indicator). doi: 10.1787/6183d527-en (Accessed on 08 February 2020)

OECD (2020), Unemployment rates by education level (indicator). doi: 10.1787/6183d527-en (Accessed on 08 February 2020)

OECD (2020), Unemployment rates by education level (indicator). doi: 10.1787/6183d527-en (Accessed on 08 February 2020)

Ottaviano, G. I. P. and G. Peri (2006). Rethinking the Effects of Immigration on Wages. NBER Working Paper No. 12497

Ruist, J. \& Bingsten, A. (2010). "Wage Effects of Labor Migration with International Capital Mobility". University of Gothenburg. Working Papers in Economics No.464. ISSN: 1403-2465.

Rybczynski, T. M. (1955). Factor Endowments and Relative Commodity Prices. Economica 22 (88), 336-341.

Valmyndigheten, (2020). "Valresultat 2018". Retrieved from: https://www.val.se/valresultat/riksdag-region-och-kommun/2018/valresultat.html Wright, R. A., M. Ellis, and M. Reibel (1997). The Linkage Between Immigration and Internal Migration in Large Metropolitan Areas in the United States. Economic Geography 73 (2), 234-254. 
11 Appendix

Table 1. Education levels on refugees 2006-2017

\begin{tabular}{|c|c|c|c|c|c|c|c|}
\hline Invandringsabr & Kon & $\begin{array}{l}\text { Befolkning } \\
\text { (antal) }\end{array}$ & $\begin{array}{r}\text { Förgymn. } \\
\text { utb }\end{array}$ & $\begin{array}{r}\text { Gymnasial } \\
\text { utb. }\end{array}$ & $\begin{array}{l}\text { Eftergymn. } \\
\text { uth. kortare } \\
\text { ân } 3 \text { ar }\end{array}$ & $\begin{array}{r}\text { Eftergymn. } \\
\text { uth. } 3 \text { ar } \\
\text { eller langre }\end{array}$ & $\begin{array}{r}\text { Andel } \\
\text { imputerade } \\
\text { varden }\end{array}$ \\
\hline \multirow[t]{3}{*}{ 2006-2009 } & Totalt & 171293 & 21 & 33 & 15 & 31 & 5 \\
\hline & Kvinner & 85252 & 22 & 31 & 14 & 32 & 4 \\
\hline & Man & 86041 & 21 & 34 & 16 & 29 & 6 \\
\hline \multirow[t]{3}{*}{$2010-2013$} & Totalt & 185241 & 21 & 29 & 16 & 34 & 8 \\
\hline & Kvinnor & 90965 & 23 & 26 & 16 & 36 & 6 \\
\hline & Măn & 94276 & 20 & 32 & 17 & 32 & 11 \\
\hline \multirow[t]{3}{*}{$2014-2017$} & Totait & 275739 & 23 & 23 & 21 & 33 & 23 \\
\hline & Kvinnor & 123779 & 23 & 20 & 22 & 34 & 20 \\
\hline & Man & 151951 & 23 & 25 & 21 & 31 & 24 \\
\hline \multirow[t]{3}{*}{ 2006-2017 } & Totalt & 632264 & 22 & 27 & 18. & 32 & 14 \\
\hline & Kvinnor & 299996 & 23 & 25 & 18 & 34 & 11 \\
\hline & Măn & 332268 & 21 & 29 & 18 & 31 & 16 \\
\hline
\end{tabular}


Table 29. The effect of the refugee change in vote shares on the change in refugee allocations, first difference estimator

(1)

VARIABLES

DeltaRefugee

$\begin{array}{lc}\text { LVSSD } & 0.0209^{* *} \\ & (0.0106) \\ \text { LVSM } & 0.00989 \\ & (0.00795) \\ \text { LVSKD } & -0.0410 * * \\ & (0.0193) \\ \text { LVSL } & 0.00188 \\ & (0.0127) \\ \text { LVSC } & 0.00315 \\ & (0.00865) \\ \text { LVSMP } & -0.00955 \\ & (0.0156) \\ \text { LVSS } & 0.00508 \\ & (0.00611) \\ \text { LVSV } & 0.00254 \\ & (0.0114) \\ \text { Constant } & 0.528 * * \\ & (0.0315)\end{array}$

Observations 290

R-squared $\quad 0.041$

Standard errors in parentheses

*** $\mathrm{p}<0.01, * * \mathrm{p}<0.05, * \mathrm{p}<0.1$

The significance of the coefficients is denoted by stars (* significance on the $10 \%$ significance level, ** $5 \%$ and ***1\%, respectively). Standard errors are in brackets and they are computed on the $5 \%$ significance level. 
Table 30. The effect of the refugee influx on wage levels, placebo test

\begin{tabular}{|c|c|}
\hline VARIABLES & $\begin{array}{c}(1) \\
\text { logWage }\end{array}$ \\
\hline $\operatorname{did} 12$ & $\begin{array}{c}0.00901^{* * * *} \\
(0.00161)\end{array}$ \\
\hline $\operatorname{did} 13$ & $\begin{array}{c}0.00453 * * * * \\
(0.00159)\end{array}$ \\
\hline $\operatorname{did} 14$ & $\begin{array}{l}0.00306 * * \\
(0.00155)\end{array}$ \\
\hline logCrimesper & $\begin{array}{l}-0.000731 \\
(0.00215)\end{array}$ \\
\hline logHigheduper & $\begin{array}{c}0.0724 * * * \\
(0.0163)\end{array}$ \\
\hline logUnempper & $\begin{array}{c}-0.0464^{* * * *} \\
(0.00320)\end{array}$ \\
\hline 2013.Year & $\begin{array}{c}0.0199 * * * \\
(0.00142)\end{array}$ \\
\hline 2014.Year & $\begin{array}{l}0.0408 * * * \\
(0.00153)\end{array}$ \\
\hline 2015. Year & $\begin{array}{c}0.0629 * * * \\
(0.00160)\end{array}$ \\
\hline 2016.Year & $\begin{array}{c}0.0942^{* * *} \\
(0.00179)\end{array}$ \\
\hline 2017. Year & $\begin{array}{l}0.120 * * * * \\
(0.00194)\end{array}$ \\
\hline 2018.Year & $\begin{array}{l}0.146 * * * \\
(0.00218)\end{array}$ \\
\hline Constant & $\begin{array}{l}5.434 * * * * \\
(0.0495)\end{array}$ \\
\hline Observations & 1,008 \\
\hline Number of Id & 144 \\
\hline R-squared & 0.981 \\
\hline
\end{tabular}

The significance of the coefficients is denoted by stars (* significance on the $10 \%$ significance level, ** $5 \%$ and ***1\%, respectively). Standard errors are in brackets and they are computed on the $5 \%$ significance level. 
Table 31. The effect of the refugee influx on unemployment levels, placebo test

(1)

\begin{tabular}{|c|c|}
\hline VARIABLES & logUnempper \\
\hline $\operatorname{did} 12$ & $\begin{array}{c}-0.0827 * * * * \\
(0.0154)\end{array}$ \\
\hline $\operatorname{did} 13$ & $\begin{array}{c}-0.0980 * * * * \\
(0.0150)\end{array}$ \\
\hline $\operatorname{did} 14$ & $\begin{array}{c}-0.0554 * * * \\
(0.0147)\end{array}$ \\
\hline logCrimesper & $\begin{array}{l}-0.0328 \\
(0.0206)\end{array}$ \\
\hline logHigheduper & $\begin{array}{c}-0.659 * * * * \\
(0.157)\end{array}$ \\
\hline logWage & $\begin{array}{c}-4.263 * * * * \\
(0.294)\end{array}$ \\
\hline 2013. Year & $\begin{array}{l}0.135 * * * \\
(0.0144)\end{array}$ \\
\hline 2014.Year & $\begin{array}{l}0.174 * * * \\
(0.0189)\end{array}$ \\
\hline 2015. Year & $\begin{array}{l}0.240 * * * \\
(0.0244)\end{array}$ \\
\hline 2016. Year & $\begin{array}{c}0.362 * * * \\
(0.0331)\end{array}$ \\
\hline 2017.Year & $\begin{array}{l}0.477 * * * * \\
(0.0402)\end{array}$ \\
\hline 2018. Year & $\begin{array}{l}0.547 * * * \\
(0.0488)\end{array}$ \\
\hline Constant & $\begin{array}{c}14.97 * * * \\
(1.773)\end{array}$ \\
\hline $\begin{array}{l}\text { Observations } \\
\text { Number of Id } \\
\text { R-squared }\end{array}$ & $\begin{array}{c}1,008 \\
144 \\
0.545 \\
\end{array}$ \\
\hline
\end{tabular}

Standard errors in parentheses

*** $\mathrm{p}<0.01, * * \mathrm{p}<0.05, * \mathrm{p}<0.1$

The significance of the coefficients is denoted by stars (* significance on the $10 \%$ significance level, ** 5\% and

***1\%, respectively). Standard errors are in brackets and they are computed on the $5 \%$ significance level. 
Table 32. The effect of the refugee influx on crimes per capita and assault per capita, placebo tests

\begin{tabular}{lc}
\hline VARIABLES & $\begin{array}{c}(1) \\
\text { logCrimesper }\end{array}$ \\
\hline o.treated & - \\
did12 & -0.0217 \\
& $(0.0260)$ \\
did13 & $-0.0496^{*}$ \\
& $(0.0255)$ \\
did14 & -0.0392 \\
& $(0.0246)$ \\
logUnempper & -0.0907 \\
& $(0.0569)$ \\
logHigheduper & 0.226 \\
& $(0.263)$ \\
logWage & -0.186 \\
& $(0.546)$ \\
2013.Year & -0.0241 \\
& $(0.0251)$ \\
2014.Year & 0.00185 \\
& $(0.0330)$ \\
2015.Year & 0.0170 \\
& $(0.0428)$ \\
2016.Year & 0.00907 \\
& $(0.0588)$ \\
2017.Year & 0.0105 \\
& $(0.0722)$ \\
2018.Year & -0.0269 \\
& $(0.0868)$ \\
Constant & -0.983 \\
& $(3.068)$ \\
Observations & 1,008 \\
Number of Id & 144 \\
R-squared & 0.048 \\
\hline \multicolumn{1}{c}{ Standard errors in parentheses } \\
& $* 0.01, * * 0.05,{ }^{*} \mathrm{p}<0.1$ \\
& \\
& \\
&
\end{tabular}

The significance of the coefficients is denoted by stars ( ${ }^{*}$ significance on the $10 \%$ significance level, ** $5 \%$ and *** $1 \%$, respectively). Standard errors are in brackets and they are computed on the $5 \%$ significance level. 
Table 33. The effect of the refugee influx on the subsets of crimes per capita: Assault, Fraud, Sexual and Theft, placebo tests

\begin{tabular}{|l|llll|}
\hline In(Crimes per capita) sorted by: & Assault & Fraud & Sexual & Theft \\
\hline \multirow{4}{*}{ did12 } & $-0,108^{* * *}$ & $-0,233^{* * *}$ & $-0,135$ & $0,0930^{* * *}$ \\
& $(0,0403)$ & $(0,0807)$ & $(0,0909)$ & $(0,0289)$ \\
& $-0,128^{* * *}$ & $-0,258^{* * *}$ & $-0,0321$ & 0,00574 \\
& $(0,0394)$ & $(0,0789)$ & $(0,0888)$ & $(0,0283)$ \\
did14 & $-0,0378$ & $-0,224^{* * *}$ & $-0,0936$ & $-0,00585$ \\
& $(0,0382)$ & $(0,0764)$ & $(0,0856)$ & $(0,0274)$ \\
In(Higheduper) & $01,158^{* * * *}$ & $-2,201^{* * *}$ & $1,842^{* *}$ & $0,546^{*}$ \\
& $(0,408)$ & $(0,816)$ & $(0,916)$ & $(0,293)$ \\
In(Unempper) & 0,114 & $-0,171$ & 0,103 & 0,00825 \\
& $(0,0881)$ & $(0,176)$ & $(0,197)$ & $(0,0632)$ \\
In(Wage) & $1,586^{*}$ & $-1,445$ & 2,610 & $-0,0534$ \\
& $(0,845)$ & $(1,691)$ & $(1,898)$ & $(0,606)$ \\
\hline time fe & yes & yes & yes & yes \\
unit fe & yes & yes & yes & yes \\
\hline$R^{\wedge} 2$ & 0,102 & 0,163 & 0,103 & 0,265 \\
\hline
\end{tabular}

The significance of the coefficients is denoted by stars (* significance on the $10 \%$ significance level, ** 5\% and ***1\%, respectively). Standard errors are in brackets and they are computed on the 5\% significance level. 
Table 34. The effect of the refugee influx Vote shares of $M, K D, C, S$ and $V$, placebo tests

\begin{tabular}{|c|c|c|c|c|c|}
\hline In(Voteshare) sorted by: & M & KD & C & $\mathrm{s}$ & v \\
\hline did14 & $\begin{array}{l}-0,0608^{* * *} \\
(0,0142)\end{array}$ & $\begin{array}{l}-0,103^{* * *} \\
(0,0346)\end{array}$ & $\begin{array}{l}0,232^{* * *} \\
(0,0315)\end{array}$ & $\begin{array}{l}0,0757^{* * *} \\
(0,0109)\end{array}$ & $\begin{array}{l}0,117^{* * * *} \\
(0,0214)\end{array}$ \\
\hline In(Crimesper) & $\begin{array}{l}0,0687^{* * *} \\
(0,0297)\end{array}$ & $\begin{array}{l}0,0627 \\
(0,0723)\end{array}$ & $\begin{array}{l}0,0586 \\
(0,0658)\end{array}$ & $\begin{array}{l}-0,0336 \\
(0,0229)\end{array}$ & $\begin{array}{l}-0,0760^{*} \\
(0,0446)\end{array}$ \\
\hline In(Higheduper) & $\begin{array}{l}-0,337 \\
(0,227)\end{array}$ & $\begin{array}{l}0,936^{*} \\
(0,552)\end{array}$ & $\begin{array}{l}-0,618 \\
(0,502)\end{array}$ & $\begin{array}{l}0,109 \\
(0,175)\end{array}$ & $\begin{array}{l}0,490 \\
(0,341)\end{array}$ \\
\hline In(Unempper) & $\begin{array}{l}-0,118^{* * *} \\
(0,0576)\end{array}$ & $\begin{array}{l}-0,0318 \\
(0,140)\end{array}$ & $\begin{array}{l}-0,156 \\
(0,127)\end{array}$ & $\begin{array}{l}0,0874^{*} \\
(0,0443)\end{array}$ & $\begin{array}{l}0,203^{* *} \\
(0,0864)\end{array}$ \\
\hline In(Wage) & $\begin{array}{l}-0,247^{* * *} \\
(0,510)\end{array}$ & $\begin{array}{l}-2,672^{* *} \\
(1,239)\end{array}$ & $\begin{array}{l}-1,228 \\
(1,128)\end{array}$ & $\begin{array}{l}-0,285 \\
(0,392)\end{array}$ & $\begin{array}{l}-0,457 \\
(0,765)\end{array}$ \\
\hline $\begin{array}{l}\text { time fe } \\
\text { unit fe }\end{array}$ & $\begin{array}{l}\text { yes } \\
\text { yes }\end{array}$ & $\begin{array}{l}\text { yes } \\
\text { yes }\end{array}$ & $\begin{array}{l}\text { yes } \\
\text { yes }\end{array}$ & $\begin{array}{l}\text { yes } \\
\text { yes }\end{array}$ & $\begin{array}{l}\text { yes } \\
\text { yes }\end{array}$ \\
\hline $\mathrm{R}^{\wedge} 2$ & 0,798 & 0,830 & 0,717 & 0,852 & 0,812 \\
\hline
\end{tabular}

The significance of the coefficients is denoted by stars (* significance on the $10 \%$ significance level, ** $5 \%$ and $* * * 1 \%$, respectively). Standard errors are in brackets and they are computed on the $5 \%$ significance level. 
Table 35. Descriptive statistics about the density of foreign-born inhabitants in Swedish municipalities in the year 2015

\begin{tabular}{|c|ccccc|}
\hline Variable & Obs & Mean & Std. Dev. & Min & Max \\
\hline Foreign born & 290 & 0,13405 & 0,05885 & 0,04725 & 0,404 \\
\hline
\end{tabular}

Videos:

Video 1. The marketing campaign in Staffanstorp, can be retrieved from the link below:

https://t.co/rYn4fiQL8F?amp=1 